\title{
Allergie, Mikrobiom und weitere epigenetische Faktoren
}

4.1 Das Mikrobiom des Darms - 49

4.1.1 Außen-Innen: Wie die Darmflora das Immunsystem kontrolliert - 56

4.1.2 Innen-Außen: Wie das Immunsystem das Mikrobiom kontrolliert - 60

4.2 Das Mikrobiom der Atemwege - 60

4.3 Pränatale Einflüsse - 63

4.4 Geburtsvorgang -65

4.5 Hospitalisierung und Gestationsalter - 65

4.6 Lebensumgebung - 66

4.7 Hygiene -68

4.8 Haustiere -69

4.9 Das Mikrobiom der Haut, Waschverhalten, Hauttrockenheit und Hautschutzmaßnahmen zur Verbesserung der Hautbarriere - 70

4.10 Vitamin D - 73

4.11 Effekte der Ernährung auf die Entwicklung oraler Toleranz - 73

4.11.1 Säuglingsalter -73

4.11.2 Wie sollen Kinder im ersten Lebensjahr ernährt werden? - 79

4.11.3 Kindheit -81 
4.12 Ballaststoffe -85

4.13 Omega-3-Fettsäuren - 86

4.14 AGEs (advanced glycation endproducts) - 87

4.14.1 Exogene Glykierung (auch Glykation) - 87

4.14.2 Endogene Glykierung - 87

4.15 Mütterliches Rauchen - 91

4.16 Magensäure-Blocker - 91

4.17 Effekt von Antibiotika in den ersten Lebensjahren - 92

4.17.1 Guidelines: Advices for High Value Care zum

Antibiotikaeinsatz bei Infekten - 98

4.17.2 Nachteile der antibiotischen Therapie und mögliche Schäden - 104

4.18 Einfluss von Antipyretika auf die Entwicklung von Allergien - 106

4.18.1 Paracetamol - 106

4.18.2 Ibuprofen - 107

Literatur - 109 
Die Entdeckung des Mikrobioms hat die Medizin verändert. Sämtliche menschlichen Schleimhäute und die Haut sind von kommensalen Mikroben in großer Zahl und Vielfalt besiedelt und bilden mit diesen eine symbiotische Einheit. Diese wichtigen Übergangszonen, an denen der Körper Kontakt mit der Außenwelt aufnimmt, spielen eine Schlüsselrolle für die Regulation des Immunsystems und die Erhaltung der Gesundheit. Bei Einflüssen, die diese „Gemeinschaft" stören und zu Fehlbesiedlung oder geringerer Diversität führen, können Krankheiten entstehen. Seit Kurzem beginnt die Wissenschaft den Einfluss des Mikrobioms auf die Pathogenese der Allergie zu erforschen und findet immer mehr Fakten, wie sehr veränderte Lebensweisen simultan zur weltweiten Reduktion der Biodiversität und zu steigenden Allergieraten beitragen.

\subsection{Das Mikrobiom des Darms}

Die chinesische Medizin hat schon vor 2000 Jahren einen Zusammenhang zwischen Lunge und Dickdarm erkannt. Nach den Prinzipien der 5 Wandlungsphasen impliziert jegliche Behandlung des Yin-Organs Lunge (bzw. des Respirationstraktes) eine Regulation und Mitbehandlung des gekoppelten Yang-Organs, des Dickdarms. Nicht nur diese beiden Organe sind dem Element Metall zugeordnet, sondern auch die Haut als zugehörige Körperschichte und die Nase als Öffner (• Abb. 4.1).

Bei genauerer Betrachtung fällt auf, dass sämtliche Erkrankungen des ,allergischen Marsches" (s. - Abb. 4.2) in das Element Metall fallen. Sowohl Bauchschmerzen, Nahrungsmittelallergien und Ekzeme im Säuglingsalter als auch Asthma im Krabbelalter und die allergische Rhi-

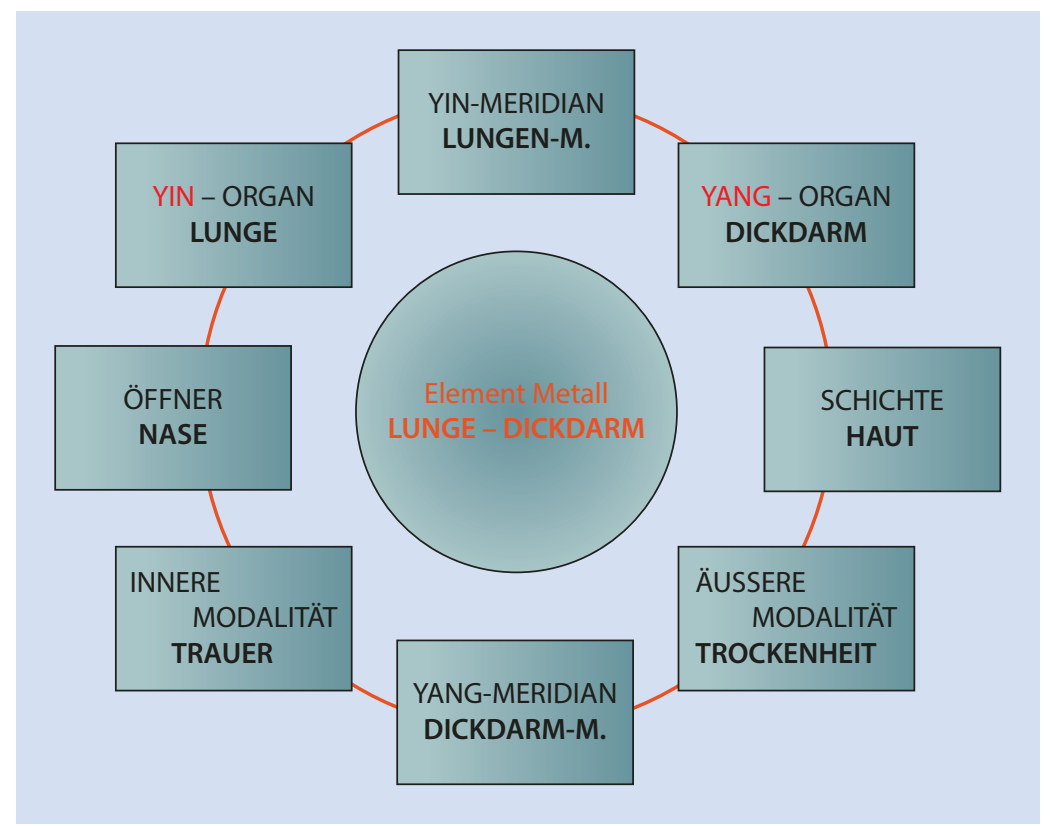

- Abb. 4.1 TCM: Element/Wandlungsphase Metall umfasst das Yin-Organ Lunge und das Yang-Organ Dickdarm. In Kontakt zur Außenwelt tritt dieses Element über die Nase, durch die die Luft eingeatmet wird. Die Lunge gilt als „äußerstes" Organ, das mit der Außenwelt in engem Kontakt steht. Seine zugehörige Schichte, die
Haut, ist ebenfalls die äußerste der 5 Schichten. Sehr empfindlich ist diese Wandlungsphase gegenüber Trockenheit. Nachdem die TCM Körper und Geist nie trennt, wird besonders der psychische Einfluss Trauer als sehr schädlich für Lunge und Dickdarm erachtet 


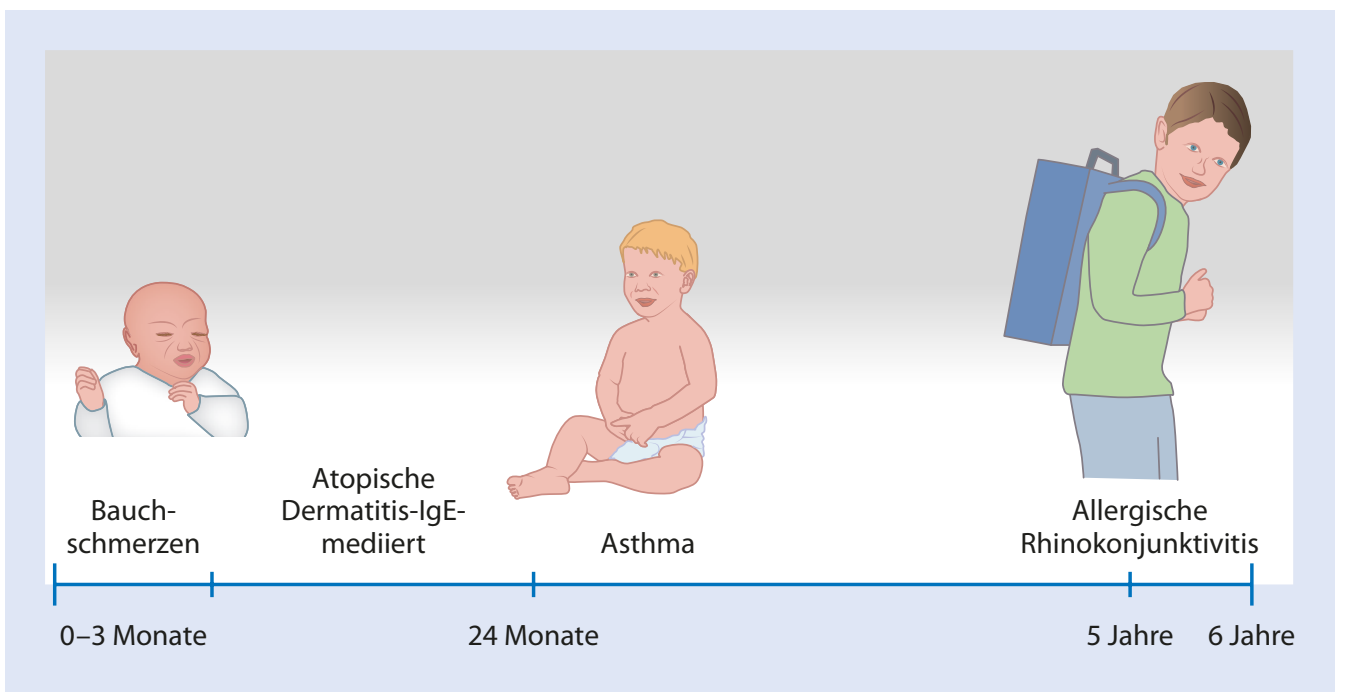

- Abb. 4.2 Der allergische Marsch beginnt im ersten Lebensjahr mit Nahrungsmittelsensibilisierung und atopischem Ekzem. Erst danach entwickelt sich das

nitis im Vorschulalter werden in der TCM dem Element Metall zugeordnet.

Die gemeinsame Behandlung von Lunge und Dickdarm erfolgte im alten China über Akupunktur, chinesische Kräutertherapie und eine Frühform der „probiotischen “ Therapie:

Eine Substanz namens Jin zhi, die Wu Tang schon $1789 \mathrm{n}$. Chr. beschrieben (Liu 2001) hat, wurde aus menschlichem Stuhl gewonnen, der in einem tönernen Topf versiegelt, 3 Jahre in der Erde vergraben wurde. Nach 3 Jahren war diese Substanz zu einer "Goldenen Flüssigkeit" geworden und wurde gemeinsam mit chinesischen Kräutern verabreicht.

Indikationen waren damals Flushes, Diarrhöen und Engegefühl im Thorax, also durchaus vergleichbar mit Urtikaria, Asthma und Nahrungsmittelallergien.

Heute ist die Verwendung der "Goldenen Flüssigkeit" in China natürlich obsolet. Fäkale Mikroflora-Transplantation (FMT) und Probiotika können jedoch als „Nachfolger" dieser Methode angesehen werden! kindliche Asthma und meist erst im Kindergarten/Vorschulalter die allergische Rhinokonjunktivitis

Die Interaktion von Lunge und Dickdarm ist auch der Grund, warum in der Komplementärmedizin auch in Europa seit Jahrzehnten Probiotika zur additiven Therapie bei allergischen Erkrankungen verwendet wurden. Die Wechselwirkung zwischen Lunge und Dickdarm wurde in den letzten 20 Jahren auch von der "modernen“ Wissenschaft wiederentdeckt.

Bengt Björksten war einer der ersten westlichen Wissenschaftler, der vorschlug, dass der permanente Druck von Bakterien, die den Darm physiologisch kolonisieren, einer Sensibilisierung gegenüber inhalativen Allergenen vorbeugen könnte. Über das darmassoziierte Immunsystem könnte es zu einer Aktivierung der Th1-Lymphozyten kommen und der Th2Dominanz entgegengesteuert werden. Bei Untersuchungen an allergischen und nichtallergischen Kindern erkannte Björksten (Björksten et al. 1999) schon 1999 eine unterschiedliche Zusammensetzung der kindlichen Darmflora. Der Stuhl nicht-allergischer Kinder enthielt eine wesentlich höhere Menge an physiologischen Darmbakterien wie Laktobazillen und Bifidusbakterien als der Stuhl allergischer Kinder, die wiederum eine größere 


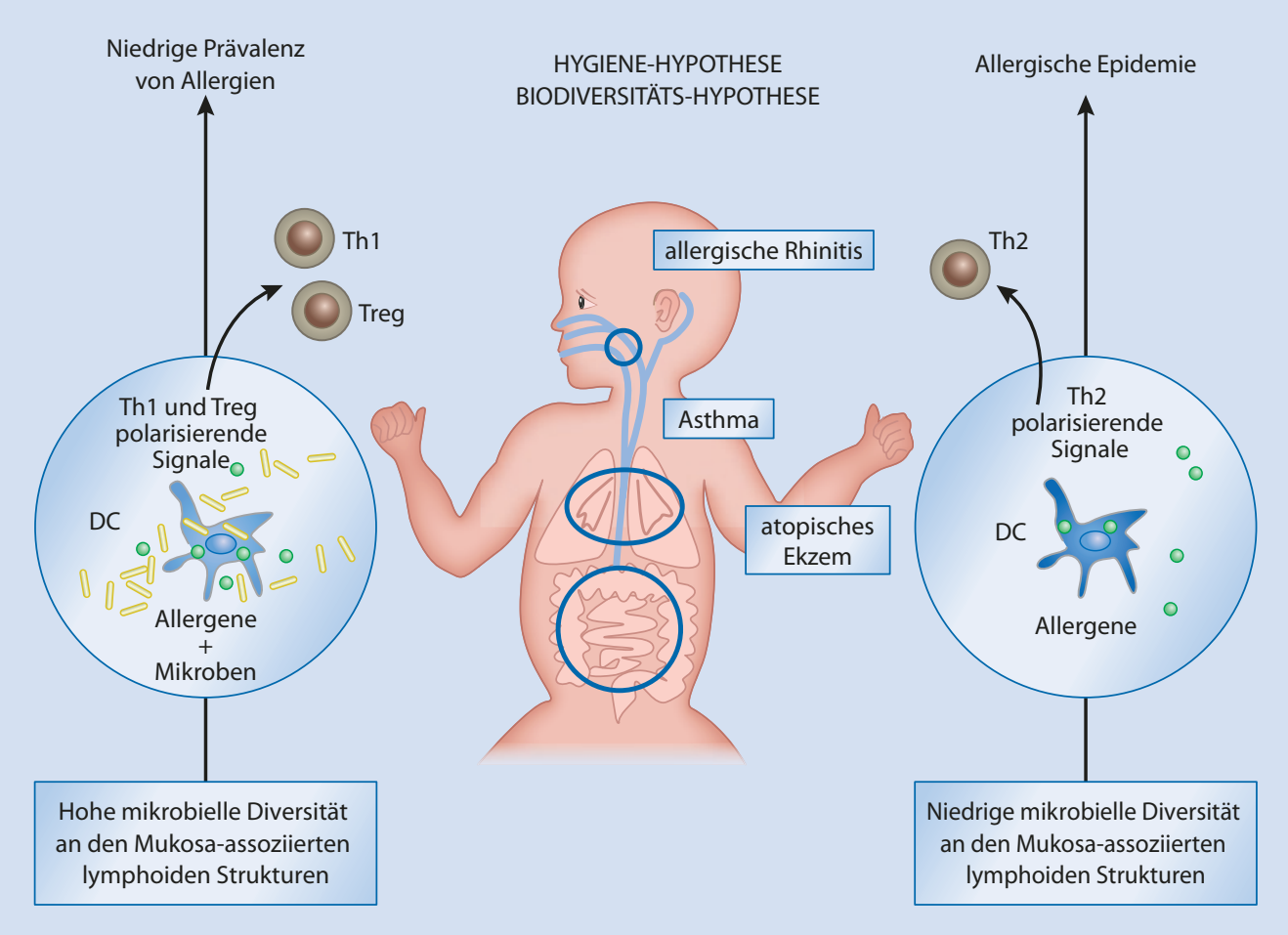

- Abb. 4.3 Hygiene/ Biodiversitäts-Hypothese: Traditioneller Lebensstil mit hoher Diversität von Mikroben an den Mukosa-assoziierten lymphoiden Strukturen bewirkt eine vermehrte Th1- und Treg-Stimulation mit niedriger Prävalenz von Atopien, während zu viel Hygiene mit verringerter Diversität der Mikroben die Entstehung von Th2-mediierten Atopien begünstigt

allergischen Marsch, gegenüber $46 \%$ in der Placebogruppe. Erstmalig war es also gelungen, präventiv das Auftreten von allergischem Geschehen bei genetisch prädisponierten Kindern zu reduzieren. Nachuntersuchungen im 4. Lebensjahr (Kalliomäki et al. 2003) brachten ähnliche Ergebnisse. Im 6. Lebensjahr konnte jedoch keine Reduktion der Häufigkeit des Auftretens der für dieses Alter typischen allergischen Rhinokonjunktivitis beobachtet werden (Kalliomäki et al. 2007).

\section{$>$ Definition der Probiotika: Lebende Mik- roorganismen, die, wenn sie Menschen in geeigneter Menge verabreicht werden, zum gesundheitlichen Nutzen betragen.}

Kalliomäkis Studien waren so bahnbrechend, dass sie sehr oft von anderen Autoren in ähnlicher Form repliziert wurden. Die derzeit akbierte Häufigkeit (23\% der Kinder) von atopischem Ekzem, der ersten Manifestation im 
tuellsten Meta-Analysen der darauffolgenden Studien zeigten eine Wirkung von Probiotika bei der primären Prävention von atopischem Ekzem, jedoch ebenfalls keine signifikanten schützenden Effekte bezüglich der Entwicklung anderer allergischer Erkrankungen. Cuello-Garcia et al. (2015) schlossen 29 Studien ein und differenzierten auch die Zeitphasen der Verabreichung der Probiotika. Die besten Ergebnisse bezüglich Ekzemreduktion (mit Follow-up bis zum Alter von 2 Jahren) wiesen jene Studien auf, die die Probiotika schon im letzten Trimester der Schwangerschaft (RR 0.71; $95 \%$ CI, 0.60-0.84) und während des Stillens (RR 0.57; $95 \% \mathrm{CI}, 0.47-0.69)$ verabreicht hatten, während Probiotika, die nur dem bereits geborenen Kind verabreicht wurde, keine signifikanten Effekte bewirkten (RR, 0.83; $95 \% \mathrm{CI}$, 0.58-1.19). Zusammenfassend wurde die Evidenz dieser Studien jedoch mit niedrig bis sehr niedrig eingestuft. Eine Meta-Analyse von Zuccotti (Zuccotti et al. 2015) inkludierte 17 Studien mit 4755 Kindern und demonstrierte ein signifikant erniedrigtes relatives Risiko für Ekzeme bei Kindern, die mit Probiotika behandelt wurde, im Vergleich zu Placebo (RR 0.78; 95 \% CI: 0.69-0.89). Jene Kinder, die mit einer Mischung aus verschiedenen probiotischen Stämmen behandelt wurden, zeigten eine noch bessere Wirkung (RR 0.54, 95 \% CI, 0.43-0.68).

Immunologisch beobachtet man einen Th1-stimulierenden Effekt von Probiotika. Lactobacillus paracasei ssp. induzierte nach Gabe während der Stillperiode mit 13 Monaten eine höhere IFN- $\gamma /$ IL-4-mRNA-Expression verglichen mit Placebo (West et al. 2009). Darüber hinaus reduzierte eine ProbiotikaMischung aus Bifidobacterium bifidum, Bifidobacterium lactis und Lactococcus lactis, präund postnatal verabreicht, die Th2-Zytokine IL-5 und IL-13 im Alter von 3 Monaten (Niers et al. 2009). Die immunmodulatorische Wirkung variiert jedoch, abhängig von Dosis, Stamm und Behandlungsdauer (Wickens et al. 2008). Probiotika haben auch das Potenzial, sekretorisches IgA, das eine wichtige Rolle bei der Stabilisierung der mukosalen Barriere- funktion spielt, zu erhöhen (Kukkonen et al. 2010) (s. - Abschn. 4.1.1).

Nach Analyse diverser Systematic Reviews kam man im Juni 2015 (also erst 14 Jahre nach der Erstpublikation von Kalliomäki) zum Schluss, dass

- die Gabe von Pro-/Präbiotika als die vielversprechendste Intervention zur Prävention des atopischen Ekzems bei Kleinkindern gilt (Madhok et al. 2015).

- Auch die World Allergy Organization WAO (Fiocchi 2015) empfahl im Jänner 2015 in ihren Guidelines die Anwendung von Probiotika zur Prävention von Ekzem bei Hochrisikokindern (Kinder mit einem allergischen Familienmitglied im 1. Verwandtschaftsgrad) sowohl während der Schwangerschaft als auch während des Stillens und in der Kindheit.

In der derzeit aktuellsten Meta-Analyse aus 2018 von 28 Studien mit 6705 Kindern zeigte sich erneut nach Einnahme von Probiotika anhand von 19 Studien ein reduziertes Risiko, an Ekzem bis zum 4. Lebensjahr (RR 0.78; $95 \%$ CI 0.68-0.90), und anhand von 11 Studien, an atopischem Ekzem (RR 0.78; 95 \% CI 0.650.92) zu erkranken (Garcia-Larsen et al. 2018).

Es gibt aber auch Studien, die keinen positiven Effekt zeigen. Hania Szajewska (Szajewska et al. 2015) von der ESPHAGAN (European Society for Paediatric Gastroenterology Hepatology and Nutrition) warnt daher, allzu euphorisch mit diesen Daten umzugehen, weil man bedenken müsse, dass die Studien mit unterschiedlichen Stämmen von Probiotika durchgeführt wurden, und man bis dato keinesfalls behaupten kann, dass alle Probiotika gleichermaßen wirksam wären. Nur ein einziger probiotischer Stamm (Lactobacillus rhamnosus $G G)$ wäre in mehr als einer randomisierten Studie getestet. Daher wird vorgeschlagen, in Zukunft Studien mit einzelnen probiotischen Stämmen durchzuführen und beim Poolen 
von Daten nicht unterschiedliche Stämme zu vermischen. Bedenken sollte man auch, dass viele Probiotika am Markt nicht als Arzneimittel, sondern als Nahrungsergänzungsmittel zugelassen sind und daher wesentlich weniger bezüglich Wirksamkeit, Inhalt und Haltbarkeit überprüft wären als Arzneimittel.

Dies ist ein Grund, warum sich viele Ärzte noch zurückhaltend mit der Verschreibung von Probiotika zur Prävention von Ekzemen verhalten.

Die Wirkung von Probiotika auf Nahrungsmittelsensibilisierung untersuchte eine $\mathrm{Me}$ ta-Analyse von 2016 (Zhang et al. 2016) anhand von 17 Studien mit 2947 Kindern und machte deutlich, dass die Kombination von präntaler mütterlicher und postnataler kindlicher probiotischer Behandlung sowohl das insgesamte Atopierisiko (RR 0.78; $95 \%$ CI 0.66-0.92) als auch das Risiko einer Nahrungsmittelsensibilisierung (RR 0.77; 95 \% CI 0.61-0.98) reduzierte.

Wurden Probiotika entweder nur präpartal oder nur postpartal verabreicht, konnten keine signifikanten Reduktionen von Atopien oder Nahrungsmittelsensibilisierungen gefunden werden. Untergruppenanalysen ergaben, dass längere Dauer der Substitution effektiver sein kann und dass Kaiserschnitt-geborene Kinder besonders von der Substitution von Probiotika profitieren. Betont sollte jedoch werden, dass die Daten dieser Studie auf positiven Skin-Prick-Tests und erhöhten IgE gegen Nahrungsmittelallergene basierten und nicht auf klinisch symptomatischer Nahrungsmittelallergie. Nahrungsmittelsensibilisierung muss jedoch nicht immer mit klinischen Symptomen und Nahrungsmittelallergie verbunden sein, obwohl Kinder mit Nahrungsmittelsensibilisierung eher dazu neigen. Studien, die den präventiven Effekt der Probiotika auf die manifeste Nahrungsmittelallergie mit klinischen Symptomen nachweisen, sind noch ausständig.

Die vorher erwähnte Meta-Analyse von Garcia-Larsen aus 2018 wies nach perinataler Verabreichung von Probiotika auch ein reduziertes Risiko einer allergischen Sensibilisierung gegenüber Kuhmilch bis zum 2. Lebensjahr nach (Garcia-Larsen et al. 2018).
Dass die Zusammensetzung des Mikrobioms im ersten Lebensjahr am Outcome einer Milchallergie beteiligt ist, offenbarte eine weitere Studie, die 226 Kinder mit Kuhmilchallergie einschloss, bis zum 8. Lebensjahr beobachtete und deren Mikrobiom mittels 16s-rRNA-Sequenzierung analysierte. Im Mikrobiom jener $56 \%$ der Kinder, bei denen sich die Milchallergie spontan wieder auflöste, fanden sich im Alter von 3-6 Monaten deutlich vermehrt Clostridia und Firmicutes, was darauf schließen lässt, dass die Zusammensetzung der Mikrobiota im frühen Leben das Outcome einer Nahrungsmittelallergie beeinflusst (Bunyavanich et al. 2016). Seither gelten Clostridia und Firmicutes als potenzielle Kandidaten für eine probiotische Therapie bei Milchallergie und werden diesbezüglich weiter erforscht.

Klare Evidenz, dass auch Allergien im Respirationstrakt durch perinatale Gabe von Probiotika verhindert werden können, gibt es derzeit noch nicht (Madhok et al. 2015; Mennini et al. 2017; Azad 2013).

Viele dieser Studien wurden in einem kurzen Zeitintervall pränatal von der 36. Schwangerschaftswoche bis zum 6. Lebensmonat des Kindes durchgeführt. Diese Zeitspanne scheint zu kurz zu sein, um die Sensibilisierung, die für respiratorische Allergene meist erst im Kindergarten-/Vorschulalter stattfindet, zu verhindern. Wahrscheinlich ist der ständige Druck der Symbionten bzw. Probiotika auf die Darmmukosa notwendig, besonders bei zusätzlichen Th2-triggernden Belastungen wie Antibiotikatherapie, ballaststoffarmer Ernähung und mit COX-Hemmern behandelten rezidivierenden Infekten im Krabbelalter. Mögliche Ursachen für die derzeit noch fehlende Evidenz eines Schutzes von Probiotika vor respiratorischen Allergien könnte eventuell auch die bisherige Verwendung der falschen Bakterienarten (Spezies und Stämme) sowie von noch nicht optimalen Kombinationen sein.

Ganz aktuell erschien im Dezember 2018 nun endlich eine Studie (Wickens et al. 2018), in der zwei verschiedene Probiotika (Lactobacillus rhamnosusHN001 oder Bifidobacterium 
lactisHN019) bzw. Placebo über eine längere Zeitspanne, nämlich:

- an Mütter von der 35. Schwangerschaftswoche bis 6 Monate nach der Geburt (wenn stillend)

- und an deren Kinder von der Geburt bis zum 2. Geburtstag verabreicht wurden.

Die Kinder dieser Studie wurden bis zum 11. Lebensjahr nachbeobachtet. Lactobacillus rhamnosus HN001, jedoch nicht Bifidobacterium lactis HN 0019 schützte in der Nachbeobachtungszeit nach 2, 4 und 6 Jahren vor atopischem Ekzem und nach 6 Jahren vor allergischer Sensibilisierung. Im Alter von 11 Jahren wurde eine signifikante Reduktion der atopischen Sensibilisierung (HR 0.71, $95 \%$ CI, 0.51-1.00, $\mathrm{P}=0.048$ ), Ekzem (HR 0.58, $95 \% \mathrm{CI}, 0.41-$ $0.82, \mathrm{P}=0.002)$ und Giemen (HR $0.76,95 \% \mathrm{CI}$, $0.57-0.99, \mathrm{P}=0.046$ ) bezogen auf die gesamte Lebensspanne in der Lactobacillus-rhamnosusHN001-Gruppe, jedoch nicht in der Bifidobacterium-lactis-HNO019-Gruppe beobachtet.

Bezogen auf das letzte Lebensjahr bei den mittlerweile 11-Jährigen zeigte die Lactobacillus-rhamnosus-HN001-Gruppe eine signifikant reduzierte Rate an Heuschnupfen $(\mathrm{RR}=0.73$, $95 \%$ CI $0.53-1.00, \mathrm{P}=0.047)$ und Ekzem $(\mathrm{RR}=0.46,95 \% \mathrm{CI} 0.25-0.86, \mathrm{P}=0.015)$.

Somit bewies diese Studie erstmals, dass die kumulativen positiven Effekte einer Probiotikatherapie in den ersten beiden Lebensjahren, die man in der frühen Kindheit bereits oftmals beobachtet hatte, mindestens über die gesamte erste Lebensdekade anhalten können und das Potenzial haben, Kinder vor der Entwicklung des gesamten Spektrums des allergischen Marsches zu schützen.

Natürlich müssen auch diese Ergebnisse reproduziert und in Meta-Analysen geprüft werden, bevor die Therapie mit Probiotika in den ersten beiden Lebensjahren in den Guidelines zur Prävention des gesamten allergischen Spektrums empfohlen werden kann.
Bisher werden Probiotika aufgrund der aktuellen Evidenz in den aktuellen Guidelines nur zur primären Prävention des atopischen Ekzems empfohlen. Umgekehrt gibt es aufgrund der etwas widersprüchlichen aktuellen Datenlage derzeit auch noch zu wenig Evidenz, um die Wirkung bei anderen Formen des allergischen Formenkreises auszuschließen. Deshalb braucht es randomisierte Studien mit gutem Design und adäquater Power, um die Effekte der Probiotika langfristig zu untersuchen. Derzeit sind weltweit mehr als 50 registrierte Studien im Gange, die die Wirkung von Prä- und Probiotika auf die Prävention von allergischen Atemwegserkrankungen untersuchen. Die Ergebnisse werden mit Spannung erwartet!

Die wissenschaftliche Allergieforschung hat dieses Thema jedenfalls zu einem Hauptfokus gemacht.

Bis dahin ist es - aufgrund der wissenschaftlichen Erkenntnisse - sicherlich nicht falsch, während der gesamten Kindheit "ein Auge auf die kommensalen Mikroben zu werfen" und besonders nach antibiotischen Therapien und Infekten eine prophylaktische Behandlung mit Prä- und Probiotika durchzuführen sowie die Kinder ballaststoffreich zu ernähren.

Das Verständnis über das Mikrobiom des Darms wurde 2007 mittels neuer Techniken der speziesspezifischen 16S-rRNA-Gensequenzierung, mit der man nun auch unkultivierbare Bakterien analysieren kann, nochmals revolutioniert (Turnbaugh et al. 2007). Dem Human Microbiom Project ist es gelungen, $\mathrm{zu}$ zeigen, dass der menschliche Körper 100 Billionen Mikroorganismen mit mindestens 1000 verschiedenen Arten beherbergt, großteils Bakterien, jedoch auch Viren, Pilze und andere Mikroben mit ca. 2 Millionen Genen (100-mal mehr als menschliche Gene), die etwa 1,5 kg wiegen. Mithilfe der "Metagenomics“ wird das Genom der gesamten vorhandenen Mikroben be- 
stimmt, das als Mikrobiom bezeichnet wird. Um die Funktion des Mikrobioms besser zu verstehen, reicht das Wissen über die taxonomische Zusammensetzung nicht aus, daher erfolgt die funktionelle Analyse des Transkriptoms mithilfe der „Metatranscriptomics“ und die Untersuchung der Metaboliten und Proteinprodukte mithilfe der „Metabolomics“. Durch diese Techniken gelingt es immer besser, die enorme Bedeutung des Mikrobioms als „endokrines Organ“ zu verstehen und eine noch nie dagewesene Einsicht in die Komplexität und Diversität der mikrobiellen Gemeinschaften, die innerhalb und auf dem menschlichen Körper leben, zu bekommen. Es wird immer klarer, dass diese mikrobiellen Gemeinschaften, insbesondere im Darm, eine Schlüsselrolle bei der Abwehr von pathogenen Organismen, aber auch bei der Entstehung und Aufrechterhaltung von Immunantworten und Immuntoleranz spielen.

Ein Drittel der physiologischen Darmflora ist bei allen Menschen ähnlich, die restlichen $2 / 3$ sind für jeden Menschen spezifisch. Somit entspricht die individuelle Darmflora des Einzelnen einer individuellen Identitätskarte (Qin et al. 2010).

Das humane Mikrobiom besteht hauptsächlich aus 4 Hauptphyla (• Tab. 4.1): den
Firmicutes, Bacteroides, Proteobacteria und Actinobacteria.

Die intestinalen Mikrobiota leben in einer hömöostatischen Beziehung mit dem Wirt. Millionen Jahre der Co-Evolution haben eine enge Vernetzung der physiologischen und metabolischen Funktionen zwischen Mikroorganismen und Wirt geschaffen.

Die allererste Aufgabe der Darmflora ist es, komplexe Nahrungsmakromoleküle abzubauen. Dies verbessert die Leistungsfähigkeit der Verdauung und damit die Energieversorgung des Wirts, sichert aber auch zur gleichen Zeit die gleichmäßige Verteilung von Nährstoffen an die Mikroben.

Das Mikrobiom ist abhängig von der Ernährung und dem stabilen Umfeld des Wirts und wandelt die für den Wirt unverdaubaren Anteile der Ballaststoffe durch Fermentierung in SCFA („short chain fatty acids“) um, die umgekehrt wieder dem Wirt zugute kommen. SCFAs wie Butyrat, Propionat und Acetat decken $10 \%$ des Energieverbrauches des Wirts. Butyrat stellt die Hauptenergiequelle für die Kolonozyten dar und wird für die Beibehaltung der Barrierefunktion des Darmepithels und die physiologische Funktion der "tight junctions“ benötigt (Lewis et al. 2010). Reduzierte Mengen

- Tab. 4.1 Bakterienarten im menschlichen Körper

\begin{tabular}{|c|c|c|c|}
\hline Abteilung & Klasse & Charakteristika & Beispiele \\
\hline Firmicutes & Bacilli; Clostridiae & $\begin{array}{l}\text { Grampositiv, unterschiedlich in der } \\
\text { Morphologie (Stäbchen, Kokken, } \\
\text { Spiralförmige) und Physiologie } \\
\text { (Anaerobier, Aerobier); inkludieren } \\
\text { symbiotische und nützliche Bakterien }\end{array}$ & $\begin{array}{l}\text { Lactobacillus } \\
\text { Ruminococcus } \\
\text { Clostridium } \\
\text { Staphylococcus } \\
\text { Enterococcus } \\
\text { Faecalibacterium }\end{array}$ \\
\hline Bacteriodetes & Bacteriodetes & $\begin{array}{l}\text { Gramnegativ, } 3 \text { große Klassen, weit ver- } \\
\text { breitet auch in der Umwelt, inkl. Erde, } \\
\text { Meerwasser }\end{array}$ & $\begin{array}{l}\text { Bacteroides } \\
\text { Prevotella }\end{array}$ \\
\hline Proteobacteria & $\begin{array}{l}\text { Gammaproteobacteria } \\
\text { Betaproteobacteria } \\
\text { Enterobacter }\end{array}$ & $\begin{array}{l}\text { Gramnegativ, inkludieren viele } \\
\text { Pathogene }\end{array}$ & $\begin{array}{l}\text { Escherichia } \\
\text { Pseudomonas }\end{array}$ \\
\hline Actinobacteria & Actinobacteria & $\begin{array}{l}\text { Grampositiv, diverse Morphologie, } \\
\text { wichtige Antibiotikaproduzenten der } \\
\text { pharmazeutischen Industrie }\end{array}$ & $\begin{array}{l}\text { Bifidobacterium } \\
\text { Streptomyces } \\
\text { Nocardia }\end{array}$ \\
\hline
\end{tabular}


von fäkalen SCFAs in der frühen Kindheit werden mit vermehrter Entwicklung von allergischen Erkrankungen assoziiert (Tan 2016) (s. - Abschn. 4.11.3). Außerdem produzieren SCFAs Vitamin K und Vitamin $\mathrm{B}_{12}$ (Conly et al. 1994; Albert et al. 1980).

Wachsende Evidenz belegt, dass die Darmflora auch eine wichtige Rolle bei der Reifung des Immunsystems und bei der Abwehr von Infektionen spielt (Hooper et al. 2012).

\subsubsection{Außen-Innen: Wie die Darm- flora das Immunsystem kont- rolliert}

Besonders in den ersten Lebenswochen „lehrt“ die Darmflora das noch unreife Immunsystem des Neugeborenen, wie es mit harmlosen, aber auch schädlichen Einflüssen der Außenwelt umgehen soll. Das darmassoziierte Immunsystem (GALT) in der mukosalen Lamina propria und Oberflächenmukosa stellt die wichtigste und flächenmäßig größte Komponente des Immunsystems des Neugeborenen dar. Das noch "naive“ reifende Immunsystem muss lernen, wie es den Körper vor Antigenen von außen schützt, aber gleichzeitig Toleranz gegenüber Nährstoffen und kommensalen Bakterien entwickelt und diese nicht abstößt. Bei dieser schwierigen Aufgabe bekommt das Immunsystem Hilfe von dem sich parallel entwickelnden Mikrobiom.

- Abb. 4.4 zeigt, dass die Epithelschicht des Neugeborenen noch sehr durchlässig ist, jedoch bereits Muzine produzieren kann, die in Form eines schützenden Schleimfilms die Epi-

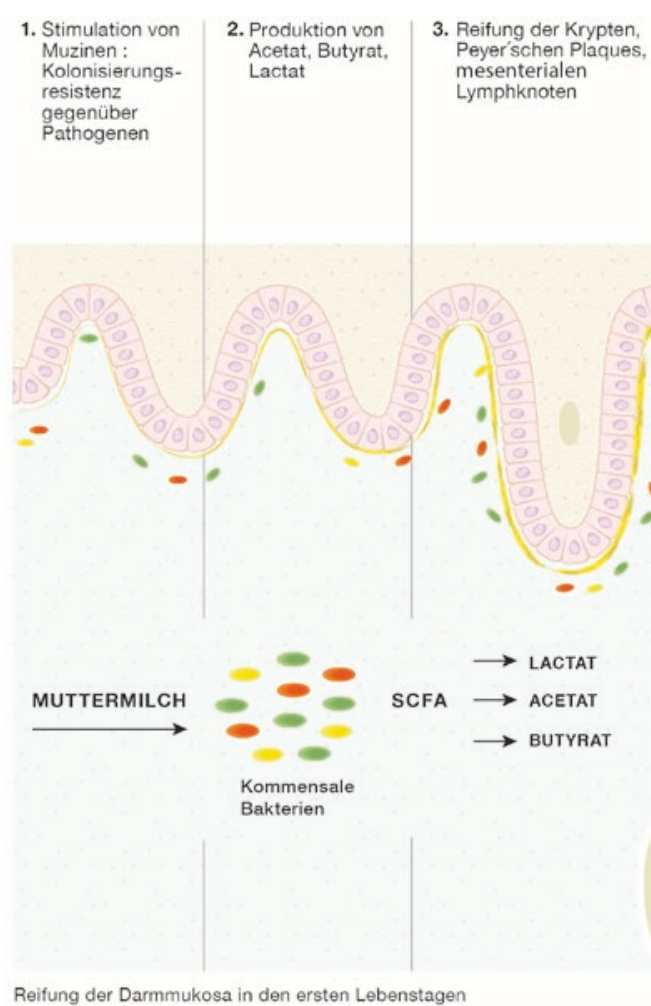

- Abb.4.4 Entwicklung des kindlichen Darms in den ersten Lebenstagen. Über Muttermilch und Umwelt kolonisiert der Darm des Neugeborenen mit kommensa-

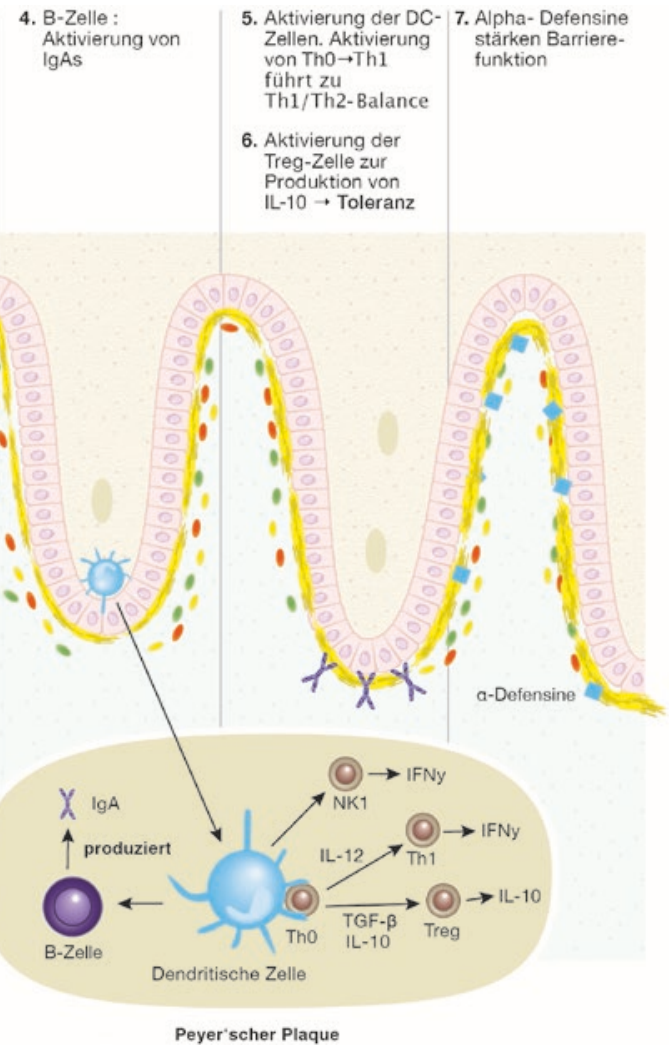

len Bakterien, die wesentlich zur Reifung des Darms, des darmassoziierten Immunsystems und zur Toleranzentwicklung beitragen 
thelzellen vor dem Eindringen von Mikroben bewahren. Diese Muzinglykane sind auch Nahrung für das sich entwickelnde Mikrobiom. $B i$ fidobakterien und Bacteroides bekommen dadurch die Möglichkeit, sich in der äußeren Darmschleimhaut nahe den Epithelzellen anzusiedeln. Diese Besiedlung schützt nun einerseits physisch vor dem Eindringen von pathogenen Mikroben, indem sie die Nischen besetzt, andererseits transformiert die Darmflora auch Nährstoffe in Acetat und Laktat und bildet dadurch eine chemische Barriere für Pathogene. Acetat und Laktat fördern wiederum das Wachstum von Butyrat-bildenden Bakterien, wie Firmicutes (Flint et al. 2012), die ebenfalls zur harmonischen Verdauung von Babys beitragen. Babys mit Koliken beherbergen weniger Firmicutes und Bacteroidetes als Babys ohne Koliken (de Weerth et al. 2013). Butyrat fördert die regulatorische Aktivität der dendritischen Zellen zur Induktion von iTreg-Zellen mit IL10-Bildung (Singh et al. 2014a), die für die Toleranzentwicklung von großer Bedeutung ist.

Die Mikrobiota beeinflussen postpartal auch die Reifung der Krypten und deren lymphoide Strukturen sowie die Reifung der mesenterialen Lymphknoten und der Peyer'schen Plaques. An keimfreien Mäusen kann die Rolle der Darmflora bei der Entwicklung des Immunsystems und bei der oralen Toleranzentwicklung besonders gut demonstriert werden. Mäuse sind ein brauchbares Modell, weil Mäuse $90 \%$ idente Gene wie Menschen besitzen, und auch die bakterielle Besiedlung des Darms der des Menschen ähnelt. An keimfrei aufgezogenen Mäusen zeigt sich im Vergleich zu Mäusen mit normaler Darmflora eine mangelnde oder fehlende Entwicklung von Lymphfollikeln und Peyer'schen Plaques (Sudo et al. 1997). Unreife und kleinere Peyer'sche Plaques produzieren weniger IgA und antimikrobielle Peptide. Die CD4 ${ }^{+}$-T-Zellen der keimfreien Mäuse produzieren vermehrt das Th2-Zytokin IL-4 und treiben das Immunsystem in eine Th2-gerichtete Dysbalance (Mazmanian et al. 2005).

Außerdem fand man in keimfrei aufgezogenen Mäusen weniger Treg-Zellen innerhalb der Peyer'schen Plaques und mesenterialen
Lymphknoten, von denen man weiß, dass diese eine Schlüsselrolle bei der Toleranzinduktion mittels IL-10 spielen (Ostman et al. 2006; s. Abschn. 3.4.4). Verabreichung von Bacteroides fragilis an keimfrei aufgezogene Mäuse führte zur Reifung des "gut-associated lymphoid tissue" (GALT) und zur Toleranzentwicklung, aber nur, wenn die Gabe in der neonatalen Periode erfolgte. Bacteroides fragilis induzieren über Treg-Zellen eine Vermehrung von IL-10 und die Entwicklung von mukosaler Toleranz (Round und Mazmanian 2010).

Somit scheint die "richtige“ Zusammensetzung des Mikrobioms für die Entwicklung der oralen Toleranz von entscheidender Bedeutung zu sein. Am Menschen verglich Ling 2014 (Ling et al. 2014) den Stuhl von 34 Kindern mit Nahrungsmittelallergie mit dem Stuhl von 45 gesunden Kindern und fand mittels 16S-rRNA-Technik bei den allergischen Kindern eine Reduktion der Bacteroidetes, Proteobacteria und Actinobacteria, während die Firmicutes stark vermehrt waren. Auch Clostridium sensu strictu (oder cluster 1) sowie Anaerobacter waren bei IgE-mediierter Nahrungsmittelallergie gehäuft $\mathrm{zu}$ sehen, während auch hier das IL-10 reduziert war.

Atarashi publizierte 2011 in Science (Atarashi 2011), dass durch orale Inokulation von Clostridium-spp.-Stämmen (cluster IV und XIV) an junge Mäuse die Ausschüttung von TGF- $\beta$ und anderen Treg-induzierenden Faktoren in den intestinalen Epithelzellen angeregt wird. Offensichtlich vermitteln dendritische Zellen die generalisierte Akkumulation der Treg-Zellen im Kolon und induzieren eine vermehrte IL-10-Produktion, die zu Toleranz führt. Dadurch wird die Aufrechterhaltung der immunologischen Homöostase begünstigt und im Kolon eine Umgebung hergestellt, die auch resistent gegenüber systemischen IgEAntworten und Kolitis ist.

Einnahme von Bifidobacterium infantis erhöhte die Zahl der FoxP3-Treg-Zellen im peripheren Blut und vermehrte die Sekretion von IL-10 bei gesunden Freiwilligen. Diese Ergebnisse weisen ebenfalls auf die Verbindung zwischen Mikrobiota und Toleranzinduktion hin (Konieczna et al. 2012). 
Eine dänische Gruppe aus Kopenhagen analysierte die intestinale Bakterienflora einer Geburtskohorte von 411 Allergie-Hochrisikokindern und fand, dass eine reduzierte Diversität 1-12 Monate postpartal das Risiko für eine allergische Sensibilisierung, Eosinophilie und für die Entwicklung einer allergischen Rhinitis bis zum 6. Lebensjahr erhöhte. Besonders eine geringere Anzahl und Vielfalt von Bacteroidetes in der frühen Kindheit führte zu einer erhöhten Wahrscheinlichkeit der Entwicklung von allergischen Manifestationen (Bisgaard et al. 2011).

Die kanadische CHILD-Studie brachte 2015 zum Vorschein, dass reduzierte Mengen an Lachnospira, Veilonella, Faecalibacterium und Rothia in den ersten 100 Lebenstagen das Risiko für Asthma erhöhen und auch mit reduzierten fäkalen SCFAs verbunden sind. Die Autoren postulierten, dass in Zukunft Mikroben-basierte Diagnostik und entsprechende Therapien in Form von Probiotika zur Vorbeugung von atopischen Erkrankungen sinnvoll wären (Arrieta et al. 2015).

Auch im Tierversuch verhinderte die Verabreichung von Lactobacillus rhamnosus an OVA-sensibilisierte Mäusen den allergischen Marsch von der atopischen Dermatitis zu allergischem Asthma oder -Rhinitis. In den mesenterialen Lymphknoten dieser Mäuse fand man eine erhöhte Anzahl von CD4 ${ }^{+}$-CD25 $5^{+}$-FoxP3Treg-Zellen und eine Reduktion der Th2-, Th17- und TSLP-Antworten (Kim et al. 2014).

All diese Studien zeigen ganz deutlich, dass die Zusammensetzung der Darmflora das Immunsystem stark beeinflusst und eine Dysbiose oft mit immunologischen Veränderungen in Richtung Atopie korreliert. Der wissenschaftlichen Community eröffnet sich derzeit ein riesiges Potenzial, durch Verwendung isolierter Bakterienstämme maßgeschneiderte Manipulation bei immunologischen Störungen durchzuführen.

\subsubsection{Der Th2-lastige Start ins Leben}

Bei atopischen Erkrankungen herrscht ein Ungleichgewicht von Th1/Th2 in Richtung Th2-Zellen mit erhöhter Ausschüttung von
Th2-spezifischen Zytokinen (s. Abschn. 3.4) und daraus resultierender IgE-Antikörpervermehrung.

Dieses pathologische, für atopische Erkrankungen typische Ungleichgewicht ist während der Schwangerschaft physiologisch (Abelius et al. 2015) und dient dazu, dass die feto-plazentare Einheit nicht von den mütterlichen Th1-Zytokinen abgestoßen wird. Findet diese physiologische Th2-Ausrichtung nicht statt, scheint die Abortusgefahr erhöht zu sein. Studien an Frauen mit habituellem Abort bewiesen, dass bei jenen Schwangerschaften die Th2-gerichtete Immunmodulation nicht eingetreten war (Piccinini et al. 1998).

Bei allergischen Müttern scheint dieses physiologische Ungleichgewicht jedoch stärker ausgeprägt zu sein, weil man während der Schwangerschaft, im Vergleich zu nicht-allergischen Schwangeren, reduzierte Antigen-induzierte IFN- $\gamma$ - und IL-10-Antworten beobachten konnte sowie reduzierte IFN- $\gamma / \mathrm{IL}-4$ und reduzierte IFN- $\gamma /$ IL-13-Ratios (Persson et al. 2012).

Im Nabelschnurblut von allergischen Müttern findet man wesentlich höhere IgE-Werte und Th2-assoziierte Chemokine (CCL22) als von nicht-allergischen Müttern. Diese erhöhten Werte stehen in direktem Zusammenhang mit der Entwicklung von allergischen Erkrankungen und Sensibilisierung deren Kinder innerhalb der ersten beiden Lebensjahre. Auch die Ratio zwischen Th2-Chemokinen CCL22 $\mathrm{zu}$ Th1-Chemokinen (CXCL10, ein IFN- $\gamma$ Chemokin) ist im Nabelschnurblut erhöht und in direkter Korrelation mit dem Auftreten von allergischen Erkrankungen beim Nachwuchs (Sandberg et al. 2009).

- Abb. 4.5 illustriert die zum Zeitpunkt der Geburt bestehende Th2-gerichtete physiologische Imbalance, die dann physiologischer Weise während und sofort nach der Geburt gegenreguliert und mit ca. 9 Monaten zu einem Th1/Th2-Gleichgewicht ausbalanciert wird. Bis dahin ist die Wahrscheinlichkeit einer verstärkten Th2-Antwort auf neue Antigene mit allergischer Sensibilisierung erhöht.

Somit wird klar, dass die Reifung der Th1Antworten und, wie man heute weiß, auch die 


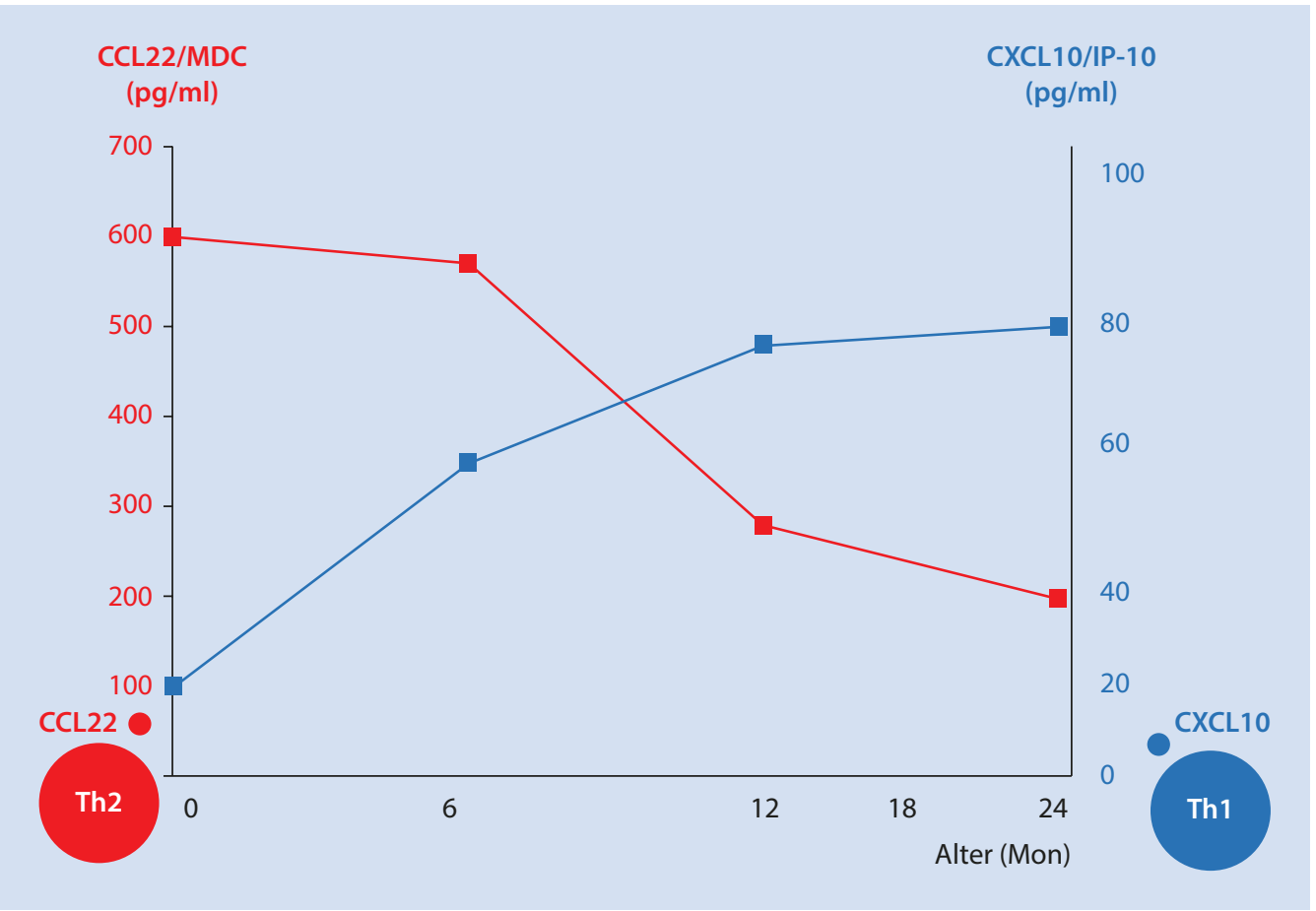

- Abb.4.5 Th1/Th2-Ungleichgewicht zum Zeitpunkt der Geburt und spätere Balance. (Mod. nach Abrahamsson et al. 2011). Das Verhältnis von Th2-Chemokinen CCL22 und Th1 Chemokinen CXCL10 verändert sich in

Entwicklung von angemessenen Treg-ZellAntworten für die Ausbildung eines reifen Immunsystems und die Toleranzentwicklung sehr wichtig sind. Um dies zu fördern, sollte bei Kindern von Anfang an eine Gegenregulation des „Th2-lastigen Starts ins Leben“ über eine Th1-Treg-Th2-Balance angestrebt werden, die durch eine Vielzahl von Maßnahmen proaktiv stimuliert werden kann, die im Folgenden im Detail besprochen werden.

\subsubsection{Persistierende Th2-Ausrich- tung als Ergebnis von man- gelnder Gegensteuerung durch die Darmflora?}

Bei einer normal verlaufenden Spontangeburt kommt der kindliche Organismus im Geburtskanal und postpartal mit den Mikrobiota der Mutter und der Umgebung in Kontakt. Durch diese physiologische Stimulation mit der müt- den ersten Lebensmonaten. Während bei der Geburt die Th2-Chemokine physiologisch vermehrt sind, tritt ca. nach 9 Monaten eine Th1/Th2-Balance ein

terlichen Vaginal- und Darmflora wird das kindliche darmassoziierte Immunsystem über Aktivierung von IL-12 und IFN- $\gamma$ aus den DCs zu einer vermehrten Differenzierung der naiven $\mathrm{CD}^{+}{ }^{+}$-T-Zelle in Richtung Th1-Antwort getriggert. Dadurch entwickelt sich im Laufe von Monaten eine Th1/Th2-Balance und auch die Toleranzentwicklung wird gefördert.

Logischerweise kann die Gabe von Probiotika in genau jener „heiklen“ prä- und postnatalen Phase eine Strategie sein, um die adäquate Entwicklung des Immunsystems zu fördern, besonders wenn die physiologischen Signale ohnehin reduziert sind.

Studien an keimfreien Mäusen zeigten eine persistierende Th2-Ausrichtung, als Ergebnis von mangelnder Gegensteuerung durch die Darmflora (Sudo et al. 1997; Mazmanian et al. 2005). Bei Kindern sieht man ebenfalls, dass hohe Th2- und niedrige Th1-assoziierte Che- 
mokine einer späteren allergischen Sensibilisierung vorausgehen. Die Präsenz von Lactobacillus Reuteri in der ersten Lebenswoche ist mit niedrigen Werten von CCL22 (Th2-Chemokin) und hohen Werten von CXLC10 (Th1-Chemokin) im Alter von 6 Monaten verbunden. Hohe Th1-Chemokine korrelieren auch mit Kindertagesbetreuung (Abrahamsson et al. 2011).

\subsubsection{Innen-Außen: Wie das Im- munsystem das Mikrobiom kontrolliert}

Das intestinale Immunsystem muss den Körper vor einem Überhandnehmen von Mikroben am Epithel schützen und deren Penetration eindämmen. Intestinale dendritische Zellen sammeln kleine Mengen Bakterien, die die Epithelbarriere bereits durchdrungen haben und senden Signale an die T-und B-Lymphozyten der Peyer'schen Plaques in der intestinalen Lamina propria, die dadurch aktiviert werden. B-Zellen sezernieren daraufhin Immunglobulin A (IgA). IgA ist das in höchster Dichte vorkommende mukosale Immunglobulin und hilft beim Aufbau der Zusammensetzung der intestinalen Mikrobiota, indem es gewisse Mikrobiota beschichtet und dadurch die Homöostase zwischen Wirt und Kommensalen stabilisiert (Pabst et al. 2016). IgAs binden sich an die Bakterien und hemmen deren Translokation durch die Epithelbarriere (Macpherson et al. 2004). Außerdem festigt IgA die mukosale Barriere, schützt das Epithel vor Pathogenen und Toxinen und verstärkt die orale Toleranz (Pabst 2012). Im Vergleich zu gesunden Kindern wurden bei allergischen Kindern veränderte IgA-Antworten und IgA-Erkennungsmuster schon im Alter von einem Monat beobachtet. Offensichtlich gehen diese veränderten IgAAntworten einer Allergie bzw. Asthmaentwicklung voraus (Dzidic et al. 2017).

Epithelzellen sezernieren auch alphaDefensine, kleine antibakterielle Peptide, die die Barrierefunktion des Darmepithels stärken und die Zusammensetzung der physiologischen Flora beeinflussen (Salzman et al. 2010).
Somit wird klar, dass das Immunsystem die Zusammensetzung, die Artenvielfalt und die Lokalisation des Darmmikrobioms beeinflussen kann. Fragen, die sich weiterhin stellen, sind, inwieweit das Immunsystem mit der Magensäure und der Darmmotiliät zusammenarbeitet, um die longitudinale Verteilung der Mikrobiota entlang des gesamten Darmes zu gewährleisten.

Das Immunsystem eines Neugeborenen entspricht somit einem Lernsystem, das bei der Geburt Hardware und Software schon bereitgestellt hat, aber noch wenige Daten besitzt. In den ersten Lebenstagen und -monaten werden „Datensätze“ zunächst durch Kontakt mit Mikroorganismen der Mutter, von Geschwistern und der natürlichen Umgebung aufgebaut und verarbeitet. Wenn die Inputs adäquat sind, kann der kindliche Organismus Toleranz entwickeln. Bei inadäquatem Kontakt mit Mikroorganismen (Kaiserschnitt, Antibiotikagabe etc.) können sich die regulatorischen Mechanismen des Immunsystems nicht richtig aufbauen und das System attackiert nicht nur $\mathrm{Pa}$ thogene, sondern auch harmlose Ziele wie Nahrungsmittel, Pollen und Hausstaub mit nachfolgender allergischer Entwicklung.

\subsection{Das Mikrobiom der Atemwege}

Nicht nur der Darm hat ein Mikrobiom, sondern auch sämtliche anderen Schleimhäute und die Haut.

Daher ist auch der Respirationstrakt nicht steril, sondern mit einer Vielzahl an mikrobiellen Populationen besiedelt. Die Lunge stellt eine der größten Schnittstellen des menschlichen Körpers mit der Außenwelt dar, indem sie täglich 8000 Litern inhalierter Luft ausgesetzt ist (Kopf 2015).

Das Mikrobiom an den Schleimhäuten der Bronchien bildet eine wichtige Frontlinie zu externen Stimuli durch virale oder allergische Antigene und initiiert immunologische Antworten des Wirtsorganismus. So gesehen ist es nicht erstaunlich, dass es bei abweichender mikrobieller Kolonisation der Atemwege zu chronisch entzündlichen Erkrankungen wie Asthma, 
zystischer Fibrose oder Infektanfälligkeit kommen kann (Huang 2014). Ein intaktes Mikrobiom der Lunge scheint für den Körper von großer Bedeutung zu sein.

Genauso wie das GALT reift auch das neonatale BALT („bronchial associated lymphoid tissue") mit seinem Immunsystem in den ersten Lebenstagen.

Gesunde neugeborene Mäuse neigen eher dazu, eine Th2-gerichtete Atemwegseosinophilie mit Ausschüttung von Th2-Zytokinen und bronchialer Hyperreaktivität nach Kontakt mit Hausstaubmilben auszubilden als erwachsene Mäuse. Eine Studie zeigte, dass sich die bakterielle Last in der Lunge und das Mikrobiom innerhalb der ersten beiden Lebenswochen erhöhen und ihre Zusammensetzung von der Dominanz der Gammaproteobakterien und Firmicutes zur Dominanz von Bacteroides ändern. Diese Veränderung ist mit einer Reduktion der aeroallergenen Hyperreaktivität der Bronchien und dem vermehrten Auftreten von Treg-Zellen verbunden.

Bei Abwesenheit der mikrobiellen Kolonisation während der ersten beiden postpartalen Wochen bleibt die Hyperreaktivität der Bronchien im Mausversuch bis zum Erwachsenenalter erhalten (Gollwitzer et al. 2014).

\section{Daher ist die physiologische Entwicklung} des Mikrobioms der Atemwege für die Programmierung von Treg-Zellen in den ersten Lebenswochen von entscheidender Bedeutung, Dysregulation kann zu anhaltender Anfälligkeit für allergische Atemwegserkrankungen führen (Gollwitzer et al. 2014).

Diese Arbeit veranschaulicht die Erkenntnisse von Abrahamsson (Abrahamsson et al. 2011) (s. - Abb. 4.5), und macht deutlich, dass dem physiologischen Th1/Th2-Ungleichgewicht, das zum Zeitpunkt der Geburt auch bei jedem gesunden Kind besteht, durch die bakterielle Kolonisation in den ersten Lebenswochen gegengesteuert werden muss.

Nicht nur der Darm, sondern auch die Bronchien und alle anderen Epithelien des
Körpers müssen die Möglichkeit bekommen, „ihr“ spezifisches Mikrobiom aufzubauen, damit das Immunsystem reifen kann und die immunologischen Abwehrmechanismen richtig aktiviert werden. Dieses „early life window of opportunity“ ist abhängig von förderlichen Umwelteinflüssen, die im Folgenden ausführlich besprochen werden, kann jedoch durch antibiotische Behandlung empfindlich gestört werden.

Die Zusammensetzung des Mikrobioms der Atemwege in den ersten Lebensmonaten dürfte auch ein Prädiktor für späteres Asthma sein, auch wenn die Kinder noch asymptomatisch sind. Eine dänische Studie untersuchte das Mikrobiom des Nasopharynx von 321 asymptomatischen Kindern und beobachtete, dass die Kolonisation mit S. pneumoniae, $H$. influenzae oder $M$. catarrhalis, aber nicht mit S. aureus im Nasopharynx eine direkte Korrelation zu späterem persistierenden Giemen (hazard ratio, 2.40; 95 \% confidence interval [CI], 1.45-3.99), schweren, akuten Asthma-Exazerbationen (hazard ratio, 2.99; 95 \% CI, 1.66-5.39) und Krankenhausaufenthalten wegen Giemen (hazard ratio, 3.85; $95 \%$ CI, 1.90-7.79) aufwies. Eosinophilie und IgE mit 4 Jahren sowie die Prävalenz von Asthma mit 5 Jahren waren bei Kindern mit neonataler Kolonisierung mit $S$. pneumoniae, $H$. influenzae oder $M$. catarrhalis signifikant erhöht. (Bisgaard et al. 2007). Auch diese Studie bekräftigt die Rolle des Mikrobioms als epigenetischen Faktor für die Entwicklung von Asthma und Allergien.

Bei bereits manifestem Asthma kann man ebenfalls eine typische Veränderung des Mikrobioms der Lunge beobachten: Das Mikrobiom der Bronchien von 65 milden und suboptimal kontrollierten Asthmatikern enthielt bei Proben der unteren Luftwege mittels Bronchoskopie wesentlich mehr Proteobakterien ( z.B. Comamonadaceae, Sphingomonadaceae, Nitrosomonadaceae, Oxalobacteraceae und Pseudomonadaceae) als das Mikrobiom von gesunden Kontrollpatienten. Die Diversität des Mikrobioms war bei jenen Asthmatikern signifikant höher, die bei einer nachfolgenden 


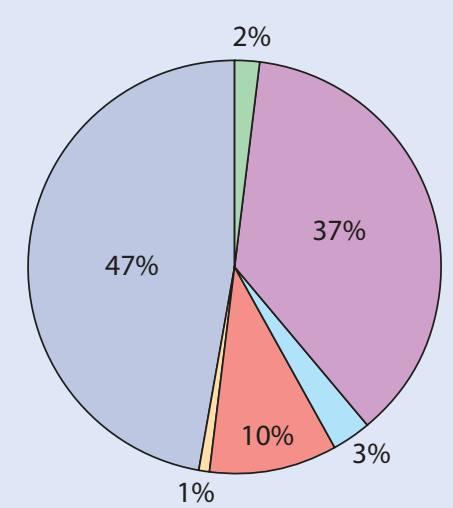

Asthma

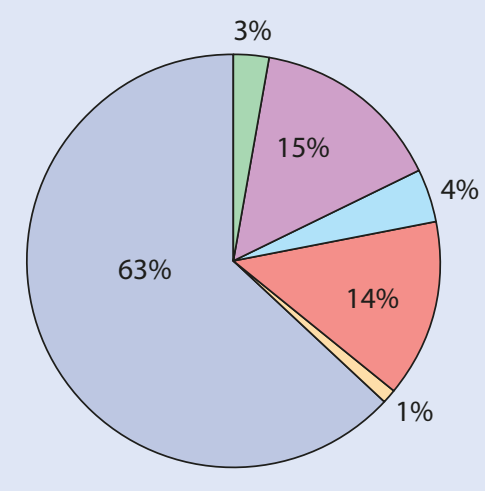

Kein Asthma
- Abb. 4.6 Mikrobielle Zusammensetzung des Sputums bei Asthma vs. Nicht-Asthma. (Mod. nach Marri et al. 2013). Das Mikrobiom der Rachenschleimhaut

Clarithromycin-Behandlung mit signifikanter Verbesserung der bronchialen Hyperreaktivität reagierten (Huang et al. 2011).

- Abb. 4.6 demonstriert, dass im Sputum bei milden Asthmatikern ohne Kortikoideinnahme mehr Proteobakterien und bei Gesunden mehr Firmicutes und Actinobacter beobachtet wurden, was darauf hindeutet, dass die Veränderungen auf Asthma selbst, und weniger auf die begleitende Kortikoideinnahme zurückzuführen sind (Marri et al. 2013).

Eine weitere Studie bestätigte diese Ergebnisse. 16S-rRNA-Bakterien-Sequenzierung an 42 Patienten zeigte 2000 bakterielle Genome per $\mathrm{cm}^{2}$ bronchialer Oberfläche. Pathogene Proteobacteria, besonders Haemophilus spp. und Moraxella spp., waren viel häufiger in den Bronchien von erwachsenen Asthmatikern als bei Gesunden. Hoch-signifikant erhöhte Proteobacteria wurden auch bei asthmatischen Kindern gefunden. Umgekehrt waren Bacteroidetes, besonders Prevotella spp., häufiger bei Gesunden, sowohl bei gesunden Kindern als auch gesunden Erwachsenen, zu sehen (Hilty et al. 2010).

In Zukunft wird es auch spannend zu beobachten sein, wie sehr Kortikoidtherapien, Antibiotika und Bronchodilatoren das Mikrobiom der Lunge beeinflussen. von Gesunden beinhaltet wesentlich mehr Firmicutes und Actinobacteria sowie weniger Proteobacteria als das Mikrobiom von Asthmatikern

Eine Studie versuchte den Unterschied zwischen dem Mikrobiom von kortikoidresistenten und kortikoidempfindlichen Asthmatikern zu untersuchen und fand keine Unterschiede bei der Vielfalt und Reichhaltigkeit der Phyla, jedoch Unterschiede auf dem Gen-Level. Zusätzlich wurden Makrophagen aus der BAL von Asthmatikern mit dem pathogenen Keim Haemophilus parainfluenzae inkubiert und man konnte beobachten, dass über Genexpression an kortikosteroidregulierten Genen die Kortikoidempfindlichkeit gehemmt werden konnte, während Inkubation mit dem physiologischen Bakterium Prevotella die Empfindlichkeit auf Kortikoide wiederherstellte (Goleva et al. 2013).

Gabe von Azitromycin bewirkte eine Reduktion von Haemophilus, Pseudomonas und Staphylococcus genera und ein Wachstum von Anaerococcus, einem wichtigen physiologischen Keim (Wong 2014). Dies könne ein Erklärungsmodell für die positiven protektiven Ergebnisse von Azithromyzin beim neutrophilen Asthma sein (s. A Abschn. 3.7.2.1 und 5.2.4.5).

Das intakte Mikrobiom der Lunge dürfte aber nicht nur Schutz vor allergischen Erkrankungen sein, sondern ist auch für die Empfänglichkeit für virale Infekte verantwortlich. Nature publizierte schon 2013 eine Studie, die zeigte, dass die Anwesenheit von Staphylococ- 
cus aureus, einem Bakterium, das physiologischerweise den unteren Respirationstrakt kolonisiert, vor Influenzaviren schützt. Bei künstlicher Infektion mit einer letalen Influenza-Dosis zeigten Mäuse, die ausschließlich mit Staphylococcus aureus im Respirationstrakt kolonisiert wurden, eine höhere Überlebensrate und einen geringeren Gewichtsverlust als Mäuse mit keimfreien Respirationstrakt. Staphylococcus aureus aktivierte die Einwanderung von Monozyten in die Alveolen, die sich zu M2-Makrophagen transformierten (vermittelt über Toll-like-Rezeptor-2), und, über Aktivierung von antientzündlichen Zytokinen und hemmenden Liganden, eine tödliche Infektion verhinderten (Wang et al. 2013).

Wenn das Mikrobiom noch unreif ist und durch Antibiotika geschädigt wird, sind Kinder auch für Infekte eher empfänglich. Heute wird immer klarer, dass kommensale Bakterien die Aktivierungsschwelle der antiviralen Abwehr beeinflussen, indem sie Typ-1- und Typ-2-Interferon-Signale triggern, die für die Abwehr gegen die meisten Viren von entscheidender Bedeutung sind (s. $>$ Abschn. 7.3). Der direkte Beweis wurde bereits insofern erbracht, als Gabe von Probiotika die Infektanfälligkeit senken konnte, und zwar entweder nasal verabreicht, direkt an die Atemwegsmukosa (Zelaya et al. 2015) oder auch oral z. B. bei Frühgeborenen (Luoto et al. 2014). Mehr dazu im - Abschn. 7.3.1.

\subsection{Pränatale Einflüsse}

Obwohl das "gesunde“ Darmmikrobiom als relativ stabile Gemeinschaft von verschiedenen Darmbakterien angesehen wird, kann es in den verschiedenen Lebensphasen zu Veränderungen in Struktur und Funktion kommen:

Die physiologische Darmflora entwickelt sich innerhalb der ersten 3 Lebensjahre zu einem Erwachsenen-artigen Mikrobiom (Yatsunenko et al. 2012) und ist in dieser Zeit besonders sensibel und abhängig von genetischen und epigenetischen Faktoren. Besonders Art und Zeitpunkt der Geburt, Wirtsgenetik, Er- nährung und Umweltfaktoren wie Geschwister, Aufenthalt in Kinderkrippen, sozialer Status, Medikation (Antibiotika) sowie Haustiere spielen eine große Rolle.

Bis vor Kurzem dachte man, der Darm sei intrauterin steril. 2013 wurden jedoch kleine Mengen von Bakterien im Mekonium und im Nabelschnurblut nachgewiesen (Cheng et al. 2013). Diese Tatsache ist deshalb wichtig, weil offensichtlich bereits die Ernährung der Schwangeren und die Zusammensetzungen von deren Darmflora den Grundstein für eine intakte Darmflora des Neugeborenen legen können.

Reduzierte Diversität von Bacteroidetes im Darm der Schwangeren wird mit einem erhöhten Risiko für das Auftreten eines IgE-assoziierten Ekzems bei deren Kindern in Verbindung gebracht und beweist die Rolle des Mikrobioms der Mutter in diesem Prozess (West et al. 2015).

2014 entdeckte man, dass auch die Plazenta Mikrobiota beherbergt (Aagaard et al. 2014).

Über ballaststoffreiche Ernährung wird die Bildung von SCFAs und Treg-Zellen im Darm der Schwangeren gefördert (s. $>$ Abschn. 4.11.3). Metaboliten von SCFAs stimulieren auch im Knochenmark die Hämatopoese mit verstärkter Bildung von Makrophagen- und DC-Vorstufen, die dann im Körper verteilt werden und z. B. in die Lunge wandern. Dort stimulieren sie die Bildung von Treg-Zellen und unterdrücken die Th2-Zelldifferenzierung (Thorburn et al. 2014).

- Abb. 4.7 demonstriert, dass Metabolite der SCFAs über die Plazenta auch in den sich entwickelnden Fetus gelangen, um dort die Entwicklung des fetalen Immunsystems und der Organe zu beeinflussen (Thorburn et al. 2014). Dadurch erhält das kindliche Immunsystem ideale Bedingungen für die Zeit nach der Geburt.

Nature (Sonnenburg et al. 2016) publizierte im Jänner 2016, dass Veränderungen des Mikrobioms durch ballaststoffarme Ernährung bei Mäusen über Generationen weitergegeben und auch noch in der 4. Generation nachgewiesen werden können!

Die gesunde Schwangere sollte keinesfalls auf bisher als allergen eingestufte Ernährung 


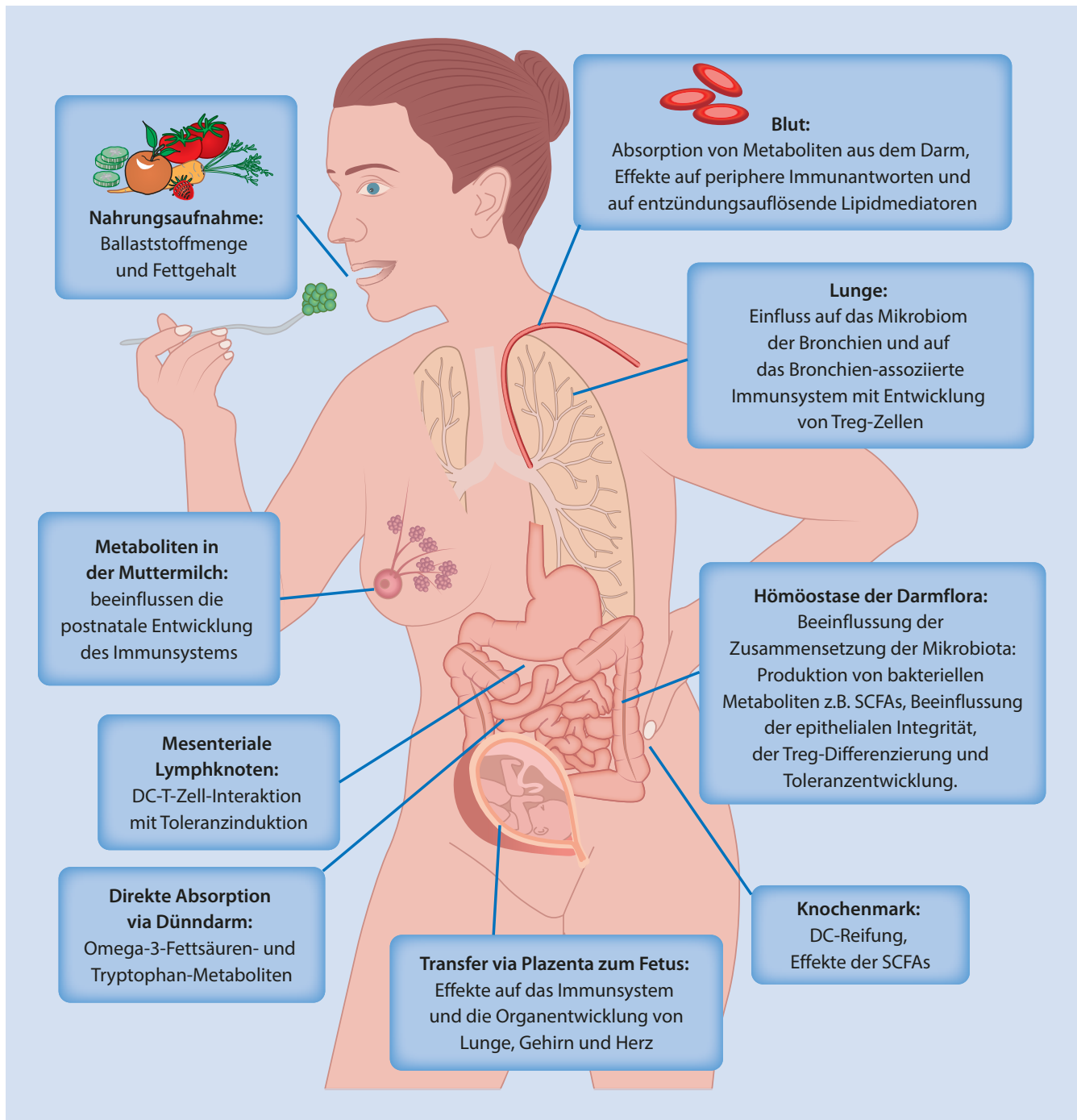

- Abb. 4.7 Pränatale Beeinflussung der immunologischen Entwicklung des ungeborenen/neugeborenen Kindes durch eine Ernährung reich an Ballaststoffen und Omega-3-Fettsäuren. Omega-3-Fettsäuren und SCFAs

wie Erdnüsse und Milch verzichten, weil sich gezeigt hat, dass der pränatale Kontakt des Kindes mit diesen Nahrungsmitteln die Toleranz fördert und das Auftreten von Allergien und Asthma reduziert (Bunyavanich et al. 2014).

Exposition zu Magensäure-Hemmern in utero (Dehlink et al. 2009) führt bei Kindern zu einer Zunahme der Entwicklung von Aller- interagieren via Knochenmark, Plazenta, Dünndarm, darmassoziiertem Immunsystem, mesenterialen Lymphknoten, Muttermilch, Blutgefäßen und Lunge mit dem kindlichen Immunsystem. (Mod. nach Thorburn 2014)

gien (OR 1.43, 95 \% CI 1.29-1.59) und zu einer Erhöhung der kindlichen Asthmarate (3,7\% der Gesamtpopulation vs. 5,6 \% der exponierten Kinder (OR 1.51, 95 \% CI 1.35-1.69).

Interessanterweise sind auch mütterliche Adipositas (BMI >30) und verstärkte Gewichtszunahme während der Schwangerschaft assoziiert mit einem erhöhten Asthmarisiko des Kindes (Forno et al. 2014). 
Als schützend stellt sich in einer aktuellen Arbeit, die im New England Journal of Medicine publiziert (Bisgaard et al. 2016) wurde, die Omega-3-Fettsäure Substitution heraus. 736 schwangere Frauen bekamen im 3. Trimenon $2.4 \mathrm{~g}$ Fischöl oder Placebo (Olivenöl) pro Tag. Innerhalb der ersten 3 Lebensjahre war das Risiko der Kinder, an persistierendem Giemen oder Asthma sowie an Infekten des unteren Respirationstrakts $\mathrm{zu}$ erkranken, in der Omega-3Gruppe um 30 \% reduziert. Bezüglich Ekzem und allergischer Sensibilisierung zeigte sich kein signifikanter Unterschied. Bestätigt wurden diese Ergebnisse durch eine aktuelle Meta-Analyse (Best et al. 2016), die einen protektiven Effekt von Omega-3-Fettsäure-Substitution in der Schwangerschaft auf die Entwicklung von allergischen Erkrankungen im Kindesalter

- mit reduzierter Inzidenz von atopischem Ekzem (RR [95 \% CI] 0.53 [0.35-0.81]), $\mathrm{P}=0.004)$

- reduziertem Auftreten von jedwedem positivem Skin-Prick-Test (0.68 [0.52-0.89], $\mathrm{P}=0.006$ )

- weniger Sensibilisierung gegen Eier (0.55 [0.39-0.76], $\mathrm{P}=0.0004$ )

- und weniger Sensibilisierung gegen jedwedes Nahrungsmittel $(0.59$ [0.46, 0.76], $\mathrm{P}<0.0001$ )

innerhalb der ersten 12 Lebensmonate feststellte (s. A Abschn. 6.8.3).

\subsection{Geburtsvorgang}

Massiveren Einfluss auf die bakterielle Besiedlung des Darms des Neugeborenen hat der Gebärvorgang. Bei der vaginalen Entbindung tritt der kindliche Organismus in Kontakt mit der mütterlichen Vaginal- und Darmflora. Vaginal entbundene Kinder beherbergen mehr Laktobazillen und Bifidusbakterien und weniger hautassoziierte Staphylococcus ssp. als mittels Kaiserschnitt entbundene Kinder (Dominguez-Bello et al. 2010). Eine Meta-Analyse zeigte bereits 2008, dass Kaiserschnitt-entbundene Kinder ein 20 \% erhöhtes Risiko haben, an Asthma zu erkranken (Thavagnanam et al. 2008).
2018 wurden Daten von 887.960 Geburten aus 13 großen prospektiven Kohortenstudien in einem systematischen Review mit MetaAnalyse analysiert (Keag et al. 2018) und demonstrierten ebenfalls, dass Kaiserschnittentbundene Kindern ein erhöhtes Risiko haben, bis zum Alter von 12 Jahren an Asthma zu erkranken (OR 1,21 [95 \%CI] 1,11-1,32).

In dem Licht, dass Kaiserschnitte in den letzten Jahrzehnten rapide zunahmen und in Westeuropa 24,5\%, in Nordamerika $32 \%$ und in Südamerika $41 \%$ aller Geburten ausmachen (NHS Choices 2016), erscheint eine Pilotstudie, die 2016 in Nature vorgestellt wurde, sehr interessant: Hier wurde mütterliches Vaginalsekret auf deren mittels Kaiserschnitt entbundene Neugeborene appliziert und daraufhin eine Anreicherung der oralen, intestinalen und Hautflora ähnlich wie bei vaginal entbundenen Kindern beobachtet, ganz zum Unterschied von Kaiserschnitt-Kindern ohne Exposition. Über die Langzeit-Gesundheitskonsequenzen konnten die Autoren noch keine Auskunft geben, jedoch klar demonstrieren, dass der fehlende Kontakt der Kaiserschnittkinder zu den vaginalen Mikroben durch den Transfer zumindest teilweise ausgeglichen werden konnte (Dominguez-Bello et al. 2016).

\subsection{Hospitalisierung und Gestationsalter}

Bei Frühchen zeigte sich eine geringe Vielfalt der fäkalen Mikrobiota (Jacquot et al. 2011), mit niedrigeren Mengen an Bifidobakterien und Bacteroides, aber mehr Proteobacteria (Butel et al. 2007). Auffällig ist auch eine hohe interindividuelle Variabilität und abrupte Verlagerungen von Bakterienarten und -stämmen, besonders ein vermehrtes Vorkommen von Clostridium difficile, die dann auch häufig rezidivierende Infektionen mit nekrotischer Enterokolitis auslösen. Kinder mit Clostridium-difficile-Infektionen im ersten Lebensmonat erkranken im frühen Schulalter signifikant häufiger an Asthma und Giemen (Van Niemwegen 2011). 
Bei Hausgeburten kommen Kinder offensichtlich mit mehr Keimen in Kontakt. Kinder von atopischen Eltern hatten eine $50 \%$ Reduktion des Asthmarisikos, wenn diese bei einer vaginalen Hausgeburt im Vergleich zu einer vaginalen Spitalsgeburt zur Welt kamen (Van Niemwegen 2011).

\subsection{Lebensumgebung}

Die berühmten zum Teil auch in Österreich durchgeführten „Bauernhofstudien“ ließen die Welt aufhorchen und lenkten schon um die Jahrtausendwende den Blick auf die Bedeutung der Konfrontation mit vielen verschiedenen Mikroben aus der Umwelt. Kontakt von kleinen Kindern zu Ställen mit Viehhaltung und das Trinken von nicht-pasteurisierter Milch sind direkt assoziiert mit geringerem Auftreten von Asthma, Heuschnupfen und allergischer Sensibilisierung. Je früher und je länger die Kinder in Kontakt mit Ställen kommen, desto geringer ist das Risiko. Am geringsten ist das Allergierisiko allerdings, wenn die Mütter bereits in der Schwangerschaft regelmäßig Zeit im Stall verbringen. Dies führte schon 2001 zur Vermutung, dass das Immunsystem durch äußere Einflusse epigenetisch bereits intrauterin moduliert wird (Riedler 2001).

Kurz darauf erkannte man anhand von Beobachtungen an mehreren tausend Kindern der GABRIELA- und der PARSIFAL-Studie, dass wider Erwarten - die Höhe der EndotoxinWerte aus Matratzen indirekt mit dem Auftreten von Allergien korreliert. Endotoxine sind Lipopolysaccharide (LPS) aus Zellwandbestandteilen von Bakterien, Staub und Pilzen. Das Risiko für Asthma reduziert sich, je mehr Bakterien (Listeria monocytogenes, Bacillus sp., Corynebacterium sp.) und Pilze (Penicillium sp., Cladosporium sp. und andere) in den Matratzen von Kindern gefunden werden (Ege et al. 2011). 2016 veröffentlichte das NEJM wieder eine Arbeit, in der die beiden genetisch ähnlichen amerikanischen Volksgruppen von Hutterern und Amischen beobachtet wurden (Stein et al. 2016). Beide Gruppen sind ursprünglich aus Bayern und Südtirol nach Nordamerika ausgewandert und leben völlig zurückgezogen ein Leben, fast ohne Einflüsse der heutigen Zeit, mit vielen Kindern, fettreicher Nahrung, minimaler Luftverschmutzung, trinken rohe Milch und haben eine geringe Adipositasrate sowie minimalen Tabakgenuss. Der einzige Unterschied besteht in der Art, Landwirtschaft zu betreiben. Während die Amischen traditionelle Landwirtschaft mit Pferden und Einzelfamilien-Haushalten betreiben, leben die Hutterer in hoch-industrialisierten kommunalen Landwirtschaftsgemeinschaften. Die Prävalenz von Asthma bei Schulkindern von Amischen versus Hutterern beträgt 5,2 \% versus $21,3 \%$, und von allergischer Sensibilisierung $7,2 \%$ versus $33,3 \%$. Dieser erstaunlich große Unterschied wird mit dem direkten Stallkontakt der Amischen erklärt, der für ein höher exprimiertes A20 verantwortlich sein dürfte.

A20 ist ein kürzlich entdecktes Enzym, das von Lungenepithelzellen produziert wird und die Th2-Aktivierung hemmt (Ma und Malynn 2012).

Insbesondere in der Nähe von landwirtschaftlichen Betrieben mit Milchkühen enthält die Luft größere Mengen an bakteriellen Endotoxinen. Die durch Lipopolysaccharide (LPS) aus Zellwandbestandteilen ausgelöste entzündungsdämpfende Wirkung ist abhängig von einer erhöhten Produktion des Enzyms A20 in den Lungenepithelzellen. Mäuse, denen dieses Enzym fehlt, können durch LPS-Vorbehandlung keinen Allergieschutz entwickeln. Dagegen löst der Kontakt mit den Milben bei ihnen besonders starke Asthmasymptome aus. Auch Asthmatiker scheinen weniger A20 produzieren zu können, wie an Zellkulturen gezeigt wurde. An Epithelzellen gesunder Menschen unterdrückte eine Behandlung mit LPS jedoch die Th2-aktivierten Entzündungsreaktionen und offenbarte den schützenden Effekt bei intaktem A20. Bei der seltenen Variante eines Polymorphismus des Gens, das A20 kodiert, kann der schützende „Bauernhofeffekt " nicht eintreten, was erklärt, warum manche Kinder auf Bauernhöfen - trotzdem unter Allergien leiden (Schuijs et al. 2015). 
Zusätzlich dürfte der schützende Effekt der mikrobiellen „Staub“-Stimulation auch auf eine Aktivierung der Gene MyD88 und Trif mit nachfolgender Produktion von TNF und IL-1 zurückzuführen zu sein.

MyD88 und Trif sind wichtige Adaptorproteine, die die Signalwege zwischen Mikrobe und den Toll-like-Rezeptoren (TLR) regulieren (s. A Abschn. 5.2.3.2).

Auch hier zeigt sich deutlich, dass nicht nur das Mikrobiom des Darms für die Aufrechterhaltung des immunologischen Gleichgewichtes verantwortlich sein dürfte, sondern auch das Mikrobiom der Atemwege. Die Luft enthält große Mengen an Bakterien, Viren, Pilzen, Archaea, Sporen, Pollen, Pflanzenbiomasse und Staub. Abhängig von der Umgebung werden in 24 Stunden $10^{6}$ bis $10^{10}$ Bakterien bzw. Archaea eingeatmet und ein gewisser Teil der Zellbestandteile bleibt in den Atemwegen und aktiviert das entzündungsdämpfende A20.

Ganz ähnliche Beobachtungen machte man auch in Polen, wo 2003 und 2012 eine Kleinstadt namens Sobotka mit nur 4000 Einwoh-

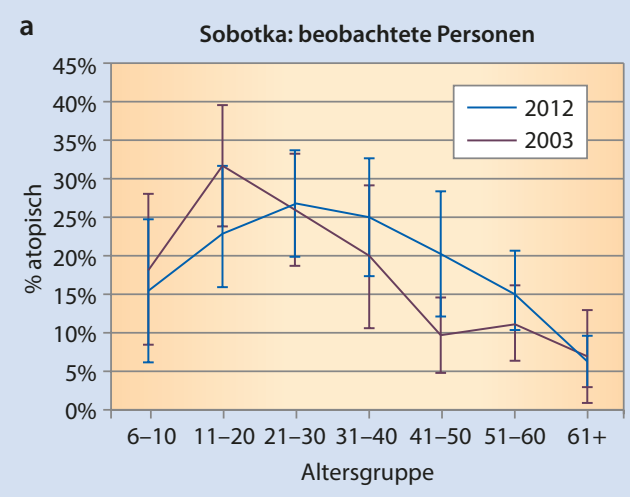

- Abb. 4.8 Alterabhängige Prävalenz von Atopie in Sobotka (a) und den umliegenden Dörfern (b) 2003 und 2007. a: In der polnischen Kleinstadt Sobotka beobachtete man bereits 2003 bei eher jüngeren Menschen bis zum 40. Lebensjahr hohe Raten von Atopien, bei Älteren noch selten. 2012 veränderte sich die Atopierate bei Jüngeren kaum, stieg jedoch im höheren Alter an. b: In den nern und die etwa $10 \mathrm{~km}$ entfernten umliegenden Dörfer beobachtet wurden (Sozanska et al. 2014). Zwischen den beiden Beobachtungszeiträumen lag der Beitritt zur EU im Jahre 2004. Die Allergieraten unterschieden sich 2003 zwischen der Kleinstadt Sobotka und den umliegenden Dörfern deutlich. Obwohl Sobotka nur wenige Kilometer von den Dörfern entfernt liegt, hatten 2003 19,9 \% der Bevölkerung eine Atopie, im Vergleich zu 7,3 \% in den Dörfern (s.• Abb. 4.8). Hatten 2003 noch 24,3 \% der Dorfbewohner Kontakt zu Kühen (damals besaßen noch viele Landbewohner einzelne Kühe für den Eigenbedarf), waren es 2012 nur mehr 4 \%. 35 \% der Dorfbewohner tranken 2003 noch unpasteurisierte, rohe Kuhmilch, während dies 2012 nur mehr $9 \%$ taten.

2012 hatte sich die Atopierate in Sobotka kaum verändert (20\%), während die Dorfbewohner fast aller Altersklassen eine Steigerung auf durchschnittlich 17,8 \% aufwiesen und sich somit an die Bewohner von Sobotka anglichen. Unter Bezugnahme vieler verschiedener Parameter wurde als ursächlich stärkster protektiver Effekt in dieser Studie die Kuhhaltung identifiziert.

Diese Studie zeigt, wie schnell Atopien als Ergebnis der „Modernisierung“ ganze Regionen

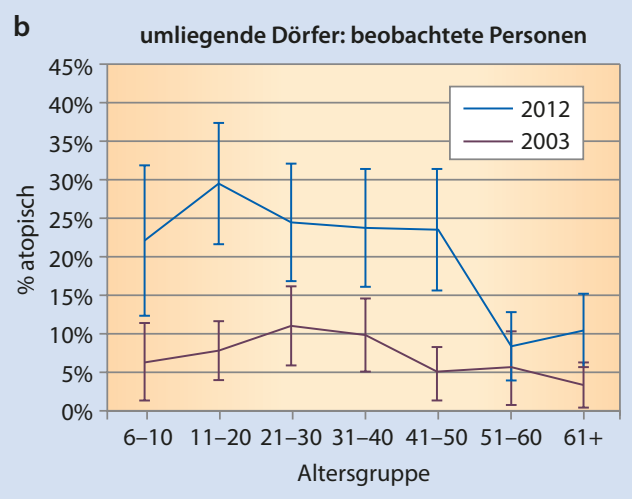

umliegenden Dörfern war die Atopierate 2003 in jeder Altersstufe deutlich niedriger als im Ort Sobotka, im Jahr 2013 stieg die Prävalenz auch in den Dörfern deutlich an und es gab kaum mehr Unterschiede zur benachbarten Kleinstadt Sobotka. Blaue Linien: Atopieraten von 2012, violette Linien: Atopieraten von 2003. (Mod. aus Sozanska et al. 2014) 
befallen können, in diesem Fall durch Wegfallen eines jahrhundertealten Brauchs der Tierhaltung in kleinem Umfang, die nach dem Beitritt Polens zur EU 2004 unökonomisch geworden war.

Auch in einem weiteren Kontinent, im südlichen China, offenbart ein Vergleich zwischen dem städtischen Guang zhou und einer benachbarten Landregion in Cong hua, mit Geflügelhaltung und erhöhter Endotoxinbelastung durch Ackerbau, ähnliche Ergebnisse mit reduziertem Risiko für Asthma bei Kindern der ländlichen Region (Feng et al. 2016).

Eine finnische Studie macht deutlich, dass Atopien auch seltener in Wohnumgebungen mit nahem Wald und landwirtschaftlich genutztem Land auftreten und die Menge an "grüner" Umgebung die Biodiversität des Hautmikrobioms positiv beeinflusst (Ruokolainen et al. 2015). Grüne Umgebung, besonders in den ersten Lebensjahren, scheint über Umwelt-Mikrobiota das kommensale Mikrobiom des Menschen Richtung Immuntoleranz zu beeinflussen (Hanski et al. 2012).

Diese Tatsache ist umso bedeutsamer, weil die UNO annimmt, dass 2050 zwei Drittel der Weltbevölkerung in städtischer Umgebung mit wenig Grünflächen und reduziertem Kontakt zu Natur und Biodiversität leben werden (United Nations 2008). Schon heute verbringen die Engländer $90 \%$ ihrer Zeit in Innenräumen (Indoor Air Quality 2019).

Ganz aktuell wurde aus geographischen Daten von bayrischen Kindern der GABRIELA Studie berechnet, dass ein Bauernhof in der Nachbarschaft, im Radius von maximal 100 Metern Entfernung zum Wohnort, einen deutlich schützenden Effekt auf die Asthma- und Atopieentstehung hat, während ein Abstand von mehr als 500 Metern das Risiko einer Atopie sogar erhöht. In dieser Studie wurde der schützende Effekt der Farm bei Nicht-Bauernhofkindern hauptsächlich durch Trinken von unpasteurisierter, roher Kuhmilch erklärt (Müller-Rompa et al. 2018). Dies ist auch der Grund, warum die Wissenschaft bereits an Milchprodukten arbeitet, die die positiven Eigenschaften der unpasteurisierten Kuhmilch, aber kein Risiko für etwaige Infektionensübertragungen wie $\mathrm{z}$. B. Tbc in sich tragen.
Interessanterweise beobachtete man in dieser Studie auch Unterschiede zwischen den verschiedenen Bauernhofkindern. Lebten diese Kinder auf Bauernhöfen mit anderen benachbarten Farmen innerhalb von 50 Metern, war dies verbunden mit einer höheren bakteriellen Diversität und höherem Endotoxinkontakt als bei jenen Bauernhofkindern ohne andere Farmen im engeren Umkreis. Dies bestätigte die Ergebnisse aus der Studie mit Amischen und Hutterern, dass kleinere, „traditionell“ geführte Bauernhöfe einen größeren Schutzeffekt bieten als „industrialisierte“ Landwirtschaft.

Somit gibt es hinsichtlich Reduktion des Atopierisikos gute und „bessere“ Farmen!

\subsection{Hygiene}

Der Terminus „Hygiene-Hypothese“ ist irreführend und sollte nicht mehr verwendet werden. Durch falsche vereinfachende Kommunikation geriet Hygiene in den Ruf, Allergien zu verursachen. Exzessive Sauberkeit soll das Anwachsen der Allergieraten verursacht haben. Das heutige Verständnis zeigt jedoch, dass die relevanten, vor Allergien schützenden, mikrobiellen Kontakte fast ausschließlich über Ernährung, Vermeiden von Antibiotika und Lebensstilmaßnahmen herbeigeführt werden. Die Änderung des Begriffs in Mikroflora (oder Biodiversitäts-)-Hypothese statt Hygiene-Hypothese stellt klar, dass wir den Schutz vor Infektion - besonders vor resistenten Keimen - durch geeignete Hygienemaßnahmen in Krankenhäusern, Arztpraxen und zu Epidemiezeiten maximieren müssen, andererseits aber die Beibehaltung der Exposition und dadurch die Besiedlung der Epithelien mit essenziellen Mikroben fördern sollten.

Gezielte Desinfektion ist in Zeiten von resistenten Keimen extrem wichtig, weil deren Vermeidung globale Priorität hat. Beste Standards von Hygiene sind notwendig zur Vermeidung der stillen Übertragung von antibiotikaresistenten Keimen in Krankenhäusern, aber auch durch gesunde Keimträger im Alltag (Bloomfield et al. 2016). 
In entwickelten Ländern ziehen sich $7 \%$ aller Patienten im Krankenhaus Infektionen mit resistenten Keimen zu, besonders Clostridium difficile, Methicillin-restistente Staphylococcus aureus (MRSA), Pseudomonas und neue Stämme von E. coli (World Health Organization 2015). Auch zur Vermeidung von viralen Infekten wie Norovirus, Ebola, SARS, Influenza und auch Rhinovirus stellt Hygiene den ersten wichtigen Schritt dar.

Kampagnen für „targeted hygiene“ sind im Laufen. Auch in Österreich wurden diese Hygienestandards nicht nur in allen Krankenhäusern, sondern auch in allen Arztpraxen eingeführt und werden seit Kurzem streng überprüft. Eine Meta-Analyse zeigte, dass alleine die Maßnahme der Verbesserung der Händehygiene in einer Reduktion der gastrointestinalen Infektionen um $31 \%$ und der respiratorischen Infekte um $21 \%$ resultierte (Aiello et al. 2008). Eine europaweite Initiative - das e-bug project - hat das Ziel, dass alle Kinder die Schule mit dem Wissen über ge- zielte, sinnvolle Hygienemaßnahmen verlassen (The e-bug project 2018).

\subsection{Haustiere}

Der Kontakt zu Haustieren im ersten Lebensjahr reduziert das Risiko einer allergischen Sensibilisierung im Schulalter. Das Risiko eines positiven Skin-Prick-Tests im Schulalter ist bei Kindern ohne Haustiere im ersten Lebensjahr $33 \%$, bei 2 oder mehr Haustieren (Katzen oder Hunde) $15,4 \%$ und somit deutlich reduziert (Ownby et al. 2002) • Abb. 4.9.

Bereits in der Schwangerschaft scheint der Kontakt zu Katzen und Hunden allergieprotektiv zu wirken. Kinder, in deren Haushalt Katzen oder Hunde leben, haben schon im Nabelschnurblut signifikant reduzierte IgE-Werte im Vergleich zu Haushalten ohne Hunde und Katzen (Aichbhaumik et al. 2008). Besonders Haustiere, die auch ins Freie dürfen, bringen Mikroben aus Luft, Erde und Wasser in den

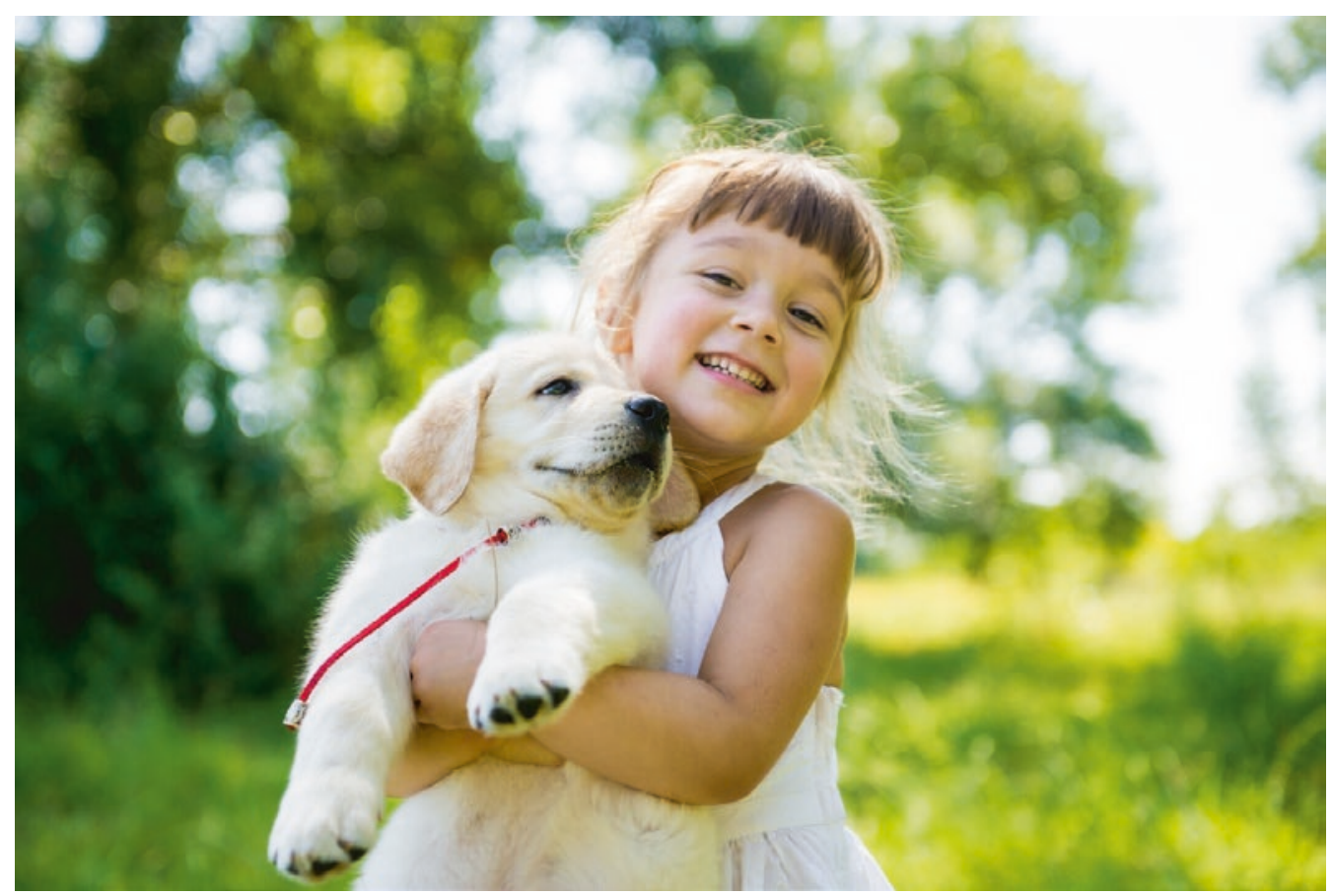

- Abb. 4.9 Tierkontakt schützt vor Atopien. Je früher und intensiver Kinder in direkten Kontakt mit Bauernhöfen/Ställen kommen, umso geringer ist das Risiko der Entwicklung einer Atopie 
Wohnbereich, die sich protektiv auswirken dürften (Fujimura et al. 2010).

Wenn bereits eine Sensibilisierung besteht, ist vom Kontakt mit Haustieren abzuraten.

\subsection{Das Mikrobiom der Haut, Waschverhalten, Hauttrocken- heit und Hautschutzmaßnah- men zur Verbesserung der Hautbarriere}

Die Haut des neugeborenen Kindes ist von der eiweiß- und fettreichen Vernix caseosa bedeckt, die das Baby bereits intrauterin schützt, aber auch postpartal vor Kälte sowie schädlichen Noxen abschirmt und die Entwicklung der Hautbarriere mit einem ausgewogenen Mikrobiom begünstigt.

Aus diesem Grund empfiehlt man heute diese Käseschmiere nicht sofort nach der Geburt abzuwaschen, sondern die Haut nur mit einem trockenen Tuch sehr sanft abzuwischen. Babys sollten nach Abfall der Nabelschnur (oder evtl. auch schon davor) in den ersten Wochen und Monaten nicht unbedingt täglich, aber zumindest 2- bis 3-mal/Woche gebadet werden (Blume-Peytavi et al. 2016).

Nach und nach kommt die kindliche Haut mit Mikroorganismen der Umwelt in Kontakt. Das Mikrobiom der Haut weist physiologisch, je nach Körpernische, große lokale und altersspezifische Unterschiede auf.

Die atopische Dermatitis ist oft die erste Manifestation des allergischen Marsches und tritt bei 15-30\% aller Kinder, jedoch auch bei 2-10\% der Erwachsenen auf (Seite und Bieber 2015). Sie ist gekennzeichnet durch eine Störung der Epithelbarriere mit gestörter antimikrobieller Peptidproduktion, veränderter Fettzusammensetzung und erhöhtem transepithelialen Wasserverlust (TEWL). Durch die mangelnde Barrierefunktion wird der Eintritt von Irritantien, Allergenen und Pathogenen erleichtert, die in den Keratinozyten die Freisetzung von TSLP aktivie- ren und entzündliche Th2-Immunantworten auslösen (• Abb. 4.10). Die Th2-Zytokine IL-4 und IL-13 stören auch ihrerseits wieder die Bildung der antimikrobiellen Peptide und der "tight junctions" der Hautbarriere.

Bei atopischer Dermatitis ist die mikrobielle Diversität reduziert und bei $90 \%$ aller Patienten findet man eine kutane Besiedlung mit Staphylococcus aureus (Seite und Bieber 2015), dessen übermäßiges Wachstum mit der Schwere der Erkrankung und akuten ekzematösen Exazerbationen direkt korreliert.

- Staphylococcus aureus verletzt über Proteasen (ähnlich wie das Hausstaubmilbenallergen) die epidermale Integrität.

- Staphylococcus-aureus-Besiedlung hemmt die Filaggrin-Bildung.

- Staphylococcus-aureus-Superantigene Enterotoxin A und B initiieren über Aktivierung von TSLP typische Th2- und B-Zell-Antworten.

- Staphylococcus aureus produziert auch $\delta$-Toxine, die die Mastzellen stimulieren, und $\alpha$-Toxine, die die Keratinozyten zerstören (Geoghegan et al. 2018).

Dem Wachstum von Staphylococcus aureus kann durch kommensale Koagulase-negative Bakterien (CONS) wie Staphylococcus epidermidis, Staphylococcus hominis und Staphylococcus lugdunensis gegengesteuert werden (Geoghegan et al. 2018).

Besonders Staphylococcus epidermidis aktiviert antimikrobielle Peptide der Keratinozyten sowie Tight-junction-Proteine und induziert die Bildung von lokalen FoxP3Treg-Zellen, die überschießende Immunreaktionen hemmen und besonders für die frühkindliche Toleranzentwicklung von großer Bedeutung sind (Yamazaki et al. 2017).

Zur gesunden Hautflora zählt man auch Corynebakterien, Propionibacterien, Acinetobacter, Prevotella, Proteus und Streptococcus, die bei der atopischen Dermatitis oftmals reduziert sind (Bjerre et al. 2017). Studien, die versuchen, das Hautmikrobiom mittels lokaler 
Auslösung der atopischen Dermatitis

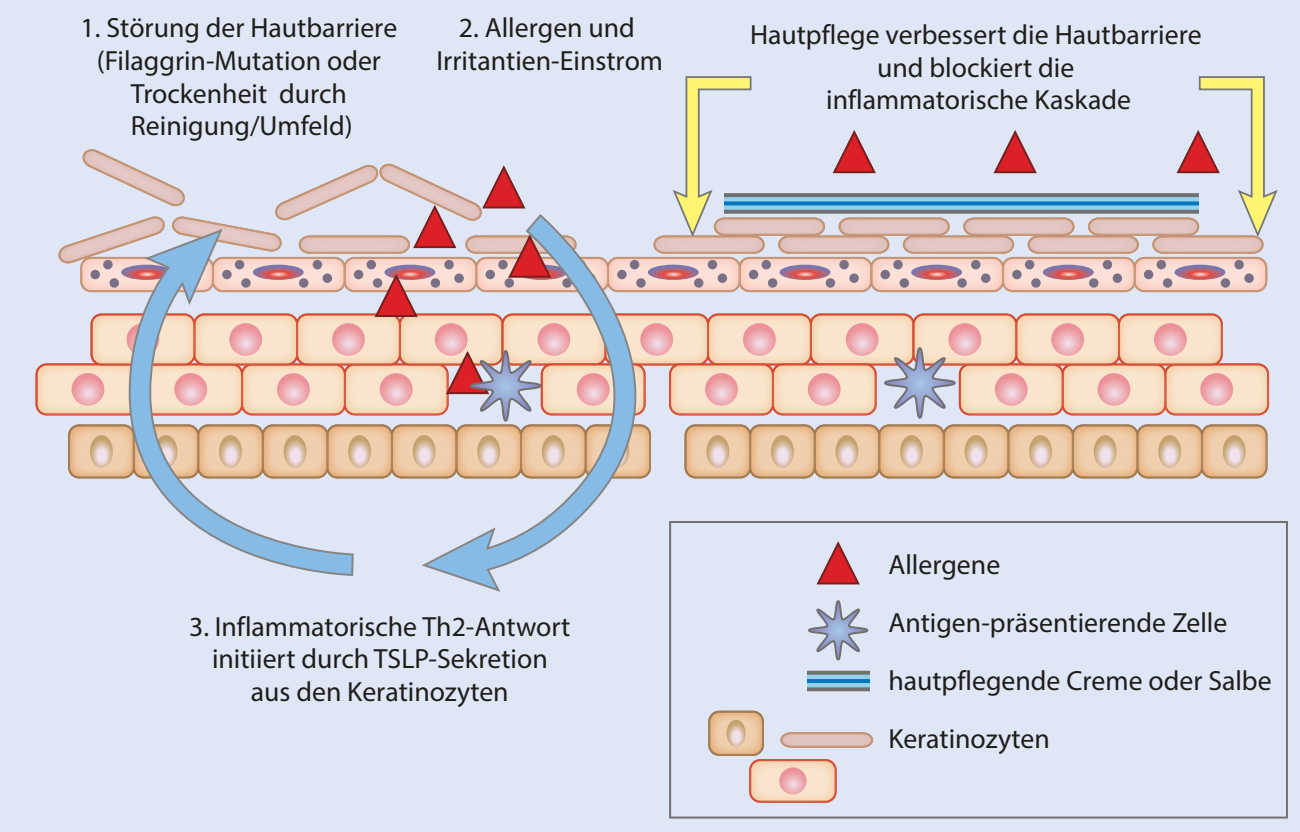

\section{Prävention der atopischen Dermatitis} und blockiert die flammatorische Kaskade

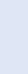

(n)

- Abb. 4.10 Primäre Prävention der atopischen Dermatitis (Mod. nach Simpson et al. 2014). Routinemäßiges Eincremen verbessert die Hautbarriere, hemmt das

Zufuhr von bestimmten Keimen gezielt zu regenerieren, sind im Laufen und könnten einen neuen, zusätzlichen Therapieansatz darstellen.

Die Hautbarriere spielt bei der Entwicklung des atopischen Ekzems eine wesentliche Rolle und kann durch regelmäßiges routinemäßiges Eincremen und Befeuchten der Haut verbessert und geschützt werden (s. - Abb. 4.10): In einer Studie wählten Eltern zwischen Sonnenblumenöl mit hohem Linolensäure/Ölsäure-Anteil, einer Creme bzw. Gel (Doublebase-Gel oder Cetaphil-Creme), oder einer Salbe (flüssiges Paraffin $50 \%$ in weißem, weichem Paraffin oder Aquaphor-Heilsalbe) aus und trugen diese auf die gesamte Körperoberfläche des Babys, außer der Kopfhaut, 2x täglich, möglichst frühzeitig postpartal, auf. Dadurch konnte das Risiko für das primäre Auftreten einer atopischer Dermatitis in den ersten 6 Monaten im Vergleich zu einer Kontrollgruppe halbiert werden (Simpson et al. 2014).
Eintreten von Allergenen, verhindert Aktivierung von TSLP durch Keratinozyten und inflammatorische Zellantworten

Diese Ergebnisse wurden von einer japanischen Studie bestätigt, die in der 32. Lebenswoche ebenfalls ein um $32 \%$ reduziertes Auftreten einer atopischen Dermatitis/Ekzem nach regelmäßigem Auftragen einer Hautemulsion beobachtete (Horimukai et al. 2014).

Offensichtlich gelingt es bei prädisponierten Kindern mit subklinischer Hautbarrieren-Dysfunktion durch weichmachende Cremen/ Salben/Öle über Hautbefeuchtung, Barrierestabilisierung und Reduktion der Permeabilität, die Trockenheit und Rissigkeit der Haut zu verbessern und das Eintreten von Allergenen und Irritantien in die Epidermis zu reduzieren.

Mehr noch, die PEBBLES-Pilotstudie (Lowe et al. 2018) brachte zum Vorschein, dass auch der allergische Marsch blockiert werden kann: Auftragen einer Ceramid-/Cholesterolhaltigen Mixtur 2-mal/Tag bei 80 Kindern, neonatal bis zum 6. Lebensmonat, führte nicht nur zu einem Trend in Richtung reduziertem 
Auftreten eines atopischen Ekzems im Alter von 6 und 12 Monaten, sondern auch zur Tendenz einer reduzierten Nahrungsmittelsensibilisierung im Alter von 12 Monaten, 6 Monate nach Beendigung der Therapie.

Da auch schon bei Mausversuchen epikutan eine Sensibilisierung auf Ovalbumin mit erhöhtem Serum-IgE und Hyperreaktivität der Bronchien ausgelöst werden konnte (Spergel et al. 1998), vermutet man derzeit, dass die Hautbarriere auch als Ort der Sensibilisierung gegenüber Nahrungsmittelallergenen angesehen werden muss, was in der Folge zu einer Nahrungsmittelallergie, aber auch zur Entwicklung von allergischem Asthma führen kann.

Daher nimmt man heute an, dass durch die defekte Hautbarriere eine Antigen-Penetration erleichtert wird, die eine verstärkte Sekretion von TSLP aus den Keratinozyten nach sich zieht. Dadurch werden DCs aktiviert und triggern die vermehrte Th2-Differenzierung, mit folgendem IgE-Switching in Richtung IgEProduktion (Ziegler et al. 2006). Durch die folgende Verteilung der Memory-T-Zellen in den Blutkreislauf kann über die defekte Epithelbarriere der Haut nicht nur die erhöhte Th2-Differenzierung mit folgender atopischer Dermatitis ausgelöst werden, sondern auch der atopische Marsch mit Nahrungsmittelallergie, Asthma und allergischer Rhinitis in Gang gesetzt werden.

Auch die Interaktion zwischen TSLP und den Langerhans'schen Zellen dürfte nach epikutaner Sensibilisierung gegenüber Nahrungsmittelallergenen eine vermehrte IgE-Produktion fördern (Nakajiama et al. 2012).

Hautschutz stellt daher eine wichtige primäre Präventionsmaßnahme für den allergischen Marsch dar. Zukünftige Studien werden die mögliche Schutzfunktion der Hautbarrieren-Verbesserung durch Cremen/Öle/Salben - bezüglich Reduktion der IgE-Sensibilisierung noch besser erforschen.

Die ideale Therapie zur Wiederherstellung der Barrierefunktion sollte
- den vermehrten transepithelialen Wasserverlust reduzieren,

- die Hydration des Stratum corneums verbessern,

- und die Haut vor dem Eindringen von Allergenen schützen.

Derzeit werden zum Hautschutz physiologische Ceramid-hältige Produkte auf Lipidbasis (Ceramid-Cholesterol-freie Fettsäuren im Verhältnis 3:1:1) empfohlen, die in das Stratum corneum eindringen können und in die Keratinsynthese eingebunden werden. Dadurch haben diese Produkte auch als Therapie der atopischen Dermatitis die Fähigkeit, die Inflammation und den Juckreiz zu reduzieren (Lee et al. 2014).

Im Februar 2018 publizierten Glatz et al. (2018), dass routinemäßiges Eincremen auch das Mikrobiom der Haut beeinflusst. Über Abstriche an Wangen, Kniekehlen und Ellenbeugen von 6 Monate alten Kindern entdeckte man mittels 16S-rRNA-Sequenzierung eine allgemein erhöhte mikrobielle Diversität und signifikant vermehrt Streptococcus salivarius in der mit Emolliantien behandelten Gruppe. Gemeinsam mit einem signifikant erniedrigten pH-Wert dürfte die bakterielle Vielfalt für die positiven Effekte von Emolliantien auf die Hautbarriere verantwortlich sein, die auch in dieser Studie zu einem selteneren Auftreten von atopischer Dermatitis in der Emolliantiengruppe im Vergleich zur Kontrollgruppe führte.

Der pH-Wert der Haut ist mit 4.5-5.5 etwas saurer als im übrigen Körper. Dieser „Säureschutzmantel“ hemmt die Permeabilität, schützt die Hautbarriere und stärkt die antimikrobielle Abwehrfunktion. Das Wachstum von Staphylococcus aureus, der bei einem $\mathrm{pH}$-Wert von 7.5 am besten gedeiht, kann durch niedrige pH-Werte reduziert werden (Lee et al. 2014).

Aktuelle Guidelines empfehlen daher, auch bei der Körperwäsche auf nicht-seifenhaltige Reiniger mit neutralem oder niedrigem $\mathrm{pH}$ Wert zurückzugreifen, da alkalische Seifen 
mit den Proteinen und Lipiden des Stratum corneum interagieren und Irritationen der Epithelbarriere sowie Austrocknung der Haut verursachen (Eichenfield et al. 2014).

Auch Waschen der Haut mit hartem Wasser, reich an Kalziumkarbonat und Magnesiumkarbonat kann die Hautbarriere beeinflussen. Kinder, die in Gegenden mit hartem Wasser leben, haben eine höhere Wahrscheinlichkeit, an einer atopischen Dermatitis zu erkranken, als Kinder aus Gegenden mit weichem Wasser (Engebretsen et al. 2016). Waschen mit Sodium-Lauryl-Sulfat, einem Tensid, gemeinsam mit unterschiedlich hartem Wasser, führte zu verstärkten Sodium-Lauryl-Sulfat-Ablagerungen an jenen Hautstellen, die mit hartem Wasser gewaschen wurden. Diese Ablagerungen erhöhten den transepidermalen Wasserverlust und verursachten Irritationen, besonders bei Patienten mit atopischer Dermatitis und Fillaggrin-Mutation, während der Chlorgehalt des Waschwassers die Hautbarriere nicht veränderte. Ionenaustauschende Wassererweicher hemmten die negativen Effekte des harten Wassers und reduzierten das Risiko, eine atopische Dermatitis zu entwickeln (Danby et al. 2018).

\subsection{Vitamin D}

Die Evidenz bezüglich Vitamin-D-Einnahme und der Entwicklung von allergischen Erkrankungen ist sehr widersprüchlich.

Klare Evidenz besteht bereits bezüglich der positiven Wirkung der Gabe von Vitamin-D in der Schwangerschaft. Beobachtungen an Schwangeren zeigten, dass mütterlicher Vitamin-D-Mangel zwischen der 16. und 20. Gestationswoche zu mangelnder fetaler Lungenentwicklung führen kann, die Lungenfunktion im Alter von 6 Jahren beeinflusst sowie die Wahrscheinlichkeit einer Entstehung von Asthma erhöht (Zosky et al. 2014).

Gabe von Vitamin D an Schwangere reduzierte das Risiko für rezidivierendes Giemen
(Devereux et al. 2007), aber auch von Asthma und allergischer Rhinitis des Kindes (Erkkola et al. 2009). Wenn Vitamin-D allerdings erst im 2. oder 3. Trimester der Schwangerschaft verabreicht wurde, zeigten die Ergebnisse keinen eindeutigen Effekt (Maslova et al. 2013). Auch die Analyse von 2 weiteren Studien mit Vitamin-D-Supplementierung während der Schwangerschaft wies einen signifikanten schützenden Effekt vor Asthma und rezidivierendem Giemen der Nachkommen nach (Wolsk et al. 2017).

Bei Verabreichung von Vitamin-D an Kinder in der frühen Kindheit sind die Daten nicht so eindeutig und derzeit sind noch keine Empfehlungen möglich: Ganz aktuell zeigte eine finnische Geburtskohorten-Studie, dass Vitamin-D-Einnahme in den ersten 4 Lebensjahren das Auftreten von atopischem und nicht-atopischem Asthma im Alter von 5 Jahren sogar erhöhte (Nwaru et al. 2017) (!).

Aktuelle epidemiologische Studien wiesen ambivalente Beobachtungen auf, bei denen sowohl zu niedrige als auch erhöhte Vitamin-DWerte bei Kindern als Risikofaktor für die mangelnde Ausbildung von oraler Toleranz mit nachfolgender Nahrungsmittelallergie identifiziert werden konnten (Suaini et al. 2015).

\subsection{Effekte der Ernährung auf die Entwicklung oraler Toleranz}

\subsubsection{Säuglingsalter}

Die ersten Lebensmonate im Leben jedes neuen Erdenbürgers werden auch als "early life window of opportunity" bezeichnet, weil in dieser entscheidenden Zeit die initialen Phasen der bakteriellen Kolonisation auf mukosalem Level des Darms, der Bronchien und der Nase (GALT, BALT, NALT („nasal associated lymphoid tissue“) stattfinden, die zum Ausgleich der relativen Th2-Lastigkeit zum Zeitpunkt der Geburt von entscheidender Bedeutung sind.

Der initiale Kolonisierungsprozess verläuft parallel mit der Entwicklung unseres metabolischen-, kognitiven- und Immunsystems und 
kann diese positiv und negativ beeinflussen. Die Entwicklung einer Symbiose scheint für die Gesundheit des gesamten späteren Lebens von großer Bedeutung zu sein (Martin et al. 2010). Die Zusammensetzung der intestinalen Flora hängt mit der Nahrungsaufnahme zusammen und verläuft in 2 wichtigen Etappen: Von der Geburt bis zum Abstillen und vom Abstillen bis zur Etablierung des Mikrobioms eines „Erwachsenen“ ca. im Alter von 3 Jahren. Gekennzeichnet sind diese Phasen durch unterschiedliche und immer vielfältiger werdende Ernährung.

Von Anfang an muss das Immunsystem jedoch beim Nahrungsaufbau die mukosale und systemische Nichtbeantwortung von immer neuen Nahrungsmittelallergenen fördern und orale Toleranz entwickeln:

Dieser Prozess ist komplizierter als angenommen. Man weiß bereits, dass Nahrungsmittelantigene zunächst über Transzytose via M-Zellen (Bestandteile der Follikel-assoziierten Epithelzellen, die Peyer'sche Plaques oder andere lymphoide Strukturen umhüllen) bzw. über Transzytose via Enterozyten oder Diffusion zwischen den Epithelzellen die Lamina propria des Darms erreichen. Dort werden sie von migrierenden dendritischen Zellen phagozytiert und wandern $\mathrm{zu}$ den mesenterialen Lymphknoten (MLN), um dort den naiven T-Zellen präsentiert zu werden. Hier induzieren sie die Differenzierung in Treg-Zellen mit Produktion von IL-10, das antiinflammatorische Eigenschaften hat. Nach der initialen Induktion in den MLN kommt es zur Expansion von nahrungsmittelantigenspezifischen Treg-Zellen, die das antiinflammatorische Umfeld aufrechterhalten (Kim et al. 2012; Hadis et al. 2011).

All diese Mechanismen werden getriggert und sind abhängig vom Mikrobiom des Darms, das die adäquate Induktion der Treg und die Th1/Th2-Balance fördert. Wenn sich die $\mathrm{Zu}$ sammensetzung des Mikrobioms nicht ideal aufbaut oder sich ändert, kann sich der Prozess der Toleranz nicht entwickeln bzw. bricht zusammen. Typischerweise beobachtet man dann eine vermehrte Differenzierung in Th2Zellen mit nahrungsmittelspezifischen IgEs, verstärkter Infiltration von Mastzellen in die intestinale Mukosa und auch Anaphylaxie nach Re-Exposition.

Pionierbakterien bei Neugeborenen sind Staphylococcus, Streptococcus und Enterococcus, die ein anaerobes Umfeld schaffen, in dem Bifidusbakterien, Bacteroides, Clostridium und Eubacterium spp. gedeihen können, die dann bereits nach den ersten beiden Lebenswochen überwiegen (Wopereis et al. 2014).

\subsubsection{Stillen}

Muttermilch ist die natürliche Form der Ernährung im frühen Leben. Bakterienstämme, besonders Bifidusbakterien, die in der Muttermilch vorkommen, translozieren aus dem Darm der Mutter und über die mesenterialen Lymphknoten in die Brustdrüse (Makino et al. 2011). Gestillte Kinder (s. - Abb. 4.11) weisen eine Dominanz von Bifidusbakterien auf, während Flaschenkinder eher weniger Bifidusbakterien, dafür aber mehr Firmicutes und Bacteroidetes beherbergen (Yatsunenko et al. 2012). Andere Studien fanden im Darm von gestillten Kindern ebenfalls vermehrt Bifidusbakterien und Laktobazillen (Harmsen et al. 2000) sowie eine geringere Anzahl von Clostridium difficile und E. coli im Vergleich zu nicht-gestillten Säuglingen (Penders et al. 2006).

Muttermilch enthält Immunglobuline, Zytokine, Lysozyme und HMOs (Human-MilkOligosaccharide). Diese HMOs fungieren als Präbiotika, indem sie das Wachstum der kommensalen Bakterien, besonders der Bifidobakterien, stimulieren. HMO-induzierte Bifidusbakterien erhöhen die Expression von IL-10 an intestinalen Epithelzellen und verbessern die "tight junctions“ des Darmepithels (Chichlowski et al. 2012). Daher fördern HMOs über Reifung der Darmmukosa und Schutz der Epithelbarriere die Toleranzentwicklung.

(Menschliche) HMOs, an Mäuse mit Nahrungsmittelallergie verfüttert, hemmten die Mastzelldegranulation und vermehrten die IL10-exprimierenden Treg-Zellen (CastilloCourtade et al. 2015).

Trotzdem scheint keine direkte Assoziation zwischen der Dauer des exklusiven Stillens und dem Schutz vor allergischen Erkrankungen in- 


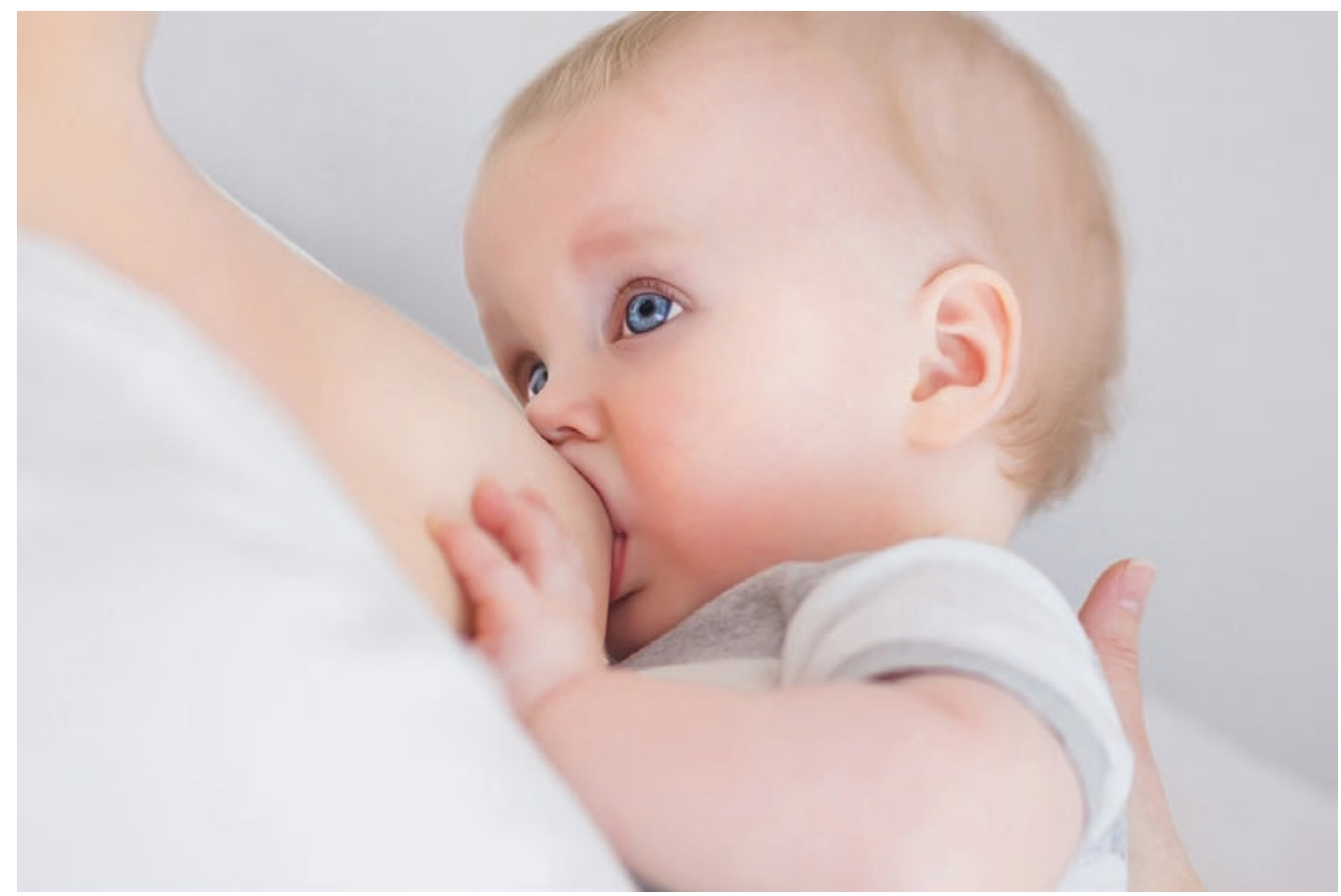

- Abb. 4.11 Muttermilch enthält Bifidusbakterien und Laktobazillen. Aktuelle Guidelines empfehlen Stillen bis zum 6. Lebensmonat und exklusives Stillen bis zum 4.-6. Monat

nerhalb der ersten 6 Lebensjahre zu bestehen, wie eine relativ aktuelle Studie vom April 2015, die 335 Kinder aus Kopenhagen beobachtet hatte, demonstrierte (Jelding-Dannemand et al. 2015).

Obwohl Stillen vor frühzeitigem Giemen schützen dürfte (Taussig et al. 2003), konnte auch ein weiteres Review von 2017 keinen eindeutigen allergieprotektiven Effekt von exklusivem Stillen nachweisen (Heinrich 2017). Trotzdem befürworten die Autoren dieses Reviews die aktuellen Guidelines der WHO und EAACI, die Stillen bis zum 6. Monat und exklusives Stillen bis zum 4.-6. Monat empfehlen, auch wegen „anderer gesundheitsfördernder Effekte“.

Muttermilch beeinflusst durch ihre einmalige Mischung von HMOs und antimikrobiellen Proteinen, aber auch durch den hohen mütterlichen IgA-Gehalt das neonatale Mikrobiom. IgA ist das wesentlichste Immunglobulin an Schleimhäuten und neutralisiert harmlose Nahrungsantigene, Toxine und pathogene Mikroben. Weiters verhindert IgA deren Eindringen ins Epithel (Macpherson et al. 2008). Die
Muttermilch enthält auch mütterliche IgGKomplexe, die das kindliche Immunsystem schützen. Somit haben mütterliche IgA und IgG eine wichtige Rolle in der Nicht-Beantwortung von Reizen harmloser Mikrobiota und Nahrungsmittelantigenen und der damit verbundenen Toleranzentwicklung (Wopereis et al. 2014).

Mütter müssen unbedingt wissen, dass sie durch Stillen ein lebenslanges gesundes Mikrobiom für ihre Kinder schaffen können. Nachdem das Neugeborene sein primäres Mikrobiom hauptsächlich von der Mutter erwirbt, sollte bereits der Gynäkologe großes Augenmerk auf das intestinale und vaginale Mikrobiom der Mutter legen und die Mütter diesbezüglich ernährungsmäßig beraten.

$$
\begin{aligned}
& \text { Achtsamkeit gegenüber der Bedeutung } \\
& \text { der Mikrobiota und jenen Faktoren, die } \\
& \text { diese stören könnten, sollte Teil der } \\
& \text { antenatalen Bildung/Geburtsvorbereitung } \\
& \text { von Schwangeren werden. }
\end{aligned}
$$


Bei nicht-gestillten Allergie-Hochrisikokindern (mindestens ein Elternteil ist Allergiker) konnte die Zugabe von Präbiotika: kurzkettiger GOS (Galacto-Oligosaccharide) und langkettiger FOS (Fructo-Oligosaccharide) zur Flaschennahrung bis zum 6. Monat das Risiko einer atopischen Dermatitis signifikant und das Risiko für allergische Rhinokonjunktivitis und Urtikaria tendenziell bis zum 5. Lebensjahr reduzieren (Arslanoglu et al. 2012).

\subsubsection{Präbiotika und Synbiotika}

( Definition der Präbiotika: Nicht verdaubare Lebensmittelbestandteile, die ihren Wirt günstig beeinflussen, indem sie das Wachstum und/oder die Aktivität einer oder mehrerer Bakterienarten im Dickdarm gezielt anregen und somit die Gesundheit des Wirts verbessern.

Nach Analyse der bisher vorhandenen Studien (Cuello-Garcia et al. 2016) wiesen zwei Studien mit Präbiotika ein reduziertes Auftreten von Asthma, rezidivierendem Giemen (RR: 0.37, 95 \% CI: 0.17-0.80) bzw. seltenerer atopischer Dermatitis und allergischer Urtikaria nach und eine weitere entdeckte ein reduziertes $\mathrm{Ri}$ siko bezüglich Nahrungsmittelallergien (RR: 0.28, 95 \% CI: 0.08-1.00).

Daraufhin empfahl die World Allergy Organisation die Anwendung von Präbiotika als Ergänzung bei nicht voll gestillten Kindern, nicht jedoch in der Schwangerschaft oder bei ausschließlichem Stillen (Cuello-Garcia et al. 2016).

Auch die Zahl der Infektionskrankheiten wurde durch Verabreichung von Präbiotika bei gesunden Kindern (Bruzzese et al. 2009), aber auch bei zu Atopie neigenden Kindern allgemein und auch speziell des oberen Respirationstrakts verringert (Arslanoglu et al. 2008). In letzterer Studie erhielten die Kinder in den ersten $6 \mathrm{Mo-}$ naten täglich $8 \mathrm{~g}$ GOS/FOS und wurden bis zum Ende des 2. Lebensjahres nachbeobachtet.

\section{$>$ Definition der Synbiotika: Kombination} von Präbiotika und Probiotika

Gabe von Synbiotika (GOS/FOS plus Bifidobacterium breve) an 5 Monate alte Kinder mit Neurodermitis zeigte ein reduziertes Fortschreiten des allergischen Marsches in Richtung Asthma. Nach einem Jahr hatten 5,6 \% der Synbiotika-Kinder mit Asthmamedikamenten begonnen, im Vergleich zu 25,6 \% der Kontrollgruppe (Arslanoglu et al. 2012). Auch Kukkonen (Kukkonen et al. 2007) beobachtete 2007 anhand von 1223 Müttern mit Hochrisikokindern eine signifikante Reduktion des atopischen Ekzems bei 2-Jährigen, nachdem sie Pro- und Präbiotika (GOS) erhalten hatten, sowie eine Reduktion von IgE-assoziierten Erkrankungen.

Eine Meta-Analyse (Chang et al. 2016) zeigte Evidenz, dass die Verwendung von Synbiotika bei der Behandlung von atopischer Dermatitis besonders bei Kindern im Alter von mindestens einem Jahr und älter erfolgreich und zur Prävention von atopischer Dermatitis gut geeignet ist (RR 0.44 [95 \% CI] $0.11-1.83 ; \mathrm{P}=0.26$ ).

Diese Studien untermauern die Rolle eines intakten Mikrobioms zur Vorbeugung von allergischen Erkrankungen und zeigen, dass Prävention durch Modulation der Flora möglich ist. Noch sind nur wenige Maßnahmen in die aktuellen Guidelines aufgenommen, die Erkenntnisse der letzten Jahre machen die Zusammenhänge zwischen allergischer Entwicklung und Mikrobiom jedoch immer wahrscheinlicher.

\subsubsection{Interaktion zwischen Nahrungsaufbau und Mikrobiom}

Die Nahrungsaufbauphase im ersten Lebensjahr scheint mit einer starken Verlagerung der mikrobiellen Gemeinschaften einherzugehen.

- Abb. 4.12 (Petschow et al. 2013) illustriert die individuelle Häufigkeit und Diversität bestimmter Bakterienklassen in den ersten 3 Lebensjahren anhand eines Kindes mittels Gensequenzierung und deren Variation durch 


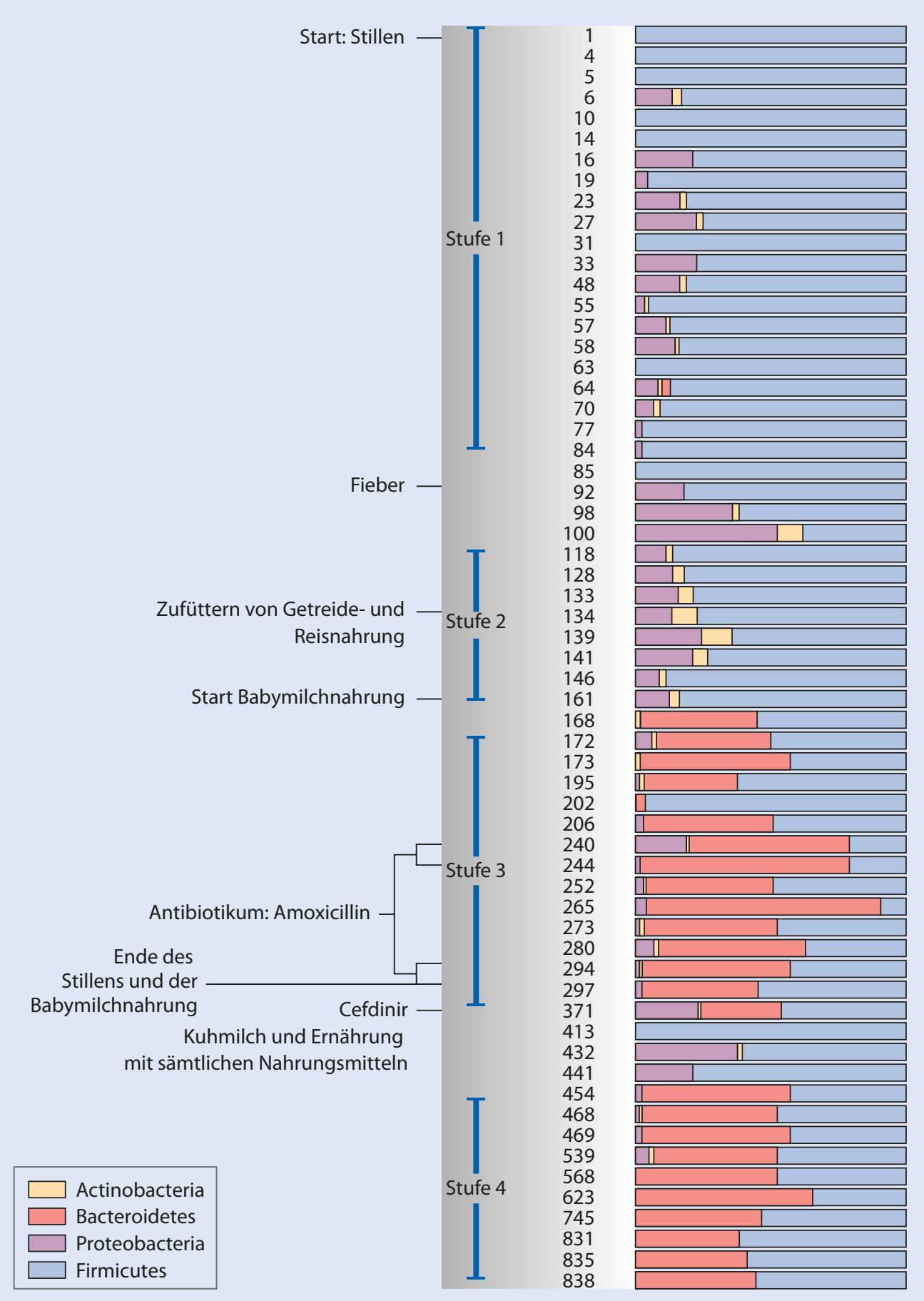

- Abb. 4.12 Veränderung der Bakterienarten/-menge in den ersten 3 Lebensjahren anhand eines Einzelfalls. Anfänglich überwiegen die Firmicutes. Durch diverse äu- ßere Einflüsse verändert sich die individuelle Zusammensetzung des Darm-Mikrobioms (Mod. nach Petschow et al. 2013) 
äußere Einflüsse, wie Umstellung auf feste Nahrungsmittel und Antibiotikagabe.

Nach Einführung von fester Nahrung ab dem 4. Lebensmonat verändert sich die $\mathrm{Zu}$ sammensetzung des Mikrobioms. Noch immer dominieren Bifidusbakterien, jedoch beobachtet man bereits eine größere Vielfalt von Bacteroides und Clostridium cluster IV und $X I V$, die Butyrat-Produzenten sind (Wopereis et al. 2014). Butyrat hat als SCFA eine wichtige Bedeutung für die Homöostase und dürfte bei der Entwicklung der oralen Toleranz gegenüber Nährstoffen, die in diesem Lebensalter ununterbrochen notwendig ist, von entscheidender Bedeutung sein (Tan et al. 2016).

Bacteroides fragilis, mit dem immunmodulatorischen Molekül Polysaccharid A (Round und Mazmanian 2009) und Clostridium cluster IV und XIV (Atarashi 2011; Atarashi et al. 2013) sind potente Induktoren der Foxp3+ Treg-Differenzierung und verstärken über Schutz der Integrität der Epithelbarrieren die Aufrechterhaltung der oralen Toleranz gegenüber diätetischen Antigenen.

Im März 2015 zeigten die CHILD Study Investigators (Azad et al. 2015), dass eine geringe mikrobielle Vielfalt und eine erhöhte Enterobacteriaceae/Bacteroidaceae Ratio in den ersten 3 Lebensmonaten mit häufigerem Auftreten einer Sensibilisierung gegen Nahrungsmittel einhergehen. Dazu wurden 166 kanadische Kinder im Alter von 12 Monaten mittels Skin-Prick-Test auf Nahrungsmittelsensibilisierung getestet und das Mikrobiom mittels 16S-rRNA-Sequenzierung im Alter von 3 und 12 Monaten erfasst. Bei 12 Kindern (7,2\%) fand man mit 12 Monaten eine Allergie auf mindestens ein Nahrungsmittel. In der Darmflora dieser Kinder beobachtete man, im Vergleich zu den Skin-Prick-Test-negativen Kindern, ein vermehrtes Auftreten von Enterobacteriaceae und eine reduzierte Anzahl von Bacteroidaceae, sowohl mit $3 \mathrm{Mo-}$ naten als auch mit 12 Monaten. Jede Erhöhung der Enterobacteriaceae/Bacteroidaceae-Ratio um ein Quartil war mit einem verdoppelten Risiko für eine Nahrungsmittel- allergie zum 1. Geburtstag verbunden (OR 2.02, 1.07-3.80). Umgekehrt war eine erhöhte Vielfalt der Bakterien des Mikrobioms im Darm um ein Viertel, im Alter von 3 Monaten, assoziiert mit einer $55 \%$ Reduktion des Risikos für eine Nahrungsmittelallergie zum Zeitpunkt des ersten Geburtstages (OR 0.45, 0.23-0.87).

Bacteroides spp. sind wertvolle Produzenten von SCFAs (Maslowski 2011). Da Bacteroides spp. auch die Reifung des Immunsystems in der frühen Kindheit über die Th1/Th2-Balance beeinflussen, scheinen sie für das homöostatische Gleichgewicht im Darm einen wertvollen Beitrag zu leisten (Mazmanian et al. 2005).

\subsubsection{Probiotika}

In letzter Zeit gibt es auch schon einige erfolgversprechende Studien zur Prävention und Behandlung von Nahrungsmittelallergien mittels Probiotika:

I) Am Menschen war eine Therapie mit Lactobacillus rhamnosus $G G$ effektiv zur Prävention von Kuhmilchallergie in der frühen Kindheit und zeigte auch „preliminary evidence" als Therapie bei bereits bestehender Kuhmilchallergie, indem die Th2-Tendenz zugunsten einer Th1/ Th2-Balance verbessert wurde (Cosenza et al. 2015).

I) Therapeutische Gabe von Lactobacillus brevis HY7401 reduzierte in Hühnereiweiß-allergischen Mäusen die systemische Anaphylaxie und hemmte die Th2-Zytokine, während die Th1-Zytokinproduktion induziert wurde (Lee et al. 2013). Bei $\beta$-Lactoglobulin-sensibilisierten Mäusen beobachtete man nach Gabe von Lactobacillus paracasei $L 9$ eine Induktion von regulatorischen dendritischen Zellen mit Vermehrung der Treg-Zellen in den mesenterialen Lymphknoten um $52 \%$ und dadurch eine Allergie-reduzierende Wirkung (Yang et al. 2015). 
Da dieses Gebiet der Forschung noch extrem jung ist, gibt es noch keine Evidenz für die Behandlung mit Probiotika bei Nahrungsmittelallergie (De Silva et al. 2014), ein tieferes Verständnis der zugrunde liegenden Mechanismen wird aber vielleicht auch hier in der Zukunft neue therapeutische Wege, aber vor allem auch präventive Wege öffnen.

Gegen Ende des ersten Lebensjahres findet man mit Erweiterung der Nahrungsmittelvielfalt auch Faecalibacteriae und Roseburiae. Mit etwa 3 Jahren hat sich ein stabiles „Erwachsenen-Mikrobiom" ausgebildet, das individuell ist und den Menschen durch das ganze Leben begleitet (Yatsunenko et al. 2012).

\subsubsection{Wie sollen Kinder im ersten Lebensjahr ernährt werden?}

Bezüglich Ernährung setzte in letzter Zeit ein großer Umdenkprozess ein. Bis zum Jahr 2015 empfahl man, Hochrisikokinder (Kinder mit einem Allergiker im 1. Verwandtschaftsverhältnis) im ersten Lebensjahr sehr vorsichtig zu ernähren und mit Beikost erst am Ende des ersten Halbjahres zu beginnen sowie gewisse Nahrungsmittel wie Kuhmilch und Nüsse innerhalb des ersten Lebensjahres komplett zu vermeiden. Tiermodelle erbrachten jedoch Hinweise, dass die oftmalige niedrig dosierte Antigenexposition durch Nahrungsmittel die Induktion von Treg-Zellen und damit die Toleranzentwicklung fördert, während hochdosierte orale Exposition die Treg-Zellen zerstört (Weiner et al. 2011).

Am Menschen wurden diese Erkenntnisse in einer Aufsehen erregenden Studie, die im März 2015 im New England Journal of Medicine publiziert wurde, bewiesen ( $\mathrm{Du}$ Toit et al. 2015). Die Frage war, ob man Hochrisikokindern Erdnüsse im ersten Lebensjahr anbieten sollte oder sie eher einer strengen Erdnusskarenz unterzieht, um einer späteren Entwicklung von Erdnussallergie entgegenzuwirken.

Dazu wurden 640 Hochrisikokinder mit atopischem Ekzem, Ei-Allergie oder beidem, älter als 4 Monate und jünger als 11 Monate, zunächst in 2 Gruppen aufgeteilt: jene mit positivem Skin-Prick-Test auf Erdnüsse und jene mit negativem Skin-Prick-Test.

Dann erhielt eine Hälfte der Skin-Pricknegativen Kinder 2 g Erdnüsse pro Tag und eine Hälfte der Skin-Prick-positiven Gruppe in aufsteigender Dosis bis zu 3.9 g Erdnüsse pro Tag, während die beiden anderen Gruppen unter Erdnusskarenz standen. In jener SkinPrick-negativen Gruppe, die täglich Erdnüsse bekommen hatte, entwickelten nach 60 Monaten nur 1,9\% der Kinder eine Erdnussallergie, im Vergleich zu 13,7 \% der Kinder in der Erdnuss-vermeidenden Gruppe.

In der ursprünglich Skin-Prick-positiven Gruppe hatten nach 60 Monaten 10,6 \% der Erdnuss-essenden Gruppe eine Erdnussallergie, verglichen mit 35,3 \% der Vermeidungsgruppe. Diese Erkenntnisse machen deutlich, dass frühkindliche Gabe von kleinen Mengen Erdnüssen die Häufigkeit der Entwicklung von Erdnussallergien bei Hochrisikokindern senkt, selbst wenn der Skin-Prick-Test bereits positiv ist.

Ebenfalls in diese Richtung weist eine Studie (Koplin et al. 2010), die 2589 australische Kinder beobachtete und zeigen konnte, dass Kinder, die Ei erst ab dem 10. Monat angeboten bekamen, ein deutlich erhöhtes Risiko einer Ei-Allergie hatten (OR 1.6 [95 \% CI 1.0-2.6]) als Kinder, die Eier bereits seit dem 4. und 6. Monat regelmäßig aßen. Noch größer fiel der Unterschied bei Kindern aus, die erst nach dem ersten Lebensjahr Eier erhielten. Hier war die Wahrscheinlichkeit, eine Ei-Allergie zu entwickeln, verdreifacht (OR 3.4 [95 \% CI 1.8-6.5]! Die Stilldauer wurde berücksichtigt und hatte keinen Einfluss. Interessant war jedoch, dass die erste Ei-Mahlzeit im Alter von 4-6-Monaten in Form eines gekochten Eis das Risiko für eine Ei-Allergie im Vergleich zur Aufnahme in gebackener Form signifikant reduzierte (OR 0.2 [95 \% CI 0.06-0.71]) (s. - Abschn. 4.14).

Diese und andere Studien führten zu einem Zurückziehen bisheriger Empfehlungen, gewisse Nahrungsmittel im ersten Lebensjahr zu meiden, und zu einem Paradigmenwechsel, nämlich genau das Gegenteil zu tun: das Im- 
munsystem frühzeitig an Umwelt-,,Antigene“ zu gewöhnen, um rechtzeitig Toleranz zu entwickeln!

Deshalb wurden daraufhin die Guidelines der Europäischen Akademie für Allergologie und klinische Immunologie EAACI (Muraro et al. 2014) geändert:

\section{Guidelines für die Ernährung von}

Kindern im ersten Lebensjahr:

- Exklusives Stillen für 4-6 Monate

- Falls Stillen nicht möglich ist, wird bei Hochrisikokindern eine hypoallergene Formelernährung in den ersten 4 Monaten empfohlen.

- Ab dem 4. Monat Einführung von Beikost inklusive Milch, Erdnüssen, Fisch und Ei bei allen Kindern, auch bei Hochrisikokindern

- Bei nicht voll gestillten Kindern: Präbiotika als Ergänzung zur Flaschennahrung

Ob die Einführung der Beikost auch schon vor dem 4. Monat sinnvoll ist, wird derzeit beobachtet. 2 Kohorten-Studien fanden eine reduzierte Nahrungsmittelsensibilisierung, wenn die $\mathrm{Zu}$ satznahrung vor dem 4. Monat eingeführt wurde (Venter et al. 2009; Joseph et al. 2011), umgekehrt zeigte eine andere Studie ein erhöhtes Risiko für eine spätere Allergie (Sausenthaler et al. 2011).

Das erste Lebensjahr dürfte jedenfalls entscheidend zur Entwicklung einer lebenslangen Toleranz beitragen und wird seiner Bezeichnung als „early life window of opportunity“ mehr als gerecht.

Bezüglich hypoallergener Formelnahrung herrschte 2016 unter Experten größte Aufregung, weil ein systematisches Review an 19.000 Patienten nachweisen konnte, dass es keine Evidenz gibt, dass partiell hydrolysierte Milchformeln das Risiko für Ekzeme senken oder vor Kuhmilchallergien schützen (Boyle et al. 2016). Die Studienautoren konnten damit nicht die seit Jahrzehnten weltweit bestehenden diesbezüglichen Guideli- nes unterstützen, die bei Hochrisikokindern die hypoallergene Formelernährung in den ersten 4 Monaten empfiehlt, wenn die Mütter nicht stillen können. Den bisherigen Studien wurde ein Interessenkonflikt vorgeworfen, weil die meisten Studien von den Herstellerfirmen finanziert wurden. Die Herstellerfirmen wurden nun aufgefordert, die Wirkung mittels prospektiver, registrierter und unabhängig geförderter Studien nachzuweisen und auch $\mathrm{zu}$ garantieren, dass keine negative Beeinflussung der Studienteilnehmerinnen bezüglich des Stillens erfolgt.

Bis dato wurden die Guidelines diesbezüglich noch nicht geändert, es wäre aber möglich, dass dies bald der Fall sein wird.

Durch die Studienergebnisse der letzten Jahre hat sich ein großer Wandel bezüglich Ernährung von Kindern im ersten Lebensjahr ergeben. Man darf gespannt sein und hoffen, dass sich diese Veränderungen positiv auf das weitere Fortschreiten der Allergieprävalenz auswirken.

In diesem Zusammenhang sei noch eine Studie zur oralen Immuntherapie von manifesten Nahrungsmittelallergien erwähnt, die Hoffnung aufkeimen lässt, dass diese Therapien bald zum Einsatz kommen könnten: Im April 2014 wurde im Lancet eine Studie vorgestellt, die positive Auswirkungen einer oralen Immuntherapie bei schwerster Erdnussallergie zeigte (Anagnostou et al. 2014). Eingeschlossen wurden 99 Kinder zwischen 7 und 16 Jahren mit sofortiger Überempfindlichkeitsreaktion nach Erdnusseinnahme, positivem Skin-Prick-Test von mehr als $3 \mathrm{~mm}$ auf Erdnüsse und positivem Doubleblind-placebocontrolled-food-challenge-Test. Auch Kinder mit schwerem Asthma bronchiale sowie mit bereits durchgemachten lebensbedrohlichen Reaktionen nach Erdnusseinnahme wurden nicht ausgeschlossen.

Orale Gabe von Erdnussantigen in aufsteigenden Mengen von 2-800 mg/Tag konnte eine Desensibilisierung auslösen. $64 \%$ der Kinder (24 von 39 Patienten) der aktiven Gruppe, aber kein einziges Kind der Placebogruppe (0/46) tolerierten 1400 mg Erdnuss- 
protein (entspricht 10 Erdnüssen) und $86 \%$ der aktiven Gruppe tolerierten 800 mg Erdnussprotein (entspricht 5 Erdnüssen) nach 26 Wochen Therapie. Nach weiteren 26 Wochen, in denen die Placebogruppe im Sinne eines Cross-over-Designs ebenfalls Erdnussprotein in aufsteigenden Mengen erhalten hatte, tolerierten 91 \% der Kinder 800 mg Erdnussprotein. Nebenwirkungen waren mild: Jucken im Mund nach Erdnusseinnahme und selten Giemen, jedoch keine schweren Nebenwirkungen. Dies war die erste Studie, die die orale Desensibilisierung bei einer repräsentativen Bevölkerung mit Erdnussallergie studierte, nämlich inklusive jener Patienten mit schwersten Erdnussallergien mit bereits aufgetretenen lebensbedrohlichen Situationen. Nicht überprüft wurde, wie lange die orale Immuntherapie erfolgen muss. Die Autoren nehmen an, dass der regelmäßige Kontakt mit Erdnussallergen wahrscheinlich über mehrere Jahre notwendig ist, damit effektiver Schutz im Alltag vorhanden ist. Dies deckt sich mit der zuvor beschriebenen Studie, dass der ständige Druck auf das GALT notwendig ist, um Toleranz zu erzielen.

Diese herausragende Phase-2-Studie muss noch von weiteren Studien bestätigt werden, bevor diese Form der oralen Immuntherapie von den Guidelines empfohlen wird und in Europa zur Anwendung kommt.

\subsubsection{Kindheit}

Die moderne westliche Ernährung mit hohem Fett- und Zuckergehalt und niedrigem Faseranteil unterscheidet sich markant von der Nahrungsaufnahme unserer neolithischen Vorfahren, mit denen sich unser Mikrobiom seit mehr als 10.000 Jahren gemeinsam entwickelte. Die signifikante Veränderung konnte in einer Studie, die die intestinale Flora von städtischen europäischen Kindern mit der von ländlichen, afrikanischen Kindern aus Burkina Faso verglich, veranschaulicht werden (De Filippo et al. 2010). Die afrikanischen Kinder in ländlicher Umgebung essen hauptsächlich pflanzliche Nährstoffe mit hohem Fasergehalt und niedrigem Fettgehalt, während europäische Kinder eine Ernährung mit hohem tierischen Fettgehalt und Zucker sowie mit wenigen pflanzlichen Polysacchariden bevorzugen. In der Darmflora der Kinder aus Burkina Faso, die mehr pflanzliche Ernährung zu sich nehmen, fand man einen höheren Gehalt an Bacteroidetes und Prevotella als bei den europäischem Kindern, die unter fettreicher Ernährung mehr Firmicutes beherbergten. Darüber hinaus beobachtete man bei europäischen Kindern signifikant weniger SCFAs.

Auch in Stuhlproben von allergischen Kindern wurde eine reduzierte Menge an SCFAs gefunden (Böttcher et al. 2000).

SCFAs sind Metaboliten, die von den kommensalen Bakterien im Darm aus Ballaststoffen produziert werden und wichtige Funktionen für die Homöostase des Mikrobioms haben. Besonders im distalen Kolon werden Ballaststoffe von den kommensalen Bakterien fermentiert und produzieren dort große Mengen an SCFAs: Acetat, Propionat und Butyrat. Je mehr Ballaststoffe mit der Nahrung aufgenommen werden, desto mehr SCFA werden produziert.

\subsubsection{Wirkung der SCFAs auf die Mukosabarriere}

SCFAs haben eine positive Wirkung auf die Gewebereparatur und schützen den MagenDarm-Trakt vor ulzerativen Prozessen. Hier scheint der Darmsymbiont Faecalibacterium Prausnitzii große Bedeutung zu haben, sowohl durch seinen starken antiinflammtorischen Effekt mit starker Induktion der IL-10-Sekretion als auch mit seiner Eigenschaft, Butyrat und Proprionat $\mathrm{zu}$ produzieren und die Mukosabarriere zu schützen (Sokol et al. 2008). Die antiinflammatorische Wirkung der SCFAs auf das Darmepithel dürfte jedoch von der Bindung an den G-Protein-gekoppelten Rezeptor GPR43 in der Darmepithelzelle abhängig sein. Eine Studie fand, dass Mäuse mit fehlendem GPR43 und niedrigen SCFA-Werten schwere Kolitis, aber auch Asthma und Arthritis entwickelten (Maslowski et al. 2009). 
Die Stabilität der Mukosabarriere spielt eine wichtige Rolle. Einer der bekannten Effekte der SCFAs ist es, die Darmepithelzellen $\mathrm{zu}$ aktivieren und einen schützenden und antiinflammatorischen Schleimfilm zu produzieren. Wieder können hier die Bacteroides die Becherzell-Differenzierung und die Expression von Genen für die Schleimproduktion im Darm fördern. Studien, die ballaststoffreiche Nahrung wie Brokkoli und Heidelbeeren (Blaubeeren) verwendeten, zeigten positive Effekte auf die Kolonmukosa, mit Vermehrung von Becherzellen an den Kolonkrypten und erhöhter Konzentration von Butyraten (Paturi et al. 2012; Lewis et al. 2010).

Der Ballaststoffgehalt von Nahrungsmitteln kann über Veränderung der Zusammensetzung der Darm- und Lungenmikrobiota auch das immunologische Umfeld der Lunge beeinflussen und antiallergische Wirkungen entfalten.

\subsubsection{Wirkung der SCFAs auf die Hämatopoese und Th2-Ant- worten}

Wurden Mäuse mit ballaststoffreicher Diät gefüttert, änderte sich zunächst die Zusammensetzung der Ratio zwischen Firmicutes und Bacteroides des Mikrobioms zugunsten der Bacteroides, mit erhöhten zirkulierenden SCFA-Werten und Schutz vor allergischen Atemwegserkrankungen im Vergleich zu Mäusen mit ballaststoffarmer Diät und weniger SCFAs, die dann vermehrt an Atemwegsallergien erkrankten (Trompette et al. 2014). Diese Gruppe von Mäusen erhielt eine anschließende Therapie mit der kurzkettigen Fettsäure Propionat, die zu Veränderungen der Hämatopoese im Knochenmark mit verstärkter Produktion von Makrophagen und Vorstufen von dendritischen Zellen (DCs) führte. Nach deren Aussaat in die Lunge entfalteten diese DCs hohe phagozytäre Kapazität und zeigten eine reduzierte Th2-Effektorfunktion und reduzierten den Schweregrad der allergischen Inflammation.

\subsubsection{Wirkung der SCFAs auf die Mastzellen}

In Mäusen mit Nahrungsmittelallergien hemmten SCFAs (man verwendete Oligosaccharide der menschlichen Muttermilch) die Granulation der Mastzellen und reduzierten die Symptome wie Diarrhö und Hypothermie über vermehrte Ausbildung von IL10-sezerniernden Treg-Zellen (Castillo-Courtade et al. 2015).

Diätetischer Zusatz von Butyrat für 2 Wochen bei abgestillten, 28 Tage alten Ferkeln reduzierte ebenfalls den Prozentsatz von degranulierten Mastzellen sowie deren inflammatorische Mediatoren (Histamin, Tryptase, TNF- $\alpha$ und IL-6) in der jejunalen Mukosa. Zusätzlich verbesserte die Butyrat-Substitution die Darmbarrierenfunktion und Morphologie mit erhöhten Villi und vertieften Krypten der intestinalen Mukosa, im Vergleich zu einer Kontrollgruppe (Wang et al. 2018a).

\subsubsection{Wirkung der SCFAs auf die ILC2-Zellen}

Butyrat hemmt auch die ILC2-Zellaktivität. Im Mausversuch reduzierte Butyrat die ILC2Proliferation und GATA-Expression sowie die IL-5- und IL-13-Sekretion aus ILC2-Zellen und verbesserte die ILC2-verursachte Hyperreaktivität der Bronchien und die Atemwegsinflammation (Thio et al. 2018).

\subsubsection{Wirkung der SCFAs auf die Nahrungsmittelallergie}

Bei bereits bestehenden Nahrungsmittelallergien konnte im Mäuseversuch (Tan et al. 2016) gezeigt werden, dass Nahrung mit hohem Fasergehalt die Darmmikrobiota regeneriert und die Menge der SCFAs erhöht. Faserreiche Nahrungsbestandteile wurden im Kolon von anaeroben Bakterien zu SCFAs, hauptsächlich Butyrat, Propionat und Acetat, fermentiert. Diese SCFAs binden an Metabolit abtastende G-Protein-Rezeptoren (GPR43, GPR109A, GPR41), die von intestinalen Epithelzellen und Immunzellen gebildet werden und für die epitheliale Integrität verantwortlich sein dürften. Mäuse mit fehlenden G-Protein-Rezeptoren für SCFAs 
(GPR43 am Epithel und GPR109A an den DCs) zeigten vermehrt Nahrungsmittelallergien und eine geringere Anzahl von $\mathrm{CD}_{103}{ }^{+}$-dendritischen Zellen. Bei GPR43-negativen Mäusen beobachtete man auch eine vermehrte epitheliale Permeabilität, die zu einer gesteigerten Infiltration von Bakterien in die mesenterialen Lymphknoten und zu verstärkter Inflammation führte.

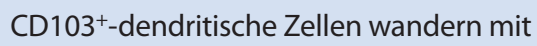
exogenen Antigenen aus Haut, Lunge und Intestinum zu den lokalen Lymphknoten. Die intestinalen $\mathrm{CD}_{103^{+}}$-dendritischen Zellen kontrollieren die inflammatorischen Antworten im Darm und tragen wesentlich zur Erhaltung der intestinalen Homöostase/Toleranz bei, indem sie die

\section{Nahrungsmittelallergie}

Ballaststoffarme Ernāhrung | wenige Kommensale
Differenzierung von Fox $3^{+}$-Treg-Zellen aus den naiven Th0-Zellen induzieren.

Das intestinale Epithel spielt eine wichtige Rolle bei der Konditionierung der $\mathrm{CD}_{103}{ }^{+}$-dendritischen Zellen, ob Toleranz oder allergische Reaktionen mit Th2-Antworten entstehen. Ballaststoffreiche Ernährung (Tan et al. 2016) führte, im Vergleich zu ballaststoffarm ernährten Mäusen, nach Antigen-Challenge mit Erdnussextrakt zu einer vermehrten Aktivierung von $\mathrm{CD}_{103}{ }^{+}$-dendritischen Zellen aus dem Dünndarm und deren Migration in die mesenterialen Lymphknoten, wo sie vermehrt die Differenzierung von Treg-Zellen anregten (s. - Abb. 4.13). Die Anzahl der Treg-Zellen in den mesenterialen Lymphknoten war nach faserreicher Ernährung im Ver-

\section{Toleranz}

Ballaststoffreiche Ernährung | viele Kommensale

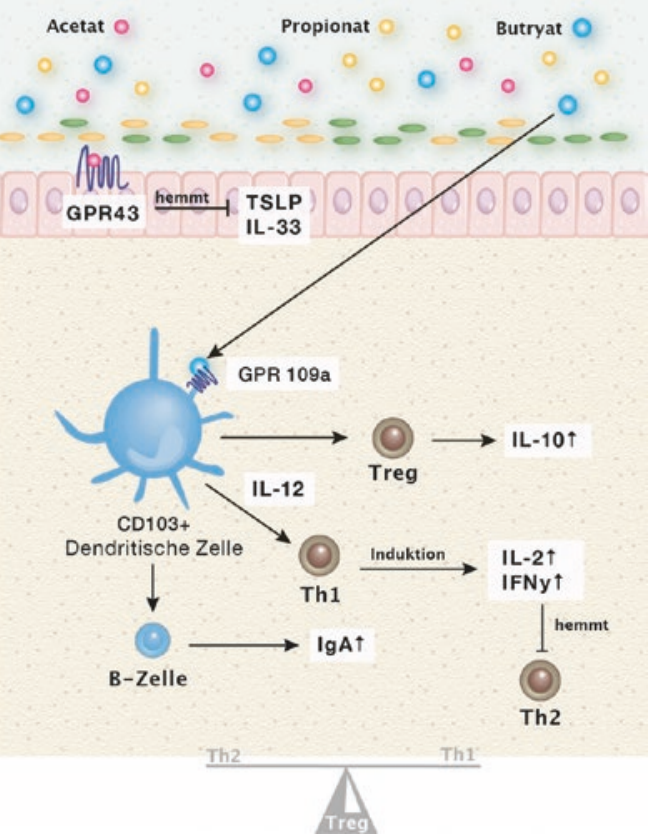

Tregs mit Ausbildung von Toleranz. Links: Bei Mangel an SCFAs und Dysbiose bewirkt die Ausschüttung von TSLP und IL-33 die vermehrte Differenzierung der Th0-Zelle in Th2-Zellen mit Prädisposition zur Entwicklung einer Nahrungsmittelallergie
- Abb. 4.13 Nahrungsmittelallergie und -toleranz. Rechts: Die SCFAs Acetat, Butyrat und Propionat binden an G-Protein-Rezeptoren (GPR43 der Epithelzellen und GPR109A der DCs) und stärken die epitheliale Integrität sowie aktivieren die vermehrte Differenzierung von 
gleich $\mathrm{zu}$ faserfreier Ernährung signifikant erhöht und resultierte in der Entwicklung von oraler Toleranz, wodurch die Mäuse vor Nahrungsmittelallergie besser geschützt waren.

Wenn Mäuse, die bereits erdnussallergisch waren, faserreich ernährt wurden, beobachtete man signifikant weniger Anaphylaxie-Zeichen, die mit niedrigeren Serum-IgE-Werten und erhöhten Treg-Zellen in den mesenterialen Lymphknoten sowie mit reduzierten Th2-Zytokinen IL-4, IL-5 und IL-13 korrelierten. Zerstörte man daraufhin mittels CD-25-depleting-Antikörper die Treg-Zellen, hob sich der schützende Effekt der ballaststoffreichen Diät auf und die Anaphylaxiezeichen und IgEWerte stiegen an. Dies zeigt, dass intakte Treg-Zellen für den Schutz vor Nahrungsmittelallergien unbedingt notwendig sein dürften.

An ballaststofffrei ernährten Mäusen beobachtete man jedoch eine höhere Genexpression von IL-33 und TSLP aus Epithelzellen des Jejunums, jenen kürzlich entdeckten Aktivatoren der allergischen Kaskade, die von Epithelzellen gebildet werden und die im $>$ Abschn. 3.3 ausführlich beschrieben wurden.

Auch direkte Fütterung von Butyrat, Acetat, aber nicht von Propionat, in Trinkwasser 3 Wochen vor der initialen Sensibilisierung auf Erdnüsse führte zu einer Reduktion des Anaphylaxie-Scores, niedrigeren IgE-Serumwerten und Induktion von $\mathrm{CD}_{103^{+}-\mathrm{DC}-Z e l l e n}$ und Treg-Zellen. Interessanterweise konnte die Gabe von Butyrat und Acetat nicht vor Nahrungsmittelallergie schützen, wenn die Darmflora davor mit Antibiotika dezimiert wurde.

Dies demonstriert, dass die positiven Effekte von faserreicher Ernährung nicht ausschließlich von SCFAs, sondern auch von anderen Faktoren, wie zum Beispiel von der Auslösung von TLR-Signalen über MyD88 (s. - Kap. 4.6) durch die Mikrobiota abhängen dürfte.

\subsubsection{Wirkung der SCFAs auf IgA}

Ernährung mit faserreicher Kost aktiviert auch die IgA-Produktion (Tan et al. 2016), die ebenfalls zur oralen Toleranz beiträgt. Indem die Darmflora IgA-Antworten des Wirts aktiviert, wird umgekehrt wieder die Zusammensetzung des Mikrobioms von IgA reguliert und vor pathogener Besiedlung geschützt. So wird die Homöostase in einer positiven FeedbackSchleife aufrechterhalten.

Zusammenfassend wird immer klarer, wie Ballaststoff-/SCFA-reiche Diät gemeinsam mit der optimalen Zusammensetzung der Mikrobiota die orale Toleranz bewahren (s. - Abb. 4.13) und vor der Entwicklung von Nahrungsmittelallergien schützen können. Dies wird durch Verstärkung der tolerogenen CD103+-DC-Funktionen erreicht. Zusätzlich ist die Toleranzentwicklung jedoch auch von epithelialen GPR43- und immunologischen GPR109a-Signalen abhängig, weil sich die Effekte der faserreichen Ernährung bei GP43- und GPR109a-Knock-out-Mäusen nicht replizieren ließen. Auch MyD88-Signale dürften in diesem komplexen Zusammenspiel eine wichtige Bedeutung haben.

Die aktuellen Forschungsergebnisse belegen immer deutlicher, dass Veränderungen von Diät, Zusammensetzung der Mikrobiota und deren Metaboliten für die Entwicklung von Nahrungsmittelallergien und deren steigende Raten in gewissen Bevölkerungsgruppen verantwortlich sind. Diese Erkenntnisse legen ein therapeutisches Vorgehen sowohl mittels ballaststoffreicher Diät als auch mittels Probiotika zur Vorbeugung und Therapie von Nahrungsmittelallergien, aber auch von allen anderen allergischen Manifestationen nahe.

Nicht zufällig geht die steigende Allergieprävalenz in vielen Ländern mit einer veränderten, „verwestlichten“ Nahrungsaufnahme einher. Der typische Amerikaner konsumiert ca. $16 \mathrm{~g}$ Ballaststoffe/Tag, somit wesentlich weniger als die empfohlenen 20-35g/Tag. Menschen aus niedrigeren sozioökonomischen Gruppen essen noch weniger Ballaststoffe (King et al. 2012). Bewohner „westlicher"Länder essen häufiger Diäten, die durch hohen Energiegehalt, industriell verarbeitete Nahrungsmittel und reduzierte Aufnahme von Früchten oder Gemüse gekennzeichnet sind.

Mittlerweile gibt es auch einige Studien, die eine Korrelation zwischen Asthmahäufigkeit und Fettleibigkeit nachweisen können (Boulet 2013). Adipositas-induziertes Asthma wird seit einiger 
Zeit sogar als eigener Phäno-/Endotyp des Asthma bronchiale klassifiziert (s. A Abschn. 3.7.2.2).

Interventionsstudien zeigten, dass eine mediterrane Diät mit hohem Gemüseanteil, Früchten, Olivenöl und Fisch Asthma vorbeugen kann (Berthon 2013).

Veränderungen der Diät bewirken innerhalb kürzester Zeit Effekte auf die Darmflora. An 98 gesunden Probanden konnte demonstriert werden, dass eine Veränderung von ballaststoffarmer/fettreicher auf ballaststoffreiche/fettarme Ernährung bereits innerhalb von 24 Stunden zu Veränderung der intestinalen Flora führte (Wu et al. 2011).

\subsection{Ballaststoffe}

\section{Ballaststoffe sind}

- genießbare Teile von Pflanzen: sämtliche essbaren Teile der Pflanze wie Schale, Blätter, Fruchtfleisch, Samen, Wurzeln: sowohl lösliche, als auch unlösliche Bestandteile,

- oder ähnliche Kohlehydrate, bestehend aus komplexen Polysacchariden, meist langkettige Zucker wie Poly- oder Oligosaccharide (Fructo-Oligosacccharide [FOS], Galacto-Oligosaccaride [GOS], Muttermilch),

- die resistent gegenüber enzymatischer und chemischer Verdauung und Absorption im menschlichen Dünndarm sind,

- und erst im Dickdarm komplett oder teilweise fermentiert werden (AACC Report 2001).

Wasserunlösliche Ballaststoffe können nicht resorbiert werden und passieren den gesamten Magen-Darm-Trakt fast unverändert:

\begin{tabular}{|l|l|}
\hline Zellulose & $\begin{array}{l}\text { aus Getreide, z. B. Weizen- } \\
\text { kleie, Früchten und } \\
\text { Gemüse }\end{array}$ \\
\hline Hemizellulose & $\begin{array}{l}\text { Arabinoxylan aus Zellwänden } \\
\text { von Pflanzen und Getreide }\end{array}$ \\
\hline $\begin{array}{l}\text { Arabinogalactan, z. B. Gummi } \\
\text { arabicum }\end{array}$ \\
\hline $\begin{array}{l}\text { Resistente } \\
\text { Stärke }\end{array}$ & $\begin{array}{l}\text { in Hülsenfrüchten, Vollkornpro- } \\
\text { dukten, Mais, Kartoffelschale }\end{array}$ \\
\hline
\end{tabular}

Pflanzliche

Lignine und

assoziierte

pflanzliche

Substanzen

Wasserlösliche Ballaststoffe werden zwar im Dünndarm weder verdaut noch absorbiert, jedoch im Dickdarm durch die dort anwesende Darmflora fermentiert. Bei diesem Prozess entstehen einerseits geruchlose Gase $\left(\mathrm{CO}_{2}, \mathrm{Me}-\right.$ than, Wasserstoff), aber auch kurzkettige Fettsäuren (SCFA), wie Buyrat, Propionat und Acetat, die wie vorher erwähnt besondere Auswirkungen auf das Immunsystem haben, jedoch auch die Fettverdauung positiv beeinflussen.

\begin{tabular}{l|l} 
Polyfructosen & $\begin{array}{l}\text { z. B. Inulin in Topinambur, Chico- } \\
\text { ree, Artischocke, Schwarzwurzel }\end{array}$
\end{tabular}

Fructo-Oligosaccaride (FOS)

Galacto-Oligosaccharide (GOS)
Arabinoxylane
z. B. Flohsamen
Polyuronide
z. B. Pectin in Fruchtschalen, Gemüsen

Quellen für unlösliche und wenig bis teilweise fermentierbare Ballaststoffe Vollkorngetreide, Weizen- und Mais-

kleie, Nüsse und Samen, Kartoffelhaut

Sesam- und Leinsamen

Gemüse: wie Chicoree, Karfiol, grüne

Bohnen, Zucchini, Sellerie, Feigenkak-

tus, Avocados, unreife Bananen

Schalen: z. B. von Weintrauben, Tomaten

Quellen für wasserlösliche, gut

fermentierbare Ballaststoffe

Hülsenfrüchte wie Erbsen und Bohnen,

Sojabohnen

Hafer, Gerste, Roggen, Chiasamen

Gewisse Gemüsearten wie Brokkoli,

Topinambur, Karotten, Schwarzwurzeln

Wurzel und Knollengemüse: Süßkartof-

fel, Zwiebel 
Flohsamen

Einige Früchte wie Feigen, Pflaumen, Beeren, reife Bananen, Apfelschalen, Quitten, Birnen Nüsse und Mandeln

Oft beinhaltet eine einzige Pflanze wasserunlösliche Ballaststoffe, wie etwa die Schale der Pflaume, und wasserlösliche Ballaststoffe, wie das Fruchtfleisch der Pflaume.

Ballaststoffe haben 3 Hauptaufgaben:

Als Füllstoffe absorbieren sie Wasser und können das Stuhlgewicht und die Regelmäßigkeit beeinflussen (wasserlöslich: Flohsamen, wasserunlöslich: Zellulose).

Viskositätserhöhende Fasern verdicken den Inhalt des Intestinaltrakts und schwächen die Zucker- und die Lipidabsorption (Flohsamen und Zellulose).

Fermentierbare Ballaststoffe werden von den Mikrobiota des Darms in kurzkettige Fettsäuren (SCFAs) umgewandelt. Die Fermentierung bewirkt die Expression von vielen Genen im Darm, die die Verdauung, den Fett- und Zuckerstoffwechsel, aber auch das Immunsystem und damit auch allergische Erkrankungen beeinflusst.

Neben der bereits intensiv erörterten Wirkung auf das Immunsystem haben SCFAs noch weitere gesundheitsfördernde Effekte (AACC-Report 2001):

- Regulation des Glukose-Transports in der intestinalen Mukosa und der Glukoseabsorption (Drozdowski et al. 2002)

- Regulation des Blutglukosespiegels mit Reduktion der Insulinausschüttung im Pankreas

- Reduktion des Blutglukosespiegels mit Verbesserung des diabetischen Stoffwechsels bzw. Reduktion des Diabetesrisikos

- Unterdrückung der Cholesterolsynthese in der Leber und Reduktion der LDL-, Cholesterin- und Trigylzeridwerte im Serum, wodurch das Risiko einer kardiovaskulären Erkrankung reduziert wird

- Reduktion des Kolon-pH: Durch Ansäuerung des Kolons wird die Entstehung von Kolonpolypen unterdrückt und die Absorption von Mineralstoffen aus der Nahrung erhöht
Guidelines zur Ballaststoffeinnahme der Academy of Nutrition and Dietetics (A.N.D.) (Academy of Nutrition 2018):

- Erwachsene sollten mindestens 20-35 Gramm Ballaststoffe/Tag einnehmen.

- Kinder sollten Ballaststoffe entsprechend ihrem Alter in Gramm aufnehmen plus 5 Gramm/Tag (z. B. 6-jähriges Kind: 6 Gramm plus $5=11$ Gramm Ballaststoffe).

- Auf ausreichende Flüssigkeitszufuhr ist zu achten.

Die Harvard School of Public Health (Harvard School of Public Health 2019) empfiehlt die tägliche Aufnahme von mindestens 20-30 Gramm, am besten in Form von Vollkornprodukten, Obst, Gemüse, Hülsenfrüchten und Nüssen.

Die FDA (Food and Drug Administration) hat bereits folgende Ballaststoffquellen als gesundheitsfördernd anerkannt (Soluble Fiber from Certain Foods and Risk of Coronary Heart Disease 2008):

- Flohsamen: 7 Gramm/Tag

- Beta-Glukan von Haferkleie, ganzem Hafer oder Haferflocken: 3 Gramm/Tag

- Beta-Glukan von Vollkorngerste oder trocken gemahlener Gerste: 3 Gramm/Tag

\subsection{Omega-3-Fettsäuren}

In den letzten Jahrzehnten nahm die Einnahme von Omega-3-Fettsäuren zugunsten von Omega-6-Fettsäuren ab. Nach Analyse der aktuellen Datenlage kam ein schwedisches Review zu dem Schluss, dass der reduzierte Verzehr von Omega-3-Fettsäuren besonders in der Schwangerschaft und frühen Kindheit ein Grund für die steigenden Allergieraten sein könnte, und schlug vor, dass Omega-3-Substitution während der Entwicklungsphase des Immunsystems positive Auswirkungen auf die Allergieentstehung haben könnte (Jenmalm und Duchén 2013).

Auch D'Auria et al. analysierten mehrere Studien mit protektiven Effekten, aber auch einige, die keinen Effekt auf die Asthmaentstehung nachweisen konnten, und schlossen daraus, dass die Gabe von Omega-3-Fettsäuren in der Kind- 
heit zumindest genug Evidenz für eine mögliche Wirkung zu haben scheint und dieser Ansatz unbedingt mit perfekt designten Studien weiterverfolgt werden sollte (D’Auria et al. 2014).

Aufgrund der positiven Ergebnisse bezüglich Prävention von Allergien in der Schwangerschaft und frühen Kindheit wurde 2017 von der Food and Drug Administration and the Environmental Protection Agency empfohlen, dass schwangere und stillende Frauen zwei bis drei Fischmahlzeiten mit niedrigem Quecksilbergehalt, also 200 bis $300 \mathrm{~g}$, pro Woche zu sich nehmen sollten ( $\triangleright$ https://www.fda.gov/Food/ ResourcesForYou/Consumers/ucm393070.htm).

Diesem wichtigen Thema ist ein eigenes Kapitel (s. Abschn. 6.8) gewidmet und wird dort näher besprochen.

\subsection{AGEs (advanced glycation endproducts)}

Nicht nur der Mangel an Ballaststoffen und Omega-3-Fettsäuren, sondern auch der zunehmende Anteil von industriell verarbeiteten Nahrungsmitteln scheint das Immunsystem des Menschen $\mathrm{zu}$ irritieren. In letzter Zeit gibt es immer mehr Hinweise, dass Verarbeitung, Konservierung, Lagerung und Sterilisation von Lebensmitteln sowie der finale Kochprozess für den Anstieg von Allergien verantwortlich sein könnten.

AGEs sind schwer abbaubare, fortgeschrittene Glykierungsendprodukte, die durch nicht-enzymatische Reaktion von Aminosäuren mit Zuckern entweder durch exogene Glykierung bei Nahrungsmittel verarbeitenden Prozessen oder durch endogene Glykierung spontan im Körper entstehen (Chuyen 2006).

\subsubsection{Exogene Glykierung (auch Glykation)}

Exogene Glykierung erfolgt, wenn Kohlehydrate gemeinsam mit Proteinen bei Temperaturen über $120^{\circ} \mathrm{C}$ erhitzt werden. Erhitzungsvorgänge wie Braten und Backen von Kuchen, Keksen und Amylase-beinhaltenden Speisen,
Langzeitlagerung, aber besonders die MaillardReaktion führen zur Entwicklung von neuen Epitopen, die AGEs genannt werden.

Die Maillard-Reaktion hat große Bedeutung in der Nahrungsmittel-verarbeitenden Industrie. In einer mehrstufigen Reaktion werden ab etwa $140{ }^{\circ} \mathrm{C}$ Aminosäuren mit reduzierenden Zuckern verbunden. Die entstehende Schiff'sche Base lagert sich mehrmals weiter um, bis der erwünschte Karamellgeruch bzw. der Röstgeruch entsteht. Die braunen, Melanoidine genannten Endprodukte sind geschmacksintensiv und für das typische Aroma von Gebratenem und Gebackenem verantwortlich (Belitz et al. 2009). Vorteil dieser Reaktion ist, dass die Melanoidine den Verderb der Nahrungsmittel hinauszögern, weil sie Luftsauerstoff binden können.

In industrialisierten Ländern verwendet die Lebensmittelindustrie die MaillardReaktion sehr häufig, weil die Endprodukte (AGEs) Geschmack, Textur und Geruch vieler Lebensmittel beeinflussen, und setzt sie daher gerne als Geschmacksverstärker, Farbstoff und zur Aufbesserung der Erscheinung von Lebensmitteln ein. Mithilfe der Maillard-Reaktion entsteht dann zum Beispiel bei langer Erwärmung der Aminosäure Cystein mit Glukose das Aroma von Bratzwiebeln, bei kurzer Erwärmung das Aroma von Braten. Auch Laugenbrezel werden über Erhöhung des $\mathrm{pH}$ Werts durch Lauge über die Maillard-Reaktion hergestellt, genauso wie Brotkruste durch trockene Hitze und Kekse durch Bestreichen mit Eiklar oder Zuckerlösung beim Backen. Auch Fleisch, Wurst, Schinken und Käse enthalten große Mengen an AGEs, die sich beim Braten, Grillen und Frittieren noch vervielfachen können (Sathe et al. 2005).

\subsubsection{Endogene Glykierung}

Auch endogen bilden sich im Serum AGEs in hoher Konzentration, besonders bei erhöhtem Angebot an Blutzucker, der dann mit körpereigenen Proteinen ohne Enzymbeteiligung reagiert (Schiekofer et al. 2003). Lebensmittel, 
die den Blutzucker am stärksten erhöhen, zeigen auch hohe AGE-Bildung.

Fruktose wirkt stärker AGEs-bildend als Glukose (Sakai et al. 2002). Weizen gilt als starker AGE-Bildner, weil das Amylopektin A des Weizens durch die Amylase schnell verdaut wird und so zu einem hohen Blutglukosespiegel führt. Auch Stress und chronische Entzündungen fördern endogen die Bildung von AGEs (Valencia et al. 2004).

Offensichtlich haben AGEs negative Auswirkungen auf die Gesundheit. AGEs stellen Risikomoleküle für den Alterungsprozess dar (Uribarri et al. 2007). AGEs scheinen mit einer beschleunigten Zellalterung und damit verbundenen degenerativen Erscheinungen einherzugehen und werden auch mit der Auslösung chronischer Entzündungen sowie kardiovaskulären Erkrankungen (Stirban et al. 2014) und der Entstehung von Diabetes in $\mathrm{Zu}$ sammenhang gebracht. AGEs fördern entzündliche Prozesse durch Bindung an spezielle AGE-Rezeptoren: RAGE (Rezeptor für AGE). RAGE wird von DCs, Makrophagen, T-Lymphozyten und B-Zellen, aber auch von Mastzellen und Basophilen exprimiert (Smith et al. 2017). Bindung der AGEs an die RAGEs von Mastzellen führt innerhalb weniger Sekunden zur Histaminfreisetzung (Sick et al. 2010).

Die Interaktion von RAGE mit Zellliganden führt zur Aktivierung des Transkriptionsfaktors NF- $\kappa B$ und Sekretion von IL-1, IL-6, TNF- $\alpha$ und Insulin-like-growth-Faktor-1. Endothelzellen exprimieren daraufhin Adhäsionsmoleküle ICAM-1 und VCAM-1, die eine endotheliale Inflammation auslösen (Chuah et al. 2013; Ott et al. 2014).

RAGE ist auch Rezeptor für HMGB1 („high mobility group box $1^{\prime \prime}$ ), einem sogenannten Alarmin, das von absterbenden Zellen bei Gewebsschäden sezerniert wird, um das adaptive Immunsystem zu aktivieren und das System über die "Gefahr zu alarmieren“. Bindung von HMGB1 an RAGE führt zu Aktivierung und Migration von Makrophagen, Neutrophilen, DCs und T-Zellen, wodurch entzündliche und oxidative Prozesse ausgelöst werden (Dumitriu et al. 2005). Somit wird verständlich, dass die Aktivierung der RAGEs durch AGEs ebenfalls inflammatorische Reaktionen auslöst.

An Neuronen beobachtete man als Folge der Glykation von Myelin entzündliche Prozesse wie die Entstehung von Neuropathien, z. B. bei Diabetes mellitus (Singh et al. 2014b), aber auch bei M. Alzheimer könnten AGEs eine pathogenetische Ursache haben (Angeloni 2014). AGEs reichern sich auch in den Augenlinsen an und induzieren dort Katarakte und Fibrosen (Raghavan et al. 2016).

Eine deutsche Gruppe erforschte 2010 (Hilmenyuk et al. 2010), ob AGEs als „NeoAntigene" eine Bedeutung bei der Entstehung von Nahrungsmittelallergien haben könnten. Dabei wurde die Reaktion von regulärem, natürlichem Ovalbumin (OVA) auf dendritische Zellen, deren immunstimulatorische Kapazität und die T-Zell-Antwort mit der Reaktion von AGE-Ovalbumin, einem durch Glykation von OVA entstandenen ,advanced glycation endproduct", verglichen.

Man erkannte, dass AGE-OVA stärker von unreifen dendritischen Zellen aufgenommen wurde als das reguläre Ovalbumin und dass es zu einer verstärkten Expression von RAGE, dem Rezeptor für AGEs, und vermehrten Th2-Immunantworten kam.

Sind AGEs auch bei Patienten mit allergischen Erkrankungen vermehrt im Serum nachweisbar?

Eine italienische Gruppe untersuchte die Menge der AGEs im Serum von Patienten mit allergischer Rhinitis im Vergleich zu einer gesunden Kontrollgruppe und fand signifikant erhöhte Werte (Di Lorenzo et al. 2013).

2015 beschrieb ein amerikanisches Forscherteam im J Allergy Clin Immunol (Oczypok et al. 2015) die Rolle von RAGE auf das allergische Geschehen näher. Der Rezeptor RAGE kommt in großer Menge in der Lunge vor und spielt eine wichtige Rolle bei der Pathogenese von asthmatischen und allergischen, entzündlichen Veränderungen der 
Luftwege, weil er die Ausschüttung der Th2Zytokine IL-5 und IL-13 fördert. IL-5 und IL-13 werden von Th2-Zellen, aber auch von Gruppe-2-innate lymphoid cells (ILC2s) sezerniert, die wiederum von dem proallergischen Zytokin IL-33 stimuliert werden (s. - Abschn. 3.3).

In diesem Versuch wurde nun gezeigt, dass RAGE die Expression von IL-33 als Antwort auf Allergenkontakt mit der Hausstaubmilbe fördert, bei Abwesenheit von RAGE (in Knock-out-Mäusen) kam es zu keiner Akkumulation von ILC2s in Mausmodellen mit allergischer Atemwegsentzündung. Dadurch konnte geklärt werden, dass der Rezeptor RAGE die lungenspezifische Akkumulation von ILC2-Zellen mediiert und dadurch die allergische Kaskade der Lunge aktivieren kann.

Diätetische AGEs und AGE-bildende Zucker könnten somit weitere wesentliche Faktoren der steigenden Prävalenz von Allergien darstellen.

Im Oktober 2018 zeigte eine Meta-Analyse von 16 Studien, dass Fastfood-Verzehr 1- bis 2-mal/Woche das Risiko für Asthma, allergische Rhinitis und Ekzem signifikant erhöht. Je mehr Fastfood, desto schlechter: Bei Konsumation von 3 oder mehr Fastfood-Mahlzeiten pro Woche zeigten sich signifikant vermehrt Rhinokonjunktivitis und Ekzem. Beim Vergleich der beiden Fastfood-Gruppen untereinander fand man in der Gruppe der $\geq 3$ Hamburgers \& Co-Esser eine signifikant erhöhte Wahrscheinlichkeit, an schwerem Asthma und schwerer Rhinokonjunktivitis zu leiden (Wang et al. 2018b).

- Abb. 4.14 zeigt den zeitlich parallelen Anstieg von Fastfood-Ketten und Zuckerverbrauch sowie Allergien in hochentwickelten Ländern. Interessanterweise nahmen in diesem Beobachtungszeitraum auch andere nichtübertragbare („non communicable“) Erkrankungen wie Morbus Crohn, Diabetes und Multiple Sklerose kontinuierlich zu (s. • Abb. 9.1).

Somit staunt man kaum mehr über Studien, die demonstrieren, dass geröstete Erd- nüsse eher Allergien auslösen als gekochte oder rohe Erdnüsse (Moghaddam et al. 2014). Obwohl im Westen und in Südostasien ähnliche Mengen Erdnüsse verzehrt werden, werden im Westen oft geröstete oder trocken geröstete Erdnüsse gegessen, während in Asien die Nahrung eher rohe, gekochte oder gebratene Erdnüsse beinhaltet.

Die Oxforder Gruppe ging der Frage nach, ob die, beim Herstellungsprozess des Röstens entstehenden, potenziellen immunmodulatorischen Eigenschaften von AGEs das allergisierende Potenzial verändern können, und konnte ein verstärktes allergenes Potenzial von gerösteten Erdnüssen zeigen.

Auch die renommierte Allergologin Kirsten Beyer demonstrierte in einer Studie, dass gekochte und in der Pfanne gebratene Erdnüsse eine wesentlich geringere IgE-bindende Kapazität haben als trocken geröstete Erdnüsse (Beyer et al. 2001). Dies wirft die Frage auf, ob beim primären Schritt der Sensibilisierung vielleicht sogar das Röstprodukt mit AGEs mehr negative immunmodulatorische Wirkung hat als die Antigenität der Erdnuss an sich.

Verstärkte immunologische Antworten nach Maillard-Reaktion konnten auch bei Hühnereiweiß im Vergleich zu AGE-Hühnereiweiß, das mittels thermischer Prozesse in Gegenwart von Zucker hergestellt wurde, gezeigt werden. Auch hier beobachtete man eine stärkere OVA-spezifische $\mathrm{CD}^{+}$-T-Zell-Aktivierung nach AGEOvalbumin an DCs als bei unbehandeltem Ovalbumin (Ilchmann et al. 2010).

Wie bereits berichtet, löste Ei in gekochter Form bei Kindern im Alter von 4-6 Monaten seltener Allergien aus als in gebackener Form (Koplin et al. 2010).

Auch Erwärmung durch die Mikrowelle erhöht den AGE-Anteil der Nahrung. In Milch, die 1 Minute in der Mikrowelle erwärmt wurde, fand man 5-fach erhöhte Mengen an AGEs, nach 3 Minuten eine Erhöhung um das 86-Fache (Uribarri et al. 2005).

Manchmal kann die Maillard-Reaktion jedoch das allergische Potenzial von Nahrungs- 

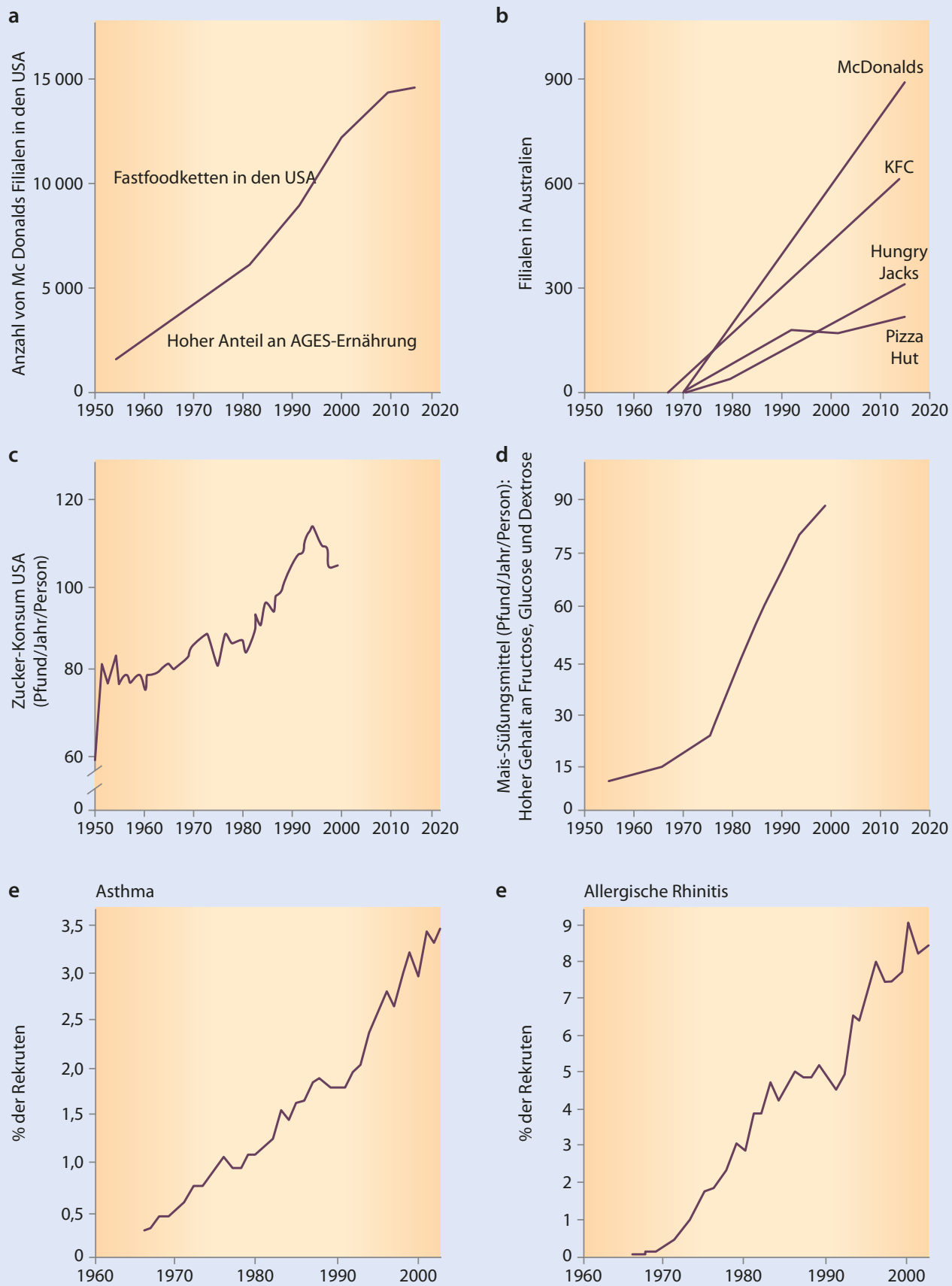

- Abb. 4.14 Paralleler Anstieg von Fastfoodketten/ Zuckerkonsum und Allergieprävalenz. Mit der massiv vermehrten Aufnahme von AGEs zwischen 1960 und
2000 geht eine Versechsfachung von Asthma und eine Verneunfachung von allergischer Rhinitis einher. (Mod. nach Smith et al. 2017 und Latvala 2005) 
mitteln aufgrund der geringen Hitzestabilität der allergenen Proteine reduzieren (bei $\mathrm{Mu}-$ scheln, Tintenfischen, Äpfeln, Kirschen), unabhängig von der Bildung von AGEs (Smith et al. 2017).

Diese Erkenntnisse sollten auch bei zukünftigen Präventionsstrategien in Betracht gezogen werden, nämlich ob man z. B. Babys ab dem 4. Monat geröstete oder rohe/gekochte Erdnüsse/Nahrungsmittel zur Prävention von Allergien anbietet.

Für die Allergieforschung und Allergieprävention wird jedenfalls ein genauer Blick auf die Nahrungsmittel-verarbeitende Industrie notwendig sein, um der weiteren Prävalenz von Allergien entgegenzuwirken.

Initiativen wie die Slow-Food-Bewegung sollten gefördert werden und die Bevölkerung, aber ganz besonders die Schwangeren und jungen Mütter aufgeklärt werden. Denn schon im Mutterleib wird das Kind mit AGE-Stoffwechselprodukten der Mutter belastet.

- Tipps für AGEs-reduzierte Ernährung

Nahrung mit hohem AGE-Anteil

- Gezuckerte Nahrungsmittel wie Kekse, Kuchen, Backwaren, Limonaden

- Verarbeitete Nahrungsmittel

- Fetthaltiges (besonders rotes) Fleisch in Kombination mit Glukose und Fruktose

- Frittierte Speisen oder trocken erhitzte Speisen

Nahrung mit niedrigem AGE-Anteil

- Obst und Gemüse

- Fisch

- Vollkornprodukte

- Nudeln

- Pasta

Empfohlene Zubereitungsmethoden

- Schongaren

- Kochen in Wasser, Dämpfen, Pochieren

- Keine hohen Temperaturen, nicht Grillen und trocken Erhitzen

\subsection{Mütterliches Rauchen}

Eine Meta-Analyse von 43 Studien zeigt deutlich, dass mütterliches Rauchen während der Schwangerschaft die Wahrscheinlichkeit von Giemen vor dem 6. Lebensjahr und ab dem 6. Lebensjahr zusätzlich auch die Wahrscheinlichkeit für Asthma erhöht (Silvestri et al. 2015). Sogar Rauchen der mütterlichen Großmutter während deren Schwangerschaft beeinflusst die Lunge des Enkelkindes! Anhand von 338 Kindern mit Asthma innerhalb der ersten 5 Lebensjahre fand man im Vergleich zu über 500 Kontrollkindern heraus, dass die Chance, Asthma zu entwickeln, verdoppelt war, wenn die Großmutter in der mütterlichen Fetalperiode geraucht hatte. Das Risiko erhöhte sich noch mehr, wenn die Mutter ebenfalls während der Schwangerschaft rauchte $(\mathrm{OR}=2.6)$, verglichen mit einer $\mathrm{OR}$ von 1.8, wenn sie nicht rauchte. Diese Studie beweist, wie epigenetische Generationen-übergreifende Einflüsse über permanente Exposition zu Weitergabe und Verstärkung des Phänotyps führen können (Li et al. 2005).

\subsection{Magensäure-Blocker}

Exposition zu Magensäure-Hemmern in utero führt bei Kindern zu einer Zunahme der Entwicklung von Allergien (OR 1.43, [95 \% CI] 1.29-1.59). Bei einer Observationsstudie an einer schwedischen Kohorte von 29.490 Kindern (Dehlink et al. 2009) war Blockade der Magensäure bei Schwangeren assoziiert mit einer Erhöhung der kindlichen Asthmarate (3,7 \% der Gesamtpopulation vs. 5,6 \% der exponierten Kinder (OR 1.51, 95 \% CI 1.35-1.69)).

Die Gruppe um die Wiener Forscherin Eva Untersmayr-Elsenhuber bewies, dass die Anhebung des $\mathrm{pH}$-Werts im Magen durch Magensäure-Hemmer zu einer Veränderung der Verdauungsfunktion des Magens mit verlängerter Persistenz von labilen Nahrungsproteinen im Verdauungstrakt führt, wodurch deren Potenzial, an $\operatorname{IgE}$ zu binden, deutlich erhöht wird. Physiologisch aktiviert die Gastrinpro- 
duktion die Parietalzellen des Magens zur Sekretion von Salzsäure, die den $\mathrm{pH}$-Wert des Magens senkt, aber auch die verschiedenen Pepsine, die als Proteasen die Nahrungsproteine aufspalten, triggert. Bei einem idealen pH-Wert zwischen 1.8 und 3.2 spalten die Proteasen die großen Proteinkomplexe in kleinere Peptide auf, die dann im Dünndarm über Pankreasenzyme weiter zerkleinert werden, um dann als Einzel-Aminosäure oder maximal als Peptid mit 3 Aminosäuren über die Enterozyten resorbiert $\mathrm{zu}$ werden. $\mathrm{Ab}$ einem $\mathrm{pH}$-Wert von 5.0 ist die enzymatische Aktivität von Pepsin deutlich herabgesetzt und die Proteine werden zu wenig aufgespalten. Nur diese daraus resultierenden größeren Peptidmoleküle lösen immunologische Antworten aus und werden dadurch zu potenziellen Nahrungsmittelallergenen (Untersmayr und Jensen-Jarolim 2008).

Bereits fünf Tage PPI (Protonenpumpenhemmer)-Einnahme steigern den $\mathrm{pH}$-Wert des Magens auf durchschnittlich pH 5.0 (Prichard et al. 1985). Die natürliche Magensäureproduktion ändert sich im Laufe des Lebens. Neugeborene haben zunächst einen $\mathrm{pH}$-Wert von 6.08.0, der 24-48 Stunden postpartal auf 1.0-3.0 abfällt, um dann trotzdem erhöht zu bleiben, bis das Erwachsenen-Niveau mit ca. 2 Jahren erreicht ist (Agunod et al. 1969).

Bei Älteren steigt der $\mathrm{pH}$-Wert des Magens wieder an, sodass $50 \%$ der 60-Jährigen höhere pH-Werte aufweisen (Davies und James 1930).

Murine Experimente in vivo zeigten, dass die Gabe von Magensäureblockern allergenspezifische IgE-Antikörper nach Einnahme von Haselnuss, Kaviar und Parvalbumin auslöste sowie eosinophile Infiltration in die Magenmukosa und Hautjucken induzierte. In der Kontrollgruppe ohne Magensäureblocker blieb die Toleranz bestehen (Untersmayr et al. 2003).

In einer klinischen Studie resultierte eine 3-monatige Gabe von H2-Rezeptorblockern oder PPI an 152 gastroenterologische Patienten in einer Booster-Wirkung bei bestehender Nahrungsmittelallergie oder in einer De-novo-IgE-Bildung gegenüber Bestandteilen der normalen Nahrung. Die ausgelöste Sensibilisierung konnte über Skin-Prick-Tests auch 5
Monate nach Beendigung der Therapie nachgewiesen werden. $12 \%$ der Patienten hatten IgE-Antikörper gegen Nahrungsmittel entwickelt (Untersmayr et al. 2005).

Bei einem Doppelblind-Versuch (Untersmayr et al. 2007) wurde Fisch vor der Einnahme von Patienten mit Fischallergie mit Magenenzymen angereichert. Dabei erhöhte sich die tolerierte Allergendosis um das 10- bis 30-Fache.

Diese Versuche veranschaulichen deutlich, dass Magensäureblocker sowohl die Sensibilisierungs- als auch die Effektorphase der Nahrungsmittelallergie massiv beeinflussen, und sollten auch im Licht der wachsenden antiulzerativen Therapien, die in westlichen Ländern bis zu $10 \%$ des nationalen Gesundheitsbudgets ausmachen, gesehen werden (Westbrook et al. 2001).

Trotz genauer Guidelines werden bis zu $60 \%$ der Magensäure-hemmenden Medikamente unsachgemäß während Krankenhausaufenthalten verschrieben und auch danach ohne Indikation als Dauermedikation weiterverwendet (Zink et al. 2005). Aus Sicht der Allergologie erscheint auch die kombinierte Gabe zur Helicobacter-pylori-Eradikation mit Antibiotika, die die Diversität der Mikroflora reduzieren, problematisch.

Patienten sollten bei Verschreibung eines Magensäureblockers auf die Möglichkeit einer Sensibilisierung gegenüber Nahrungsmitteln aufgeklärt werden.

\subsection{Effekt von Antibiotika in den ersten Lebensjahren}

Die Einführung der Antibiotika in den 1950erJahren steht in direktem zeitlichen Zusammenhang mit der „2. Welle der Allergie“ - der Zunahme von Asthma, aber auch mit einem weiteren Ansteigen der Heuschnupfenprävalenz. Viele Studien demonstrieren eine direkte Korrelation zwischen der Gabe von Antibiotika, besonders während der Schwangerschaft und frühen Kindheit, und der Entwicklung allergischer Erkrankungen. 
Marra publizierte 2009 in Pediatrics (Marra et al. 2009) eine longitudinale Kohortenstudie mit 251.817 eingeschlossenen Kindern geboren zwischen 1997 und 2003 und Follow-up mit 2-3, 3-5 und 5-9 Jahren. - Tab. 4.2 zeigt eine signifikante Assoziation zwischen Antibiotikaverbrauch im ersten Lebensjahr und folgender Asthmaentwicklung mit positiver Korrelation zur Dosis, aber unabhängig von der Art des Antibiotikums.

In einer dänischen Geburtskohortenuntersuchung beobachtete man ein fast doppelt so hohes Risiko für Asthma, wenn die Mütter im 3. Trimester der Schwangerschaft Antibiotika eingenommen hatten (Stensballe et al. 2013).

Ein 2014 herausgegebenes Review von mehr als 50 epidemiologischen Studien zeigt eindeutige Evidenz des Zusammenhanges zwischen Antibiotikagabe bei Kindern und einem erhöhten Risiko für allergische Erkrankungen (Bloomfield 2014). Diese Ergebnisse wurden ganz aktuell im Mai 2018 in einer MetaAnalyse von 34 Observationsstudien aus den letzten 5 Jahrzehnten nochmals bestätigt. Anhand von fast 400.000 Kindern sah man erneut ein erhöhtes Risiko für allergische Symptome wie Heuschnupfen, Ekzem und Nahrungsmittelallergie bei jenen Kindern, die innnerhalb der ersten beiden Lebensjahre Antibiotika bekommen hatten, im Vergleich zu Kindern ohne Antibiotikaeinnahme (Ahmadizar et al. 2018). Die Einflüsse der antibiotischen Behandlung dürften sich am schädlichsten im frühen Kindesalter auswirken, genau dann, wenn die Entwicklung des Immunsystems stattfindet. Kommt es in diesem Zeitfenster zu Störungen von "Schlüsseldarmsymbionten” mit fehlenden Signalen an das sich entwickelnde Immunsystem, so kann dies zu weitreichenden Konsequenzen führen und auch viele Jahre später die Entwicklung einer allergischen Erkrankung fördern und begünstigen.

Aber auch ältere Kinder sind gefährdet. 2016 wurde in Nature Communications eine finnische Arbeit publiziert (Korpela et al. 2016), die zeigt, dass Makrolid-Antibiotikagabe bei 2- bis 7-jährigen Kindern mit einer lang an- dauernden Veränderung der Mikrobiomzusammensetzung und des Mikrobiommetabolimus assoziiert ist. Neben einer Reduktion von Actinobacteria kommt es zur Vermehrung von Proteobacteria und Bacteroidetes und Erhöhung der Makrolidresistenz. Makrolideinsatz war mit erhöhtem Asthmarisiko assoziiert, disponierte die Kinder aber auch zu verstärkter Gewichtszunahme und Übergewicht. Asthma und Adipositas zeigten eine deutlich ausgeprägte, veränderte Zusammensetzung des Mikrobioms und werden oft gemeinsam beobachtet. Penicilline hinterließen geringere Schäden am Mikrobiom des Darms.

Eine einzige antibiotische Intervention kann zu massiven Störungen der Darmflora führen. Dethlefsen (Dethlefsen et al. 2008) analysierte mittels 16S-rRNA-Sequenzierung das Mikrobiom vor und nach einer kurz dauernden oralen Ciprofloxacin-Einnahme in typischer Dosierung für Urogenitalinfekte und Magen-Darm-Infekte. Er beobachtete nach der Therapie eine Reduktion der gesamten Darmbakterien um 1/3 und eine allgemeine Reduktion der Vielfalt. Diese Auswirkungen sind nicht nur im Darm, sondern auch an sämtlichen anderen Epithelien, die allesamt ein Mikrobiom aufweisen, sichtbar.

Jakobsson et al. analysierten die Zusammensetzung des Darm- und Rachenmikrobioms nach 7-tägiger Antibiotikatherapie gegen Helicobacter pylori mit Metronidazol $400 \mathrm{mg}$, Clarithromycin $250 \mathrm{mg}$ und Omeprazol $20 \mathrm{mg}$ 2-mal täglich. Die Analyse demonstrierte, dass die Erholung und Stabilisierung der mikrobiellen Vielfalt sowohl der intestinalen Mikrobiota als auch der Rachenmikrobiota (s. - Abb. 4.15) Monate dauern kann und auch noch 4 Jahre nach der Behandlung signifikante Unterschiede nachweisbar sind (Jakobsson et al. 2010).

Veränderungen der Darmflora können auch über mehrere Generationen weitervererbt werden (Sonnenburg et al. 2016).

Ganz aktuell beobachtete man 2018 bei neonatalen Mäusen, dass Antibiotika-induzierte Dysbiose zur beeinträchtigten Reifung der Treg-Zellen und zu verstärkten Th2-Antworten führte (Wypych und Marsland 2018). 


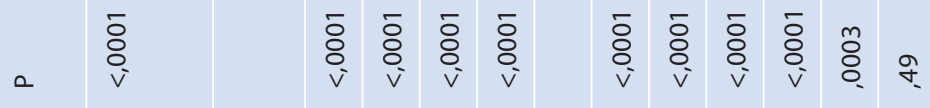

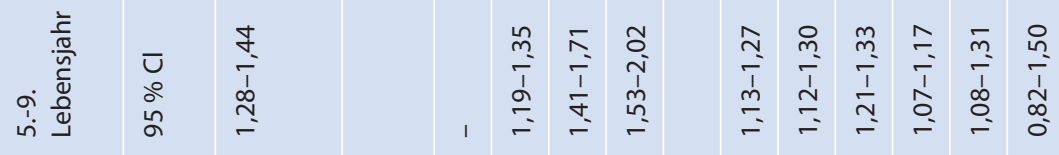

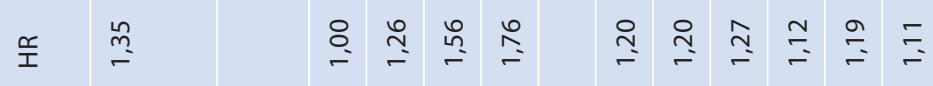

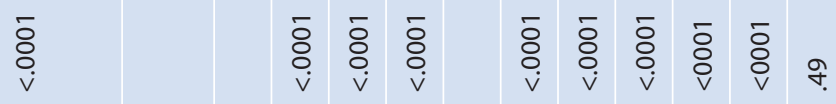

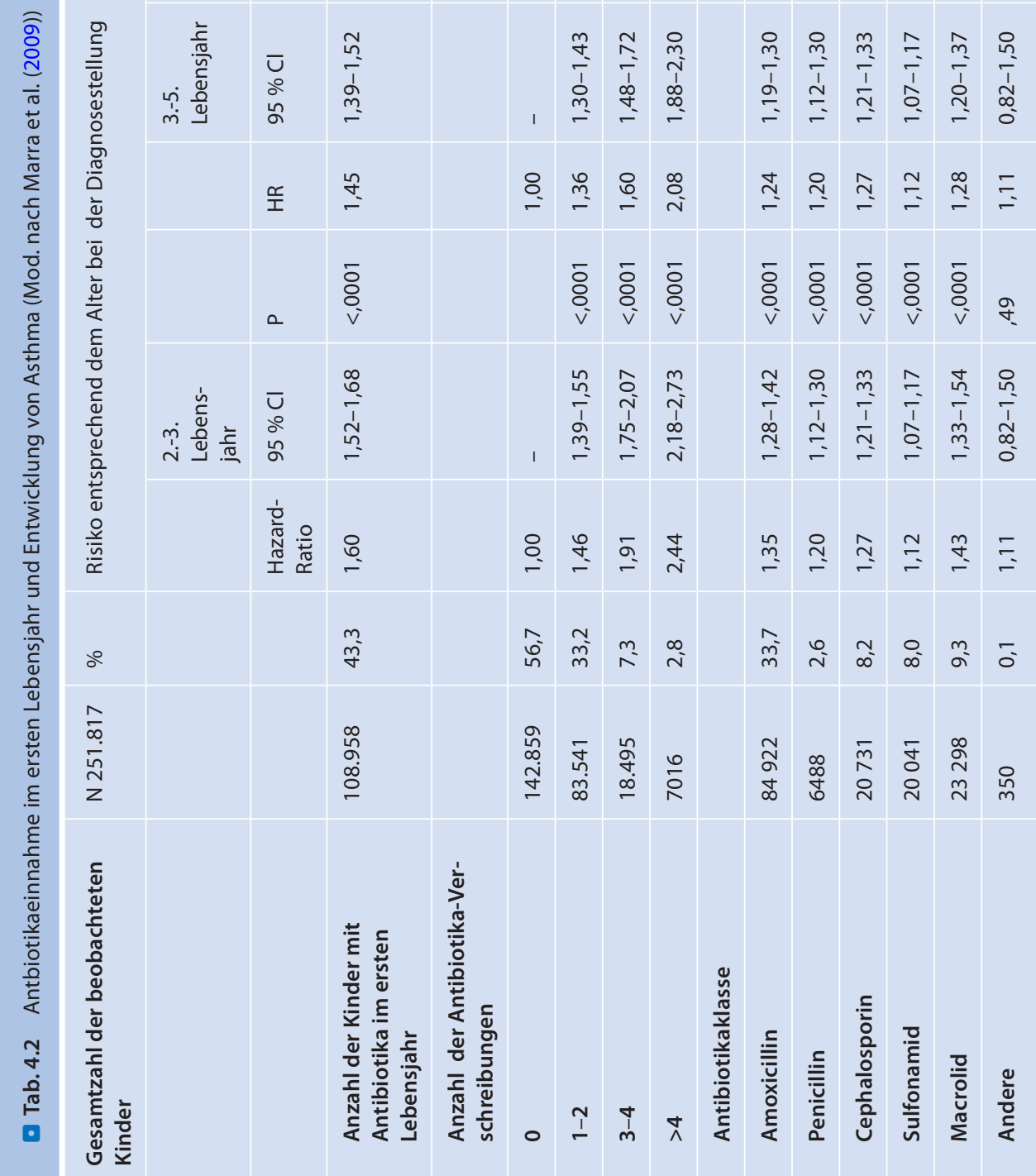



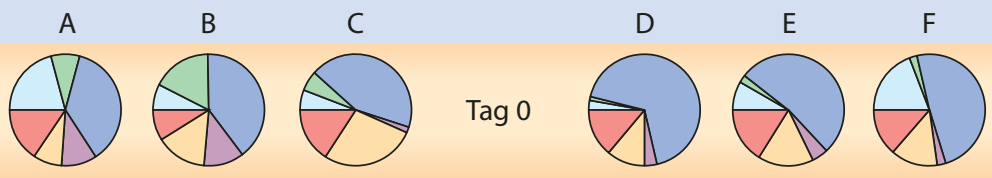

Tag 0

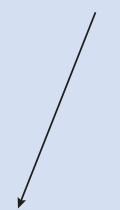

A
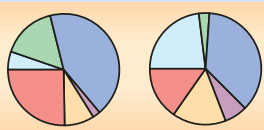

C
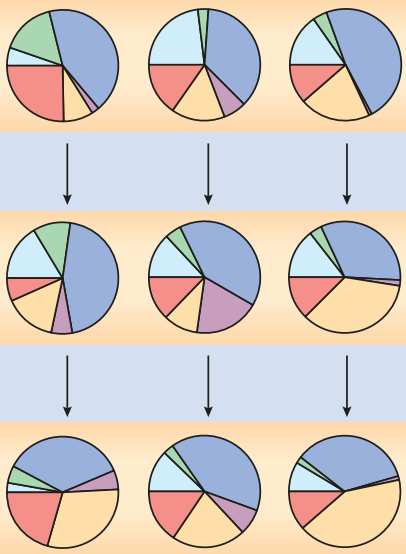

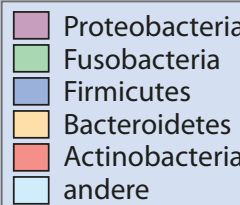

andere

Tag 8-13
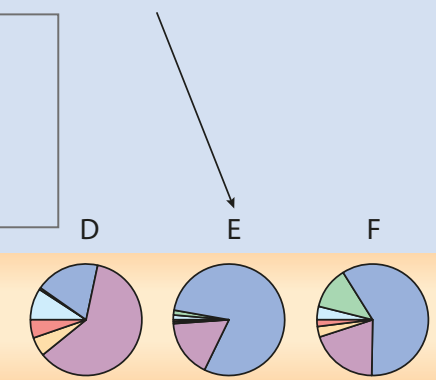

1 Jahr
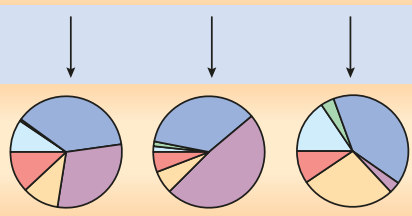

4 Jahre
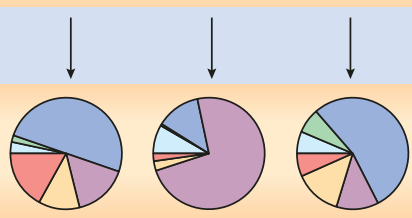

- Abb. 4.15 Auswirkungen einer Kurzzeit-Antibiotikatherapie auf das Rachenmikrobiom nach 8-13 Tagen, nach 1 Jahr und 4 Jahren. A-C: 3 Patienten ohne Antibiotikum D-F: 3 Patienten mit Antibiotikum (Mod.

Aus diesen Daten ergibt sich, dass Antibiotika nur mit größter sorgfältiger Abwägung der Indikation verschrieben werden sollten und deren Einfluss auf das Mikrobiom immer bedacht werden muss.

Die Interessenvertreter und politischen Entscheidungsträger müssen angesichts der steigenden Prävalenz von Allergien (Bloomfield et al. 2016)

- den Fokus von der Angst vor Infektion auf die wichtige gesundheitserhaltende Rolle des Mikrobioms lenken,

- den Fokus nicht nur auf die Antibiotikaresistenz legen, sondern auch auf die Kollateralschäden, die Antibiotika in der nach Jakobsson et al. 2010). Auch noch 4 Jahre nach antibiotischer Therapie ist die mikrobielle Vielfalt des Rachenmikrobioms deutlich verändert.

physiologischen Flora auslösen, und noch mehr deren vernünftigen Einsatz fordern,

- den Einfluss von Diät auf das Mikrobiom besser kommunizieren,

- die falschen, übersimplifizierenden Interpretationen der Hygiene-Hypothese berichtigen: Desinfektion im Krankenhaus und bei Infektionskrankheiten ist wichtig, um das Eindämmen der multiresistenten Keime zu vermeiden. Stattdessen soll jedoch die Verschreibung von Antibiotika reduziert und der Kontakt zu natürlichen Mikroben im Freien und zu Haustieren gefördert werden. 
Mögliche Bedenken und Auswirkungen der Antibiotika auf das Mikrobiom und das Risiko einer Störung des Immunsystems im späteren Leben müssen auch den Patienten, nicht nur dem Verschreiber erklärt werden, damit das Verlangen nach Antibiotika auch vom Patienten kritischer hinterfragt wird (Shanahan 2015). aus?

Wie sieht jedoch die Anwendung im Alltag

Aus Daten des National Ambulatory and National Hospital Ambulatory Medical Care Surveys (NAMCS und NHAMCS) der USA wurden die Indikationen für tatsächlich verschriebene Antibiotika und Art des Antibiotikums analysiert (Shapiro 2014). Die beobachteten Daten von 235.994 ambulanten Patientenkontakten in amerikanischen Praxen, Ambulanzen und Notfallaufnahmen wurden auf die gesamte Einwohnerzahl der USA hochgerechnet und ergaben, dass 2007-2009 985 Millionen Arztkontakte pro Jahr stattfanden, 812 Millionen in Ordinationen, 76 Millionen in Spitalsambulanzen und 96 Millionen in Notfallabteilungen. Unter allen Arztkontakten wurden geschätzte 101 Millionen (95 \%CI, 91-111 Millionen) Antibiotika pro Jahr verschrieben, das bedeutet bei ca. $10 \%$ aller Arztbesuche. Abb. 4.16 zeigt die Verteilung der Antibiotika-Arten. Die häufigstverschriebenen Antibiotika waren Fluoroquinolone (25\%) und Makrolide (20 \%).

Auch die Indikationen für die Verschreibung von Antibiotika wurden evaluiert. - Tab. 4.3 demonstriert, dass $41 \%$ aller Antibiotika wegen respiratorischer Infekte verschrieben wurden, die damit den häufigsten Grund der Verschreibungen darstellten. Erstaunlicherweise wurde beobachtet, dass auch im Rahmen von jenen akuten respiratorischen Infekten, bei denen Antibiotika objektiv kaum indiziert gewesen wären, trotzdem bei $51 \%$ der Patienten Antibiotika verschrieben wurden! Insgesamt kommt man dadurch pro Jahr auf 27 Millionen antibiotische Verschreibungen mit fragwürdiger Indikation nur für den Respirationstrakt (Shapiro 2014). Interessant ist auch zu beobachten, dass besonders bei fragwürdigen Indikatio-
- Abb. 4.16 Antibiotikaverschreibungen in den USA 2007-2009 (Mod. nach Shapiro 2014)

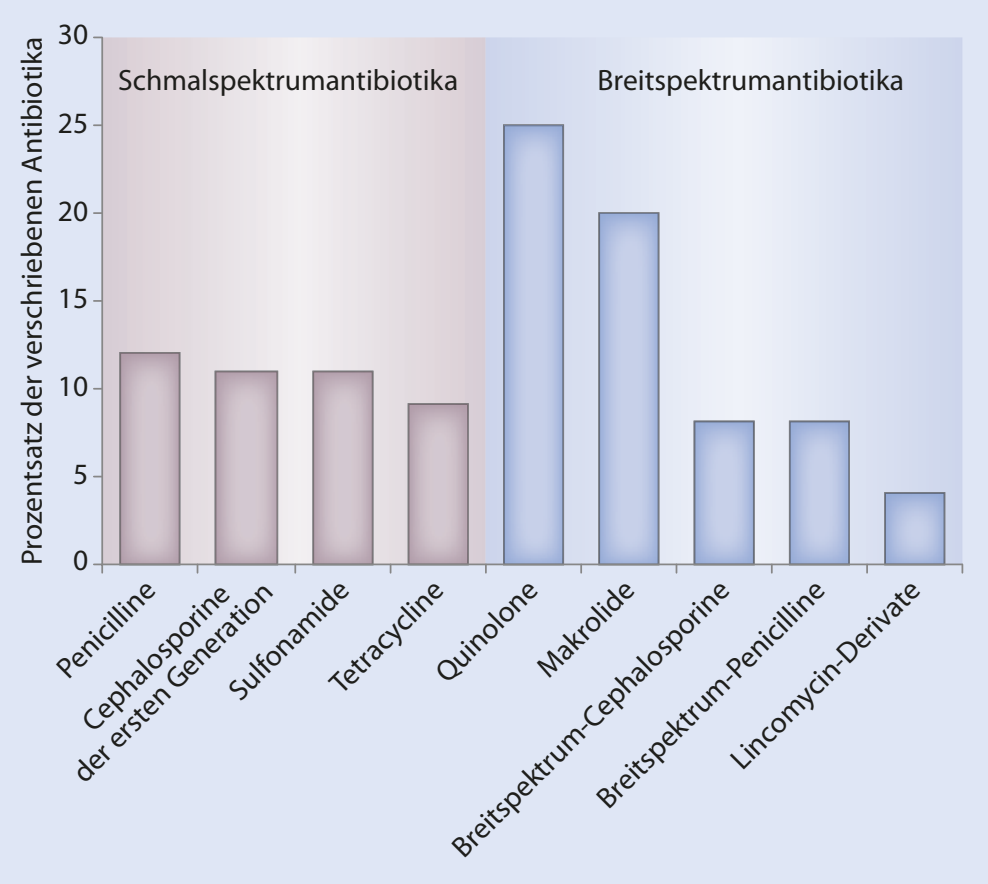


- Tab. 4.3 Antibiotikaverschreibung nach Indikation: 2007-2009 USA (Hochrechnung basierend auf 236.994 Arztbesuchen, bei denen 28.036 Antibiotika verschrieben wurden) (Mod. nach Shapiro 2014)

\begin{tabular}{|l|l}
\hline Indikationen & $\begin{array}{l}\text { Anzahl der Arztbesuche } \\
\text { (Millionen), bei denen }\end{array}$ \\
Antibiotika verschrieben \\
wurden
\end{tabular}

Prozentueller Anteil der Arztbesuche, bei denen Antibiotika verschrieben wurden

\section{Respiratorisch \\ Akuter Infekt des \\ Respirationstraktes, Antibiotika potenziell indiziert}

40

Akuter Infekt des

Respirationstraktes,

Antibiotika kaum indiziert

Andere respiratorische Indikationen, Antibiotika kaum indiziert

Andere Indikationen

Haut/Schleimhäute

Urogenitaltrakt

Harnwegsinfekt

Andere urogenitale Indikationen

Verdauungstrakt

Infektiöse Magen-

Darm-Erkrankungen

Andere Störungen des 4

Verdauungstraktes

Verschiedene Infektio- 3

nen

Operativ und postope- 1 rativ

Alle anderen Indikatio- 18

nen

Gesamtsumme
13

13

14

57

18

12

8

4

6

2

4

3

$13 \%$

$6 \%$

$3 \%$

$10 \%$

\begin{tabular}{|l|l|}
\hline $7 \%$ & $52 \%$ \\
\hline $13 \%$ & $38 \%$ \\
\hline $22 \%$ & $68 \%$ \\
\hline $60 \%$ & $69 \%$ \\
\hline $9 \%$ & $67 \%$ \\
\hline
\end{tabular}

$11 \%$

$10 \%$

$64 \%$

$77 \%$

$12 \%$

$59 \%$

$54 \%$

$47 \%$

$50 \%$

$61 \%$

$65 \%$

$80 \%$

$76 \%$

$2 \%$

$8 \%$

$8 \%$

$9 \%$

$\%$

Prozentueller Anteil von Breitbandantibiotika-Verschreibungen

$74 \%$ 


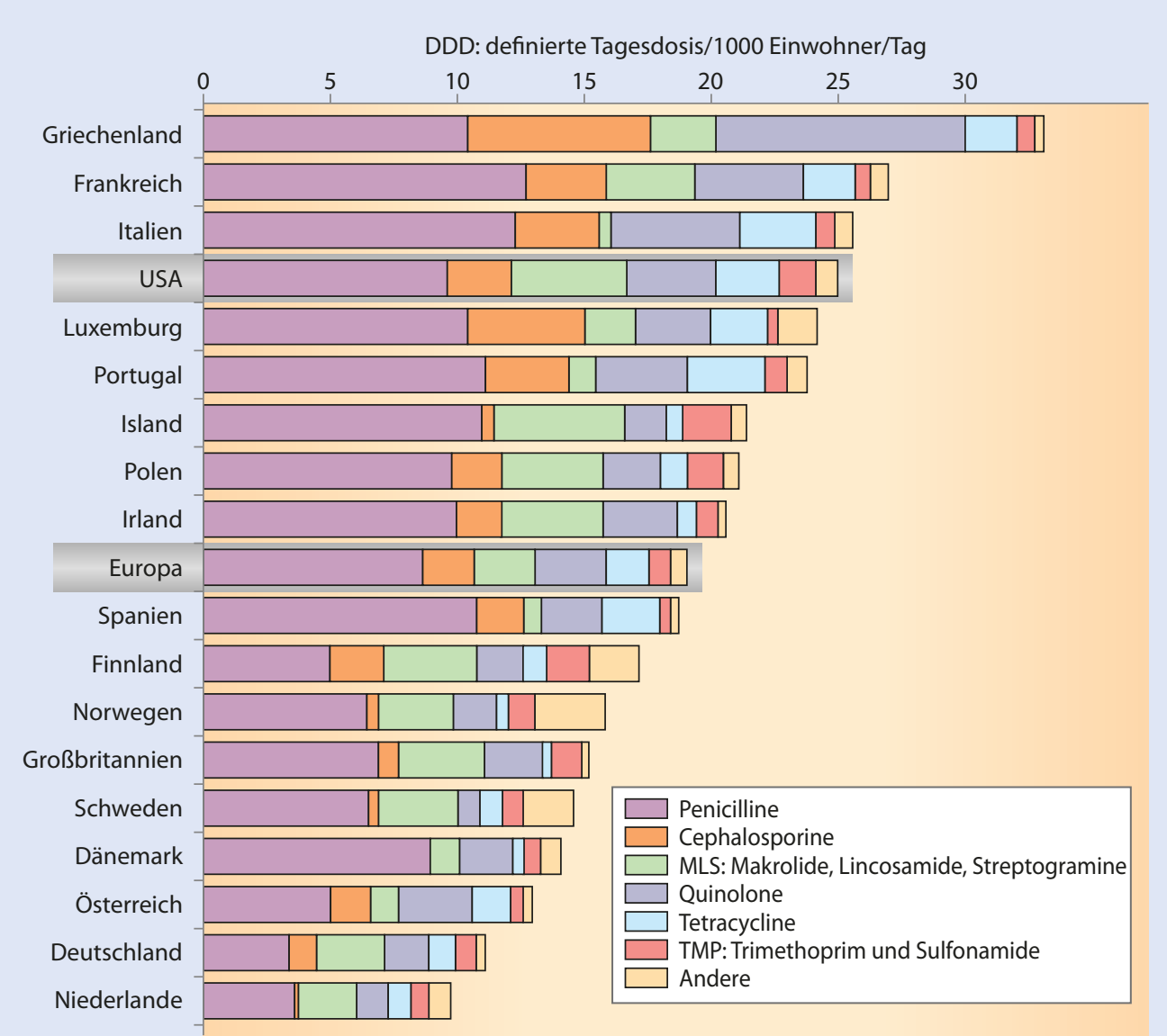

Abb. 4.17 Vergleich: Systemischer Antibiotikaverbrauch von ambulanten Patienten 2004 in den USA und 27 europäischen Ländern (Mod. nach Goossens 2007)

schüler" erwähnt, weil dort relativ wenige Antibiotika allgemein und auch seltener Breitspektrumantibiotika verschrieben werden (Goossens et al. 2007).

Um den Verbrauch von Antibiotika so gering wie möglich zu halten, hat das American College of Physicians and the Center for Diseases Control and Prevention einen "Advice for High-Value Care" herausgegeben (Harris et al. 2016), der als wichtigste Empfehlung proklamiert:

I) „Ärzte sollten keine antibiotische Therapie beim akuten Infekt (",common cold") verschreiben."

\subsubsection{Guidelines: Advices for High Value Care zum Anti- biotikaeinsatz bei Infekten (Harris et al. 2016)}

\section{Anmerkung der Autorin \\ Diese Guidelines wurden zur Reduktion des Antibiotikaverbrauchs erstellt. Der Leser möge bei diesen Guidelines auf die häufige Empfehlung von NSAR achten, die nach heutigem Wissen über die Lipid- mediatoren (s. - Kap. 6) etwas kritischer}


gesehen werden sollten. Hier besteht ein hoher Bedarf an Alternativen. Erforschung und Anwendung von TCM-Kräutern bzw. westlichen Heilpflanzen könnten Abhilfe schaffen und die symptomatische Therapie ergänzen.

\subsubsection{Die banale Erkältung}

Die banale Erkältung ist die häufigste Erkrankung in den USA. Als selbstlimitierende, milde Infektion der oberen Atemwege zeigt sie Symptome wie Niesen, Schnupfen, Halsschmerzen, niedriges Fieber, Kopfschmerzen und Krankheitsgefühl. Die Symptome sind abhängig von der inflammatorischen Antwort des Wirtsorganismus gegenüber dieser viralen Entzündung. Manchmal treten Komplikationen wie bakterielle Sinusitis, Otitis media oder akute Asthmaexazerbationen auf. Antibiotika spielen keine Rolle bei der Prävention dieser Komplikationen (Kenealy und Arroli 2013). In den USA gibt es 37 Millionen Arztbesuche wegen Erkältung und $30 \%$ dieser Besuche resultieren in der Verschreibung von Antibiotika (Schnappert et al. 2006).

- Managementstrategien: Clinical Guidelines:

- Antibiotika sollten nicht verschrieben werden, weil sie nicht effizient sind und zu einer erhöhten Gefahr von Nebenwirkungen führen (Tan et al. 2008). Die Patienten sollten angewiesen werden, dass die Symptome bis zu 2 Wochen dauern können und sie falls sich die Symptome verschlechtern bzw. die Erholung in der erwarteten Zeit nicht eintritt, nochmals den behandelnden Arzt konsultieren sollten. Die Wirkung und Risiken der symptomatischen Therapie sollen deutlich erklärt werden, und auch, dass Antibiotika nicht nützen und Nebenwirkungen haben können.

\section{Symptomatische Therapie:}

- Kombination von Antihistaminika/Analgetika/ Schleimhaut-abschwellenden Mitteln: Laut einem Cochrane-Review erleichtern diese Mittel zwar bei Erwachsenen und älteren Kindern die Symptome, sollten jedoch wegen des Risikos von vermehrten Nebenwirkungen genau abgewogen werden. Bei kleinen Kindern gibt es laut einem Cochrane-Review von 2012 keine Evidenz für Effektivität (De Sutter et al. 2012). Inhaliertes Iprotropiumbromid, inhaliertes Chromolynsodium, Antitussiva und Analgetika könnten symptomatische Erleichterung schaffen.

- Zink-Supplementierung reduziert die Tage der Infektion bei gesunden Personen, ist aber oft mit Übelkeit verbunden (Singh et al. 2013). Sowohl Vitamin C (Hemilä und Chalker 2013) als auch Echinacea (KarschVölk et al. 2014) zeigen in aktuellen Cochrane-Reviews keine Evidenz der Wirksamkeit.

\subsubsection{Banale Halsschmerzen - Pharyngotonsillitis}

Halsschmerzen waren der Grund für 4,3 \% aller Arztbesuche in den USA. Die meisten Pharyngitiden sind viralen Ursprungs und werden von Rhino-, Corona-, Adeno-, Herpes-simplex-, Parainfluenza-, Entero-, Epstein-Barr-, Influenza- und Zytomegalieviren ausgelöst.

Laut New England Journal of Medicine 2011 ist die Wahrscheinlichkeit, dass bei Halsschmerzen Streptokokken der Gruppe A als Superinfektion auftreten und Antibiotika gebraucht werden, $10 \%$ (Wessels 2011).

Die tatsächliche Verschreibungsrate von Antibiotika beträgt in den USA jedoch $60 \%$ (Barnett et al. 2014). Ausgehend von $80 \%$ Antibiotikaverschreibungen im Rahmen von akuter Pharyngotonsillitis in den 1980er-Jahren, sank die Rate im Jahr 1993 auf 70 \%, wegen folgender großer Anstrengung zur Aufklärung von 
Ärzten und Patienten bis zum Jahr 2000 auf $60 \%$, wo sie bis zum Jahr 2010 stagnierte. Das überschreitet noch immer deutlich die $10 \%$ der Patienten, die die Antibiotika wirklich bräuchten. Die verschriebenen Antibiotika waren zum größten Teil die falschen. Das Guideline-empfohlene Penicillin, das billig und gut verträglich ist, wird nach wie vor zu einem geringen Prozentsatz verschrieben. Breitspektrumantibiotika, besonders Azithromycin, sind wesentlich teurer. Die Kosten für unnötige Verschreibungen von Antibiotika für Halsschmerzen zwischen 1997-2010 betrugen mindestens 500 Millionen \$. 5-25\% der Patienten mit Antibiotika entwickeln Diarrhö, einer von 1000 Patienten braucht wegen schwerer Nebenwirkungen die Notfallambulanz.

Deshalb ruft das American College of Physicians and the Center for Diseases Control and Prevention die Ärzte auf, folgendermaßen bei Verdacht auf Streptokokken der Gruppe A vorzugehen:

Zuerst Testung der Centor-Kriterien:

1. Fieber $>38^{\circ} \mathrm{C}$

2. Fehlen von Husten (bei zusätzlichem Husten, Schnupfen und oropharyngealen Bläschen oder Ulzera ist eine virale Ursache wahrscheinlich)

3. Geschwollene vordere Halslymphknoten

4. Tonsillenexsudat

5. Kinder: jünger als 15 Jahre

Erst bei mindestens 3 Kriterien sollte ein Schnelltest oder eine Kultur auf Streptokokken der Gruppe A gemacht und das Antibiotikum nur bei positivem Ergebnis verschrieben werden.

Bei besonders unüblichen heftigen Symptomen, schweren Schluckbeschwerden, hohem Fieber und Engegefühl im Hals sollten ein Peritonsillarabszess, ein Parapharyngealabszess, eine Epiglottitis und das Lemierre-Syndrom ausgeschlossen werden, das endemisch vorkommt und durch Fusobacterium necrophorum ausgelöst wird. Das Lemierre-Syndrom ist sehr selten, tritt besonders bei Jugendlichen auf und braucht rasche Behandlung, weil es auch lebensbedrohlich sein kann.
Managementstrategien: Clinical Guidelines (nach den 2019 erschienenen Arzneiund-Vernunft-Guidelines, einer Zusammenarbeit der Österreichischen Sozialversicherungen, Ärzte, Apotheker und Pharmig/Wirtschaftskammer) ( $\triangleright$ www.arzneiundvernunft.at/uploads/190111_Leitlinie_Antiinfektiva_Onlineversion_610_DE.pdf):

- Symptomatische Therapie: Analgetika: Aspirin, Acetaminophen, NSAR auch als Lutschtablette, Salzwasser und Gurgeln mit Salbeitee

- Nach positivem Streptokokken-ANachweis: Penicillin V, Cefalexin, Cefaclor - und bei Penicillinallergie: Clarithromycin, Josamycin, Azithromycin, Roxithromycin oder Clindamycin.

Antibiotika verkürzen die Symptome bei nachgewiesenen Streptokokken um 1-2 Tage. Evidenz besteht, dass die antibiotische Therapie Komplikationen wie das rheumatische Fieber und Peritonsillarabszesse verhindert, bezüglich der Prävention von Glomerulonephritis besteht nur schwache Evidenz (Spinks et al. 2013). Eine große englische Studie weist darauf hin, dass Antibiotika zwar der Entstehung von Peritonsillarabszessen vorbeugen, dass jedoch 4000 Patienten behandelt werden müssen, um einen Peritonsillarabszess zu vermeiden (Petersen et al. 2007).

- Bedacht werden sollte auch, dass die Kolonisationsrate von Streptokokken A auch bei asymptomtischen Trägern 15-20 \% beträgt.

- Tonsillektomie, nur um rezidivierende Anginen zu vermeiden, wird bei Erwachsenen nicht empfohlen (Shulman et al. 2012).

- Studien zur Sinnhaftigkeit der antibiotischen Therapie bei Kindern zeigten Evidenz, dass antibiotische Therapie bei nachgewiesenen Streptokokken A die Dauer der Symptome inklusive Hals- und Kopfschmerzen um einen Tag verkürzt (Zwart et al. 2003).

- Ob Antibiotika die Fieberdauer verkürzen, ist unsicher. Jedoch kann die antibiotische 
Therapie die horizontale Übertragung der Erkrankung in Haushalten, Schulen und Kasernen reduzieren und so Sekundärübertragungen vermeiden.

\subsubsection{Akute Rhinosinusitis}

Akute Rhinisinusitis ist eine selbstlimitiernde Erkrankung, ausgelöst durch Viren, Allergene oder Irritantien, die eine Entzündung der Schleimhaut von Nase und Nasennebenhöhlen hervorruft. Klinische Symptome sind nasale Verstopfung und Obstruktion, purulentes Nasensekret, maxillärer Zahnschmerz, Gesichtsschmerz oder -druck, Hyposmie oder Anosmie, Ohrendruck und -schmerz. Die Symptome dauern 1-33 Tage, meist lösen sie sich nach einer Woche auf. In den USA werden jährlich 4,3 Millionen Erwachsene mit Rhinosinusitis diagnostiziert und mehr als $80 \%$ der Arztbesuche resultieren in der Verschreibung von Antibiotika, am häufigsten Makrolide (Fairlie et al. 2012). Die meisten Antibiotika für diesen Zustand sind unnötig (Garbutt et al. 2012).

Eine sekundäre bakterielle Superinfektion entsteht durch Verstopfung der Sinusostien mit Hemmung des Schleimabflusses nach primär viraler Entzündung und tritt in weniger als $2 \%$ der viralen Infekte des oberen Respirationstrakts auf (Hickner et al. 2001). Der Goldstandard zur Diagnose einer bakteriellen Rhinosinusitis wäre Sinuspunktion mit Aspiration des Sekretes. Die am häufigsten isolierten Keime sind Streptococcus pneumoniae, Haemophilus influenzae, Streptococcus pyogenes und Moraxella catarrhalis. Das Röntgen/CT der Nasennebenhöhlen hat keinen diagnostischen Wert, weil bei Verdickung der Schleimhäute und Sekret nur mit einer 61 \% Sensitivität zwischen einer viralen oder bakteriellen Genese unterschieden werden kann. Somit ist Bildgebung als diagnostisches Hilfsmittel nicht hilfreich, weil virale und bakterielle Ursachen dieselben Merkmale zeigen, erhöht die Kosten jedoch um das 4-Fache (Benninger et al. 2000). Daher ist die klinische Beobachtung das wich- tigste Kriterium zur Diagnose einer akuten bakteriellen Rhinosinusitis:

- Symptome länger als 10 Tage ohne klinische Verbesserung,

- Fieber über $39^{\circ} \mathrm{C}$,

- eitriges Nasensekret und Gesichtsscherz für mehr als 3 Tage,

- Symptomverschlechterung nach anfänglicher Besserung für mehr als 3 Tage mit neu auftretendem Fieber, Kopfschmerz und erneut verstärktem eitrigem Sekret.

- Therapie der unkomplizierten akuten Rhinosinusitis

Symptomatisch:

- Analgetika gegen Scherzen und Antipyretika gegen Fieber, topische Nasentropfen, Schleimlöser, saline Nasenspülungen, intranasale Kortikoide und Antihistaminika.

- Eigentlich selbstlimitierend, auch wenn Bakterien mitbeteiligt sind. Beim Einsatz von Antibiotika zeigte sich bei einer Meta-Analyse eine „number needed to treat" von 18 für 1 Patienten, um schneller geheilt zu sein, die "number needed to harm" wegen Nebenwirkungen war jedoch 8 (Lemiengre et al. 2012). Deshalb empfiehlt die American Academy of Otolaryngology Head and Neck Surgery anfängliches „watchful waiting“ ohne antibiotische Therapie (Rosenfeld et al. 2015). Auch die AAP (American Academy of Pediatrics) empfiehlt sogar nach einer RhinosinusitisDauer von mehr als 10 Tagen die Strategie des „watchful waiting" und die Verwendung von Antibiotika nur bei schweren Verläufen mit Fieber $>39^{\circ} \mathrm{C}$ und eitrigem Nasensekret an mehr als 3 aufeinanderfolgenden Tagen (Wald et al. 2013).

Bei der bakteriellen Superinfektion mit Symptomen gibt es verschiedene Empfehlungen:

- Die Infection Disease Society of America (IDSA) empfiehlt Amoxicillin-Clavulansäure, und Doxycyclin als Alternative. 
- Die American Academy of Allergy, Asthma and Immunology (AAAAI) rät, Amoxicillin den Vorzug zu geben.

- Auch die österreichischen Leitlinie Arznei undVernunft ( $\triangleright$ www.arzneiundvernunft.at/ uploads/190111_Leitlinie_Antiinfektiva_Onlineversion_610_DE.pdf) rät primär zu Amoxicillin-Clavulansäure oder Azithromycin oder Clarithromycin.

- Zusatztherapie mit nasalen Salzspülungen und intranasalen Kortikoiden kann den Antibiotikaverbrauch reduzieren (Hickner et al. 2001). Der Benefit der antibiotischen Therapie bezüglich Vorbeugung von Komplikationen wie orbitale Zellulitis und intrakranieller Abszess ist bis heute nicht bewiesen.

Selbst eine im Lancet publizierte Meta-Analyse fand keine signifikante Assoziation zwischen Antibiotikaverbrauch und der Rate an Komplikationen (Falagas et al. 2008).

\subsubsection{Akute unkomplizierte Bronchitis}

Die akute unkomplizierte Bronchitis ist eine selbstlimitierende Erkrankung der Bronchien mit Husten, der bis zu 6 Wochen dauern kann. Der Husten kann/muss aber nicht produktiv sein und ist mit milden konstitutionellen Beschwerden verbunden.

Die akute Bronchitis ist eine der häufigsten Erkrankungen mit 100 Millionen Arztbesuchen in den USA (10\%), und bei mehr als $70 \%$ dieser Arztbesuche werden Antibiotika verschrieben (Barnett und Linder 2014). Auch in der Pädiatrie sind die Zahlen ähnlich. Bei 2 Millionen Arztbesuchen in US-amerikanischen pädiatrischen Praxen wegen akuter Bronchitis werden bei $70 \%$ der Kinder Antibiotika verschrieben (Hersh et al. 2011).

$90 \%$ der ansonsten gesunden Patienten, die sich mit Bronchitiden in den Ordinationen vorstellen, haben Bronchitiden viraler Genese. Gelbliches Sputum oder in der Farbe wechselndes Sputum (z. B grün zu gelb) weisen nicht auf bakterielle Infektion hin. Purulenz entsteht wegen entzündlicher Zellen oder ab-

gestoßenen Epithelzellen (Gonzales et al. 2001).

Zur Diagnosestellung einer bakteriellen Ursache muss die akute Bronchitis von einer Pneumonie unterschieden werden. Folgende klinische Merkmale entscheiden:

- Tachykardie (HF >100/min)

- Tachypnoe (>24 Atemzüge/Minute)

- Fieber $>38^{\circ} \mathrm{C}$

- Typische Auskultationsbefunde wie perkutatorische Dämpfung, feinblasige Rasselgeräusche

\section{- Therapie der akuten Bronchitis}

- In den aktuellen Guidelines: keine Antibiotika bei Abwesenheit von Pneumonie! Eine Studie verglich Antibiotika (Amoxicillin/Clavulansäure) mit Ibuprofen und Placebo bei akuter Bronchitis und konnte keine Unterschiede in der Dauer der akuten Bronchitis zwischen den Gruppen erkennen (Llor et al. 2013). In einer aktuellen Meta-Analyse der Cochrane Database von 2014 fand man nur limitierte Evidenz für Antibiotika bei akuter Bronchitis, die jedoch im breiten Kontext mit vermehrten Nebenwirkungen bei Antibiotikabehandelten Patienten sowie Resistenzentwicklung und Kosten für antibiotische Behandlung gesehen werden sollte (Smith et al. 2014).

- Expektoranzien (Guaifenesin)

- Histamine der ersten Generation (Diphenhydramin)

- Fraglich: Beta-Mimetika, verbessern jedoch laut Cochrane-Meta-Analyse bei Patienten ohne Asthma und COPD die Symptome nicht (Becker et al. 2015).

- Abschwellende Mittel (Phenylephrine)

- Antibiotika nur, wenn eine Pneumonie diagnostiziert wird.

\subsubsection{Otitis media}

Die Otitis media ist eine der häufigsten entzündlichen Erkrankungen im Säuglingsalter und stellt den dritthäufigsten Verschreibungsgrund für Antibiotika in dieser Altersklasse dar. Die Prävalenz im ersten Lebensjahr liegt 
bei $18,7 \%$, im zweiten Lebensjahr bei $31,6 \%$ und im dritten Lebensjahr bei 31,7\%. Bis zum beendeten dritten Lebensjahr treten bei der Hälfte aller Kinder mit Otitis media drei oder mehr Episoden auf. Primär ist die AOM (akute Otitis media) meistens viral, der häufigste Erreger bei Kindern ist das RSV-Virus. Die bakterielle Superinfektion erfolgt meist durch Streptococcus pneumiae und Haemophilus influenzae, gefolgt von Moraxella catarrhalis und selten Streptoccoccus Gruppe A, Staphylococcus aureus sowie Streptococcus pyogenes.

\section{- Diagnose (Hersh et al. 2013)}

- Leicht bis stark vorgewölbtes Trommelfell mit oder ohne Rötung bzw. vermehrter Gefäßzeichnung, Trübung mit Verstreichen des Lichtreflexes

- Otorrhö, die nicht mit Otitis externa in Verbindung gebracht werden kann

- Otalgie

- Fieber

Therapie: Analgetika, abschwellende Nasentropfen

Antibiotika eher bei:

1. Alter des Kindes <23 Monate (lt. Guidelines sollten Säuglinge bis zum 6. Lebensmonat immer Antibiotika bekommen)

2. Beidseitig eher als einseitig

3. Fieber $>39^{\circ} \mathrm{C}$

4. Schweren Ohrenschmerzen, $>48$ Stunden

Antibiotika (Goossens et al. 2007):

- Therapie der Wahl: Amoxicillin

- Bei fehlender Symptomlinderung innerhalb von 2-3 Tagen, Säuglingen bis zum 6 . Lebensmonat, Kinder $<2$ Jahre mit bilateraler AOM, massiver Klinik bzw. vorangegangener Antibiotikatherapie in den letzten 4 Wochen: Amoxicillin/Clavulansäure

- Bei Penicillinallergie: Azithromycin, Clarithromycin, Josamycin, Roxithromycin

Die Rolle der Beobachtung bzw. „wait and see" oder „watchful waiting” statt sofortiger antibiotischer Therapie ist eine neue, wichtige
Erwägung mit akuter Otitis media und akuter bakterieller Sinusitis. Studien bei Kindern mit AOM zeigten, dass dieser Zugang den antibiotischen Verbrauch reduzieren kann und dass dieser von den Familien gut angenommen wird. Wenn engmaschige Kontrollen durchgeführt werden, entstehen keine negativen gesundheitlichen Auswirkungen (Lieberthal et al. 2013). Laut AAP (American Academy for Pediatrics) sollte „watchful waiting“ eher bei älteren Kindern, bei Einseitigkeit, ohne schwere Symptome angewendet werden und ist eine Möglichkeit zur gemeinsamen Entscheidungsfindung mit Patienten und deren Familien in Abwägung der möglichen Vorteile und Risiken der sofortigen antibiotischen Therapie. dass

Einige Studien und Meta-Analysen zeigten,

- sich mindestens die Hälfte der Patienten mit akuter Otitis media auch ohne Antibiotika erholt (Vouloumanou et al. 2009),

- Genesung mit antibiotischer Therapie beschleunigt wird (Glasziou et al. 2004),

- Genesung ohne Antibiotika weniger wahrscheinlich bei kleineren Kindern, mit beidseitiger AOM und schwereren Symptomen ist (Rovers et al. 2006).

- Eine aktuelles Cochrane-Review von 2015 (Venekamp et al. 2015) demonstrierte interessante Details: Anhand von 3401 Kindern mit 3938 Episoden von AOM aus einkommensstarken Ländern zeigte sich, dass sich nach sofortiger Antibiotikatherapie im Vergleich zu Placebo, 60 \% der Kinder komplett erholten, egal ob sie Antibiotika erhalten hatten oder nicht. Der

Ohrenschmerz war bei der antibiotisch behandelten Gruppe im Vergleich zur Nicht-Antibiotikagruppe nach $24 \mathrm{~h}$ nicht reduziert, aber nach 2-3 Tagen war der Restschmerz bei $1 / 3$ der antibiotisch behandelten Kinder geringer und nach 4-7 Tagen bei 1/4. Antibiotika reduzierten die Zahl der abnormen Tympanometrien nach 2-4 Wochen und 6-8 Wochen. Auch die Anzahl der Trommelfellperforationen war in der Antibiotikagruppe reduziert, die 
kontralateralen Episoden waren halbiert. Nach 3 Monaten jedoch hatten die Antibiotika im Vergleich zu Placebo weder die abnormen Tympanometrien noch die AOM-Rezidive reduziert. Umgekehrt war antibiotische Therapie öfter assoziiert mit Nebenwirkungen, wie Erbrechen, Diarrhö und Urtikaria.

Auch weitere Studien (Venekamp et al. 2015), die die sofortige Einnahme von Antibiotika mit „watchful waiting“ verglichen, können als Vergleich herangezogen werden und zeigten, dass sofortige Einnahme von Antibiotika den Schmerz zwischen dem 3. und 7. Tag nicht reduzierte und dass keine Unterschiede bei abnormen Tympanogrammen nach 4 Wochen sowie keine Unterschiede bei Trommelfellperforationen und AOM-Rezidiven zu finden waren. Somit gilt als bestätigt, dass „watchful waiting“ eine sinnvolle Strategie darstellt. Die Vorteile des Antibiotikums sollen gegen die Nebenwirkungen abgewogen werden. Jedes 14. Kind mit Antibiotikatherapie hatte Nebenwirkungen.

Somit ist es wichtig, zu betonen, dass - obwohl zahlreiche Studien die Wirksamkeit von Antibiotika bei AOM zeigen - sich bei der Mehrheit der Patienten schlussendlich die Symptome von selbst ohne Komplikationen lösen, unabhängig von der Therapie. Das Potenzial der Vorbeugung von Komplikationen, wie Mastoiditis, trägt zur Entscheidungsfindung, ob Antibiotika bei AOM verwendet werden, bei. Auch hier konnten die vorher erwähnten großen, randomisierten Studien und $\mathrm{Me}$ ta-Analysen keinen signifikanten Benefit erkennen, diese seltenen Komplikationen zu vermeiden. Beobachtungen einer Studie aus Großbritannien mit 1 Million AOM-Episoden demonstierten, dass sich die akute Mastoiditis meist schon bei der initialen Untersuchung präsentiert und dass die NNT („number needed to treat"), um eine Episode von Mastoiditis $\mathrm{zu}$ verhindern, 5000 beträgt (Thompson et al. 2009).

\subsubsection{Nachteile der antibioti- schen Therapie und mögliche Schäden}

Strenge Kriterien zur Indikationsstellung von Antibiotikaverschreibungen sind enorm wichtig. Bei Unklarheit, ob ein Infekt des Respirationstrakts von Bakterien ausgelöst wird oder nicht, können die Schäden der antibiotischen Therapie die Vorteile überwiegen.

1. Kurzfristige Nebenwirkungen: Antibiotika sind für die meisten ungeplanten Arztbesuche wegen Medikamentennebenwirkungen verantwortlich, alleine 150.000 jährlich in den USA (Bourgeois et al. 2009). Nebenwirkungen von antibiotischen Therapien können von mild (Durchfall und Urtikaria), über schwer (StevenJohnson-Syndrom) bis lebensbedrohlich (anaphylaktischer Schock, plötzlicher Herztod) sein. In einer Studie zu AOM entwickelten $47 \%$ der Kinder nach Amoxicillin-Clavulansäure-Therapie Diarrhö und 8,7 \% Ekzeme (Tähtinen et al. 2011).

2. Langfristige Nebenwirkungen: Es besteht immer stärkere Evidenz, dass Antibiotika, die in der frühen Kindheit - aber auch später - verabreicht werden, über Schädigung des Darmmikrobioms und dadurch auch des darmassoziierten Immunsystems langfristige und dauerhafte gesundheitsschädliche Auswirkungen auslösen können und an der Entstehung von allergischen Erkrankungen wie Ekzem, Asthma und Rhinosinusitis sowie entzündlichen Darmerkrankungen und Adipositas beteiligt sind (Kronman et al. 2012; Tsakok et al. 2013; Jedrychowski et al. 2011).

3. Die Beziehung zwischen Antibiotikaexposition und Entwicklung von antibiotischen Resistenzen auf dem individuellen, aber auch auf dem allgemeinen Bevölkerungsniveau stellt eine der ernsthaftesten Bedrohung für die Gesundheit der Menschheit dar. Das Europaen Centre for Disease Prevention and Control schätzt, dass jährlich 


\section{4,1 Millionen Europäer an nosokomialen Keimen erkranken und 33.000 Europäer jährlich an bakteriellen Infektionen mit resistenten Keimen sterben ( $\triangleright$ https://ecdc. europa.eu/en/healthcare-associated- infections). Der damit verbundene wirt- schaftliche Schaden wird von der EU mit etwa 1,5 Mrd. Euro beziffert ( $\triangleright$ https:// ec.europa.eu/germany/news/eu-geht-gegen- resistente-gefährliche-keime-vor_de). \\ Deshalb verabschiedete die EU-Kommission im Juni 2017 einen neuen Aktionsplan zur Bekämpfung antimikrobieller Resistenzen.}

In Anbetracht der wenigen neuen antibiotischen Substanzen weiß man heute, dass in $\mathrm{Zu}$ kunft Infektionskrankheiten wesentlich schwieriger zu behandeln sein werden. Meta-Analysen beweisen, dass schon ein einziges eingenommenes Antibiotikum als Folge Resistenzen im selben Individuum auslösen kann, sofort, oder aber bis 1 Jahr lang nach Einnahme. Je öfter und je länger die antibiotische Therapie durchgeführt wird, desto wahrscheinlicher ist eine Resistenzentwicklung (Costelloe et al. 2010).

Untersuchungen zeigen auch, dass die wenigsten antibiotischen Zyklen für die kürzest mögliche Zeit dem Individuum, aber auch der Gemeinschaft am zuträglichsten sind (Hicks et al. 2011). Man konnte auch nachweisen, dass bei Patienten, die schon mehrere Zyklen von einem gewissen Antibiotikum innerhalb der vergangenen 12 Monate erhalten hatten, bei neuerlicher Erkrankung unbedingt das Antibiotikum gewechselt werden sollte, um die Resistenzen nicht weiter zu erhöhen.

Auch die WHO ( www.who.int/medicines/publications/essentialmedicines/en/) führte erstmals 3 Kategorien für Antibiotika ein:

- „Access“-Gruppe: Antibiotika, die für alle jederzeit zur Verfügung stehen (z. B. Amoxicillin bei Pneumonie)

- „Watch“-Gruppe: Antibioitka als Therapie erster und zweiter Wahl bei speziellen Indikationen (z. B. Ciprofloxacin bei Zystitis)

- „Reserve“-Gruppe: nur bei schweren, lebensbedrohlichen Erkrankungen (z. B. Colistin und manche Cephalosporine)
Deshalb ist jeder Arzt aufgefordert, die Wahrnehmung für dieses Problem zu erhöhen und die inadäquate Verschreibung von Antibiotika zu reduzieren. Den Primärversorgern muss weltweit klar sein, dass sie für die Mehrheit der verschriebenen Antibiotika verantwortlich sind! Bis jetzt sehen jedoch noch zu wenige Mediziner und $\mathrm{Pa}-$ tienten die antibiotische Resistenzentwicklung als Grund, vom Gebrauch von Antibiotika Abstand zu nehmen, bzw. ziehen die individuelle und allgemeine Resistenzentwicklung nicht in Erwägung, wenn sie sich für oder gegen ein Antibiotikum im individuellen Fall entscheiden.

Bei den eigenen Kindern verhalten sich Ärzte jedoch restriktiver hinsichtlich der Verschreibepraxis von Antibiotika. An 53.733 Krankheitsepisoden bei Kindern mit „common cold" und akuter Bronchitis belegt eine Studie aus Taiwan, dass Kindern von Ärzten nur halb so viele und Kindern von Pharmazeuten nur 2/3 der Antibiotika verschrieben wurden wie dem Rest der Kinder; sie untermauert damit die Hypothese, dass die Medizin „begreifende“ Eltern einen Maßstab für realisierbare und erreichbare, mögliche Verbesserungen in der Verschreibungspraxis von Antibiotika darstellen können (Huang et al. 2005).

Anwendung von strengen diagnostischen Kriterien und Verschreibung von Antibiotika nur dann, wenn die Vorteile bestens bekannt sind, sind notwendig, um die Folgen des übermäßigen Einsatzes beim Einzelnen, aber auch in der Bevölkerung zu minimieren.

In den letzten beiden Jahrzehnten haben viele Interventionen gezeigt, dass die Raten der Antibiotikaverschreibungen durch bessere Aufklärung der Ärzte, aber auch der Patienten gesenkt werden können. Sorgen wegen der Patientenzufriedenheit limitieren oft den Erfolg dieser Interventionen, weil Patienten oft Druck auf den verschreibenden Arzt machen, und führen in Folge zu vermehrten Verschreibungen. Die Patientenzufriedenheit hängt jedoch oft von der patientenzentrierten Qualität der Behandlung ab, bei der genug Zeit und Information über die Krankheit geboten wird. 
Oft hilft es da schon, nicht von einer Bronchitis zu sprechen, sondern von einer „Verkühlung des Brustkorbes“ bzw. Informationsblätter ( $\downarrow$ www.cdc.gov/getsmart) über sachgemäßen Antibiotikaeinsatz bzw. Alternativen anzubieten, um die Symptome zu verbessern.

Eine aktuelle Studie konnte die antibiotischen Verschreibungen für Atemwegsinfekte um bis zu 85 \% reduzieren und die Patientenzufriedenheit erhöhen, wenn man den Patienten Ratschläge für symptomatische Therapie gab und erklärte, warum Antibiotika nicht indiziert wären (Mangione-Smith et al. 2015). Ein systematisches Review zeigt, dass eine vielfacettige Intervention über Aufklärung der Ärzte und Patienten in kleinen Gruppen und öffentliche Bewusstmachung durch Informationsmaterial-Verteilung am effektivsten sind (Arnold und Straus 2005).

Obwohl jeder für sich selbst verantwortlich ist, sind es die Ärzte, die die Antibiotika verschreiben.

Die Reduktion von unsachgemäßer Verschreibung von Antibiotika wird die Behandlungsqualität verbessern, die Gesundheitskosten senken, die Effektivität der Antibiotika bewahren und zur Allergieprävention beitragen.

\subsection{Einfluss von Antipyretika auf die Entwicklung von Allergien}

\subsubsection{Paracetamol}

Paracetamol, in der englischsprachigen Literatur als Acetaminophen bekannt, ist einer der häufigst verschriebenen Fiebersenker und Schmerzmittel. Nach 2 Untersuchungen im Rahmen der ISAAC-Studie an insgesamt ca. 500.000 Kindern wird Paracetamol weltweit kritisch beobachtet:

Zunächst wurde bei 205.487 6- bis 7-jährigen Kindern aus 31 Ländern gezeigt (Beasley et al. 2008), dass die Paracetamol-Verabreichung bei Fieber, sowohl im ersten Lebensjahr als auch zwischen dem 6. und 7. Lebensjahr, mit einem erhöhten Risiko für Asthma, Rhinokonjunktivitis und Ekzem assoziiert ist. Aktuelle Anwen- dung von Paracetamol war assoziiert mit einem dosisabhängigen erhöhten Risiko von Asthmasymptomen (OR 1.61) bei mäßigem Gebrauch und einer OR 3.23 bei häufigem Gebrauch.

Dieselbe Gruppe untersuchte auch 322.959 13- bis 14-jährige Kinder aus 50 Ländern (Beasley et al. 2011) und kam auch bei den älteren Kindern zu dem Ergebnis, dass der Gebrauch von Paracetamol mit einem dosisabhängigen erhöhten Risiko für Asthma, Rhinokonjunktivitis und Ekzem verbunden war (OR 1.43 für mäßigen Gebrauch, OR 2.51 für hohen Verbrauch).

Diese Daten konnten in einer Geburtskohortenstudie repliziert werden (Wickens et al. 2011). Kinder, die vor dem 15. Lebensmonat Paracetamol eingenommen hatten, zeigten im Alter von 6 Jahren ein 3.6-fach erhöhtes Atopie-Risiko, während Paracetamoleinnahme zwischen 5 und 6 Jahren dosisabhängig mit rezidivierendem Giemen und Asthmaexazerbationen zusammenhing. Im Vergleich zu Kindern, die nur kleine Mengen (bis zu 2 Einzelgaben) Paracetamol erhalten hatten, war die OR für Asthmaexazerbationen bei Kindern mit 3-10 Einzelgaben 1.63, und stieg bei mehr als 10 Einzelgaben auf 2.16. Die Atopierate war in dieser Gruppe nicht erhöht. Die Autoren schlossen, dass Paracetamol eine Rolle bei der Entwicklung von Atopien und für die Aufrechterhaltung der Asthmasymptome habe.

Eine Gruppe aus Harvard relativierte diese Ergebnisse und warf den davor erwähnten Studien eine mangelnde Bereinigung des Störfaktors „respiratorischer Infekt“" vor, der auch isoliert zu einer Vermehrung der Atopiehäufigkeit führen kann. In einer longitudinalen Studie wurde in einer Vorgeburtskohorte von 1490 Mutter/Kind-Paaren die Einnahme von Ibuprofen und Acetaminophen in der Schwangerschaft und im ersten Lebensjahr im Zusammenhang mit Asthmaentwicklung in der Kindheit beobachtet. Vor Bereinigung des Faktors respiratorischer Infekt wurde ein erhöhtes Risiko für Asthma festgestellt, das sich nach Bereinigung dieses Faktors nur mehr nach pränataler Gabe von Acetaminophen nachweisen ließ (Sordillo et al. 2015). 
(Kommentar der Autorin: Die Fragestellung Ursache-Wirkung ist in dieser Indikation besonders schwierig, wo doch Antipyretika/ Analgetika bei Kindern fast ausschließlich bei Infekten eingesetzt werden. Wahrscheinlich blieb aus diesem Grund nach Bereinung des Störfaktors nur mehr für die pränatale Gabe eine positive Korrelation übrig.)

Auch pränatale Gabe von Acetaminophen bei Mäusen zeigte ein erhöhtes Risiko für Atemwegsentzündung mit vermehrter Infiltration von Leukozyten und Eosinophilen, wenn diese Mäuse das Erwachsenenalter erreicht hatten (Karimi et al. 2015).

Der pharmazeutische Wirkmechanismus von Paracetamol ist nicht eindeutig geklärt. Einerseits hemmt es in hohen Konzentrationen die Cyclooxygenase-Aktivität von COX-1 und COX-2 und folglich die Bildung von Prostaglandinen (Gentry et al. 2015). Eine mögliche Ursache scheint die Hemmung einer Phenoxyl-Radikalbildung und der Peroxidase-Funktion zu sein, die für die COX-1- und COX-2Enzymsynthese notwendig wären. Paracetamol hemmt selektiv die Bildung von Prostaglandinen bei niedrigen Arachidonsäure- und Peroxidase-Mengen, während es bei hohen Mengen nur geringe Aktivität zeigt. Dies erklärt die Wirkung bei leichten Entzündungen und die Unwirksamkeit bei schwerer Inflammation wie primär chronischer Polyarthritis und akuter Gicht. Paracetamol dürfte eine gewisse COX-2-Selektivität haben, weil es kaum gastrointestinale Nebenwirkungen und eine nur sehr schwache antikoagulierende Wirkung zeigt. Auch hepatotoxische Nebenwirkungen sind bekannt. (Graham et al. 2013).

Zusätzlich dürften Paracetamol und seine Metaboliten auch über die sensorischen Neurone der TRP-Kanäle („transient receptor potential channels") analgetische und antipyretische Wirkungen entfalten. Aktuell wird diskutiert, dass die Wirkung von Paracetamol über N-Arachidonoylphenolamin mediiert wird. N-Arachidonoylphenolamin wird durch Konjugation des Paracetamol-Metaboliten p-Aminophenol mit Arachidonsäure im Gehirn gebildet und gilt als Aktivator des
Capsicain-Rezeptors TRPV1, der die Wiederaufnahme von Endocannabinoiden und Anandamiden in das postsynatische Neuron hemmt (Sharma et al. 2017).

\subsubsection{Ibuprofen}

Ibuprofen wird sehr häufig beim banalen Infekt in der pädiatrischen und HNO-Praxis verwendet und wird in allen Guidelines zur Fiebersenkung und Schmerzreduktion empfohlen. Ibuprofen ist ein COX-1- und COX-2-Hemmer, wobei neueste Forschungen zeigen, dass seine antiinflammatorische und analgetische Wirkung eher durch Hemmung der COX-2 als der COX-1 hervorgerufen wird (Orlando et al. 2015). Wie in den Kapiteln über die AERD und über die Lipidmediatoren (s. - Kap. 6) noch genauer beschrieben werden wird, kommt es über Veränderung des Arachidonsäure-Metabolismus $\mathrm{zu}$ einer Überproduktion von Leukotrienen sowie zu einem Mangel an antiinflammatorischen Prostaglandinen und Lipoxinen, woraus entzündliche Reaktionen in den oberen und unteren Atemwegen resultieren können (Buchheit et al. 2016). Das allergische Potenzial von Ibuprofen wurde bei hundert 6- bis 18-jährigen Kindern mit mildem oder moderatem Asthma getestet. Nach Gabe von einer Einzeldosis Ibuprofen wurde bei $2 \%$ der Kinder ein Bronchospasmus mittels Spirometrie festgestellt. Obwohl die Bronchospasmus-Rate niedrig war, raten die Autoren zur Vorsicht bei der Gabe von Ibuprofen an asthmatische Kinder (Debley et al. 2005).

Weil die Diskussion in Gang gekommen war und viele Ärzte verunsichert waren, welcher Fiebersenker $\mathrm{zu}$ bevorzugen sei, publizierte das NEJM zu diesem Thema im August 2016 eine Vergleichsstudie zwischen Paracetamol und Ibuprofen an 300 ein- bis fünfährigen Kindern mit mildem, persistierendem Asthma und verglich die Anzahl der schweren Asthmaexazerbationen, bei denen systemische Glukokortikoide gebraucht wurden, mit der Anzahl der eingenommenen Dosen von Acetaminophen/Paracetamol und Ibuprofen, die gegen Schmerzen und Fieber innerhalb einer 48-wöchigen Beobachtungspe- 
riode verbraucht wurden (Sheehan et al. 2016). Die Teilnehmer erhielten im Median 5.5 Dosen (interquartile Range 1.0-18.0) - ohne signifikanten Unterschied zwischen den Gruppen. Auch die Anzahl der akuten Exazerbationen unterschied sich nicht signifikant mit einem Median von 0.81 pro Kind mit Acetaminophen und 0.87 pro Kind mit Ibuprofen. In der Acetaminophen-Gruppe hatten $49 \%$ der Kinder mindestens eine und $21 \%$ der Kinder mindestens 2 akute Exazerbationen, verglichen mit $47 \%$ und $24 \%$ in der Ibuprofen-Gruppe. Alle Kinder erhielten Medikamente zur Standard-Asthmakontrolle und auch beim inhalativen $\beta$-MimetikaVerbrauch sah man kaum Unterschiede. Die Autoren konnten somit die praktische klinische Frage beantworten, dass Acetaminophen nicht häufiger akute Asthma-verbundene Komplikationen auslöst als Ibuprofen.

Weil aus ethischen Gründen kein Vergleich gegen Placebo durchgeführt wurde, schlossen die Autoren jedoch die Möglichkeit nicht aus, dass jeweils beide Substanzen an einem parallelen Anstieg der Exazerbationen mit steigender Anzahl der Dosen verantwortlich sein könnten. Diese Möglichkeit wurde von den Autoren jedoch aufgrund der unterschiedlichen Wirkmechanismen der Substanzen als höchst unwahrscheinlich interpretiert.

In Abb. 4.18 sieht man jedoch deutlich, dass die Anzahl der Asthmaexazerbationen mit steigender Anzahl/Dosis der beiden eingenommenen Substanzen direkt proportional zunahm, was einer Bestätigung der Studiener-

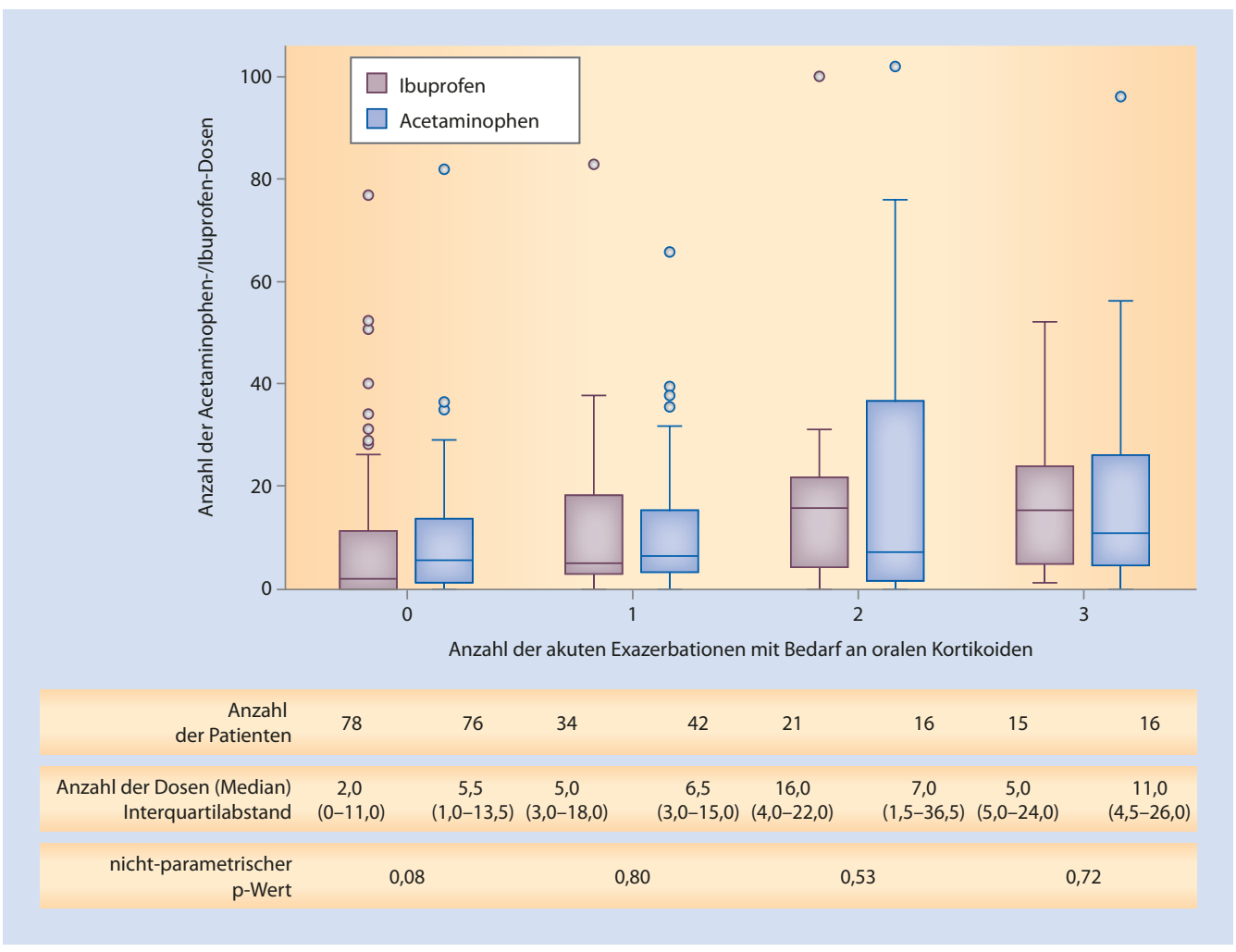

- Abb.4.18 Anzahl der Asthmaexazerbationen in Relation zur Einnahme von Ibuprofen und Acetaminophen (Mod. nach Sheehan et al. 2016). Die Anzahl der akuten Asthmaexazerbationen erhöht sich proportional sowohl mit steigender Ibuprofen- als auch Acetaminophen-Einnahme. Violette Balken: Ibuprofen, blaue Balken: Acetaminophen 
gebnisse von Beasley und Wickers entspricht. Außerdem kann man beobachten, dass die verabreichten Dosen erstaunlich hoch waren. Es wäre interessant, zu hinterfragen, ob asthmatische Kinder wirklich bis zu 36 Dosen (in der 75 Perzentile) eines Schmerzmittels/Fiebersenkers innerhalb von 48 Wochen brauchen!!

Man könnte das Ergebnis auch insofern interpretieren, als sowohl Ibuprofen als auch Acetaminophen die Anzahl der Asthmaexazerbationen proportional zur eingenommenen Menge erhöhen. Jedenfalls ist Vorsicht bei der Einnahme von Antipyretika angebracht.

\section{Fazit}

Zusammenfassend muss man feststellen, dass zur Allergieprävention maximale Anstrengungen unternommen werden sollten, akute respiratorische Infekte so sanft wie möglich zu behandeln und den Antibiotika- und Antipyretika-/Paracetamoleinsatz so niedrig wie möglich zu halten.

\section{Literatur}

AACC Report (2001) The definition of dietary fiber. Cereal Foods World 46:3

Aagaard K et al (2014) The placenta harbors a unique microbiome. Sci Transl Med 6:237ra265

Abelius MS, Janefjord C, Ernerudh J, Berg G, Matthiesen L, Duchen K et al (2015) The placental immune milieu is characterized by a Th2- and anti-inflammatory transcription profile, regardless of maternal allergy, and associates with neonatal immunity. Am J Reprod Immunol 73:445-459

Abrahamsson TR et al (2011) Th1/Th2-associated chemokine imbalance during infancy in children developing eczema, wheeze and sensitization. Clin Exp Allergy 41(12):1729-1739

Academy of Nutrition and Dietetics: www.eatright.org Zugegriffen am 10.10.2019

Agunod M, Yamaguchi N, Lopez R, Luhby AL, Glass GB (1969) Correlative study of hydrochloric acid, pepsin, and intrinsic factor secretion in newborns and infants. Am J Dig Dis 14:400-414

Ahmadizar F et al (2018) Early-life antibiotic exposure increases the risk of developing allergic symptoms later in life: a meta-analysis. Allergy 73:971-986

Aichbhaumik N, Zoratti EM, Strickler R, Wegienka G, Owndy DR, Havstad S et al (2008) Exposure to household pets influences fetal immunoglobulin $E$ production. Clin Exp Allergy 38:1787-1794
Aiello AE, Coulborn RM, Perez V, Larson EL (2008) Effect of hand hygiene on infectious disease risk in the community setting: a meta-analysis. Am J Infect Control 98:1372-1381

Albert MJ, Mathan VI, Baker SJ (1980) Vitamin B12 synthesis by human small intestinal bacteria. Nature 283:781-782

Anagnostou K et al (2014) Assessing the efficacy of oral immunotherapy for desensitisation of peanut allergy in children (STOP II): a phase 2 randomised controlled trial. Lancet 383:1297-1304

Angeloni C (2014) Role of methylglyoxal in Alzheimer's disease. Biomed Res Int. ID238485

Arnold SR, Straus SE (2005) Interventions to improve antibiotic prescribing practices in ambulatory care. Cochrane Database Syst Rev CD003539

Arrieta MC, Stiemsma LT, Dimitriu PA et al (2015) Early infancy microbial and metabolic alterations affect risk of childhood asthma. Sci Transl Med 7:307

Arslanoglu S, Moro GE, Schmitt J, Tandoi L, Rizzardi S, Boehm G (2008) Early dietary intervention with a mixture of prebiotic oligosaccharides reduces the incidence of allergic manifestations and infections during the first two years of life. J Nutr 138:10911095

Arslanoglu S, Moro GE, Boehm G, Wiens F, Stahl B, Bertino E (2012) Early prebiotic oligosaccharide supplementation reduces the incidence of some allergic manifestations in the first 5 years of life. J Biol Regul Homeost Agents 26:49-59

Atarashi K (2011) Induction of colonic regulatory T cells by indigenous Clostridium species. Science 331(6015):337-341

Atarashi K, Tanoue T, Oshima K, Suda W, Nagano Y, Nishikawa $\mathrm{H}$ et al (2013) Treg induction by a rationally selected mixture of Clostridia strains from the human microbiota. Nature 500:232-236

Azad et al (2013) Probiotic supplementation during pregnancy or infancy for the prevention of asthma and wheeze: a systematic review and metaanalysis. BMJ 347:f6471. 10.1136/bmj10

Azad MB et al (2015) Infant gut microbiota and food sensitization: associations in the first year of life. Clin Exp Allergy 45(3):632-643

Barnett ML, Linder JA (2014) Antibiotic prescribing for adults with acute bronchitis in the United States, 1996-2010. JAMA 311:2020-2022

Barnett ML et al (2014) Antibiotic prescribing to adults with sore throat in the United States, 1997-2010. JAMA Intern Med 174(1):138-140

Beasley R, Clayton T, Crane J, von Mutius et al (2008) Association between paracetamol use in infancy and childhood, and risk of asthma, rhino -conjunctivitis, and eczema in children aged 6-7 years: analysis from Phase three of the ISAAC programme. Lancet 372(9643):1039-1048 
Beasley RW, Clayton T et al (2011) Acetaminophen use and risk of asthma, rhinoconjunctivitis, and eczema in adolescents: international Study of Asthma and Allergies in Childhood Phase Three. Am J Respir Crit Care Med 183(2):171-178

Becker LA et al (2015) Beta2-agonists for acute cough or a clinical diagnosis of acute bronchitis. Cochrane Database Syst Rev 9:CD001726. 10.1002

Belitz HD, Grosch W, Schieberle P (2009) Food chemistry. Springer, Berlin, S 270-289

Benninger MS, SedoryHolzer SE, Lau J (2000) Diagnosis and treatment of uncomplicated acute bacterial rhinosinusitis: summary of the Agency for Health Care Policy and Research evidence-based report. Otolaryngol Head Neck Surg 122:1-7

Berthon BS (2013) Investigation of the association between dietary intake, disease severity and airway inflammtion in asthma. Respirology 18:447-454

Best KP et al (2016) Omega-3 long-chain PUFA intake during pregnancy and allergic disease outcomes in the offspring: a systematic review and metaanalysis of observational studies and randomized controlled trials. Am J Clin Nutr 103(1):128-143

Beyer K, Morrow E, Li XM, Bardina L, Bannon GA, Burks AW et al (2001) Effects of cooking methods on peanut allergenicity. J Allergy Clin Immunol 107:1077-1108

Bisgaard $\mathrm{H}$ et al (2007) Childhood asthma after bacterial colonization of the airway in neonates. N Engl J Med 357(15):1487-1495

Bisgaard $\mathrm{H}$ et al (2011) Reduced diversity of the intestinal microbiota during infancy is associated with increased risk of allergic disease. J Allergy Clin Immunol 28:646-652

Bisgaard $\mathrm{H}$ et al (2016) Fish oil-derived fatty acids in pregnancy and wheeze and asthma in offspring. $\mathrm{N}$ Engl J Med 375(26):2530-2539

Bjerre RD, Bandier J, Skov L, Engstrand L, Johansen JD (2017) The role of the skin microbiome in atopic dermatitis: a systematic review. Br J Dermatol 177:1272-1278

Björksten B et al (1999) The intestinal microflora in allergic Estonian and Swedish 2-year-old children. Clin Exp Allergy 29:342-346

Bloomfield SF (2014) Are antibiotics a contributory factor to the rise in allergic and other chronic inflammatory diseases? International Scientific Forum on Home Hygiene. Available online at: http://www. ifh-homehygiene.org/review/are-antibioticscontributory-factor-rise-allergic-and-otherchronic-inflammatory-diseases

Bloomfield SF et al (2016) Time to abandon the hygiene hypothesis: new perspectives on allergic disease, the human microbiome, infectious disease prevention and the role of targeted hygiene. Perspect Public Health 136(4):213-224

Blume-Peytavi U, Lavender T, Jenerowicz D et al (2016) Recommendations from a European roundtable meeting on best practice healthy infant skin care. Pediatr Dermatol 33(3):311-321

Böttcher MF et al (2000) Microflora associated characteristics in faeces from allergic and nonallergic infants. Clin Exp Allergy 30(11):1591-1596

Boulet LP (2013) Asthma and obesity. Clin Exp Allergy $43: 8-21$

Bourgeois FT, Mandl KD, Valim C, Shannon MW (2009) Pediatric adverse drug events in the outpatient setting: an 11-year national analysis. Pediatrics. 2009 Oct; 124(4): e744-e750

Boyle RJ et al (2016) Hydrolysed formula and risk of allergic or autoimmune disease: systematic review and meta-analysis. BMJ 352:i974

Bruzzese E, Volpicelli M, Squeglia V et al (2009) A formula containing galacto- and fructooligosaccharides prevents intestinal and extra-intestinal infections: an observational study. Clin Nutr 28:156-161

Buchheit KM et al (2016) Update on the management of aspirin-exacerbated respiratory disease. Allergy, Asthma Immunol Res 8(4):298-304. WAR SCHON Ref Nr 64 Kapitel 3

Bunyavanich S et al (2014) Peanut, milk, and wheat intake during pregnancy is associated with reduced allergy and asthma in children. J Allergy Clin Immunol 133(5):1373-1382

Bunyavanich S et al (2016) Early-life gut microbiome composition and milk allergy resolution. J Allergy Clin Immunol 138:1122-1130

Butel MJ, Suau A, Campeotto F, Magne F, Aires J et al (2007) Conditions of bifidobacterial colonization in preterm infants: a prospective analysis. J Pediatr Gastroenterol Nutr 44:577-582

Castillo-Courtade L, Han S, Lee S, Mian FM, Buck R, Forsythe $P$ (2015) Attenuation of food allergy symptoms following treatment with human milk oligosaccharides in a mouse model. Allergy 70(9):1091-1102. https://doi.org/10.1111/all.12650. Epub 2015 May 26

Chang YS, Trivedi MK, Jha A, Lin YF, Dimaano L, GarciaRomero MT (2016) Synbiotics for prevention and treatment of atopic dermatitis: a meta-analysis of randomized clinical trials. JAMA Pediatr 170:236-242

Cheng J et al (2013) Contribution of the intestinal microbiota to human health: from birth to 100 years of age. Curr Top Microbiol Immunol 358:323-346

Chichlowski M, De Lartigue G, German JB, Raybould HE, Mills DA (2012) Bifidobacteria isolated from infants and cultured on human milk oligosaccharides affect intestinal epithelial function. J Pediatr Gastroenterol Nutr 55(3):321-327. https://doi. org/10.1097/MPG.0b013e31824fb899

Chuah YK et al (2013) Receptor for Advanced Glycation End Products and Its Involvement in Inflammatory Diseases. Int J Inflamm, S. 403460 
Chuyen NV (2006) Toxicity of the AGEs generated from the Maillard reaction: on the relationship of food-AGEs and biological-AGEs. Mol Nutr Food Res 50:1140-1149

Conly JM, Stein K, Worobetz L, Rutledge-Harding S (1994) The contribution of vitamin K2 (menaquinones) produced by the intestinal microflora to human nutritional requirements for vitamin K. Am J Gastroenterol 89:915-923

Cosenza L et al (2015) Bugs für atopy: the Lactobacillus rhamnosus GG strategy for food allergy prevention and treatment in children. Benefic Microbes 6(2):225-232

Costelloe C, Metcalfe C, Lovering A, Mant D, Hay AD (2010) Effect of antibiotic prescribing in primary care on antimicrobial resistance in individual patients: systematic review and meta-analysis. BMJ 340:c2096pmid:20483949

Cuello-Garcia CA, Brozek JL, Fiocchi A, Pawankar R, Yepes-Nunez JJ, Terracciano L et al (2015) Probiotics for the prevention of allergy: a systematic review and meta-analysis of randomized controlled trials. J Allergy Clin Immunol 136:952-961

Cuello-Garcia CA, Fiocchi A, Pawankar R, Yepes-Nunez JJ, Morgano GP, Zhang Y et al (2016) World allergy organization-McMaster University guidelines for allergic disease prevention (GLAD-P): prebiotics. World Allergy Organ J 9:10

D'Auria l et al (2014) Omega-3 fatty acids and asthma in children. Allergy Asthma Proc 35(3):233-240

Danby SG et al (2018) The effect of water hardness on surfactant deposition after washing and subsequent skin irritation in atopic dermatitis patients and healthy control subjects. J Invest Dermatol 138(1):68-77

Davies D, James TG (1930) An investigation into the gastric secretion of a hundred normal persons over the age of sixty. Br J Med 1:1-14

De Filippo C et al (2010) Impact of diet in shaping gut microbiota revealed by a comparative study in children from Europe and rural Africa. Proc Natl Acad Sci USA 107(33):14691-14696

De Silva D et al (2014) Acute and long term management of food allergy: a systematic review. Allergy 69(2):159-167

De Sutter Al, van Driel ML, Kumar AA, Lesslar O, Skrt A (2012) Oral antihistamine-decongestant-analgesic combinations for the common cold. Cochrane Database Syst Rev 2:CD004976

Debley JS et al (2005) The prevalence of ibuprofensensitive asthma in children: a randomized controlled bronchoprovocation challenge study. J Pediatr 147(2):233-238

Dehlink E, Yen E, Leichtner AM, Hait EJ, Fiebiger E (2009) First evidence of a possible association between gastric acid suppression during pregnancy and childhood asthma: a population-based register study. Clin Exp Allergy 39:246-253
Dethlefsen L et al (2008) The pervasive effects of an antibiotic in the human gut microbiota, as revealed by deep 16SrRNA sequencing. PLoS Biol 6(11):e280

Devereux G et al (2007) Maternal vitamin D intake during pregnancy and early childhood wheezing. Am J Clin Nutr 85:853-859

Di Lorenzo G et al (2013) Differences in the behavior of advanced glycation end products and advanced oxidation protein products in patients with allergic rhinitis. J Investig Allergol Clin Immunol 23(2):101-106

Dominguez-Bello MG et al (2010) Delivery mode shapes the acquisition and structure of the initial microbiota across multiple body habitats in newborn. Proc Natl Acad Sci USA 107(26):11971-11975

Dominguez-Bello MG, De Jesus-Laboy KM, Shen N, Cox LM, Amir A, Gonzalez A et al (2016) Partial restoration of the microbiota of cesarean-born infants via vaginal microbial transfer. Nat Med 22:250-253

Drozdowski LA et al (2002) Short chain fatty acids and total parenteral nutrition affect intestinal gene expression. J Parenter Enter Nutr 26(3):145-150

Du Toit G et al (2015) Randomized Trial of peanut consumption in infants at risk for peanut allergy. N Engl J Med 372:803-813

Dumitriu IE, Baruah P, Valentinis B, Voll RE, Herrmann M, Nawroth PP et al (2005) Release of high mobility group box 1 by dendritic cells controls T cell activation via the receptor for advanced glycation end products. J Immunol 174:7506-7515

Dzidic M et al (2017) Aberrant IgA responses to the gut microbiota during infancy precede asthma and allergy development. J Allergy Clin Immunol 139(3):1017-1025

Ege $M$ et al (2011) Exposure to environmental microorganisms and childhood in asthma. $\mathrm{N}$ Engl J Med 364:701-709

Eichenfield LF et al (2014) Guidelines of care for the management of atopic dermatitis. J Am Acad Dermatol 71(1):116-132

Engebretsen KA, Bager P, Wohlfahrt J, Skov L, Zachariae C, Nybo Andersen AM et al (2016) Prevalence of atopic dermatitis in infants by domestic water hardness and season of birth: cohort study. J Allergy Clin Immunol 139:1568-1574

Erkkola M, Kaila M, Nwaru BI, Kronberg-Kippila C, Ahonen S, Nevalainen J, Veijola R, Pekkanen J, llonen J, Simell O, Knip M, Virtanen SM (2009) Maternal vitamin $D$ intake during pregnancy is inversely associated with asthma and allergic rhinitis in 5-year-old children. Clin Exp Allergy 39:875-882

Fairlie T, Shapiro DJ, Hersh AL, Hicks LA (2012) National trends in visit rates and antibiotic prescribing for adults with acute sinusitis [Letter]. Arch Intern Med 172:1513-1514

Falagas ME et al (2008) Comparison of antibiotics with placebo for treatment of acute sinusitis: a meta- 
analysis of randomised controlled trials. Lancet Infect Dis 8(9):543-552

Feng $M$ et al (2016) Associations of early life exposures and environmental factors with asthma among children in rural and urban areas of guangdong, China. Chest 149(4):1030-1041

Fiocchi A (2015) World Allergy Organization-Mc. Master Guidelines for Allergic Disease Prevention: probiotics. World Allergy Organ J 8(1):4

Flint HJ, Scott KP, Louis P, Duncan SH (2012) The role of the gut microbiota in nutrition and health. Nat Rev Gastroenterol Hepatol 9:577-589

Forno E et al (2014) Maternal obesity in pregnancy, gestational weight gain, and risk of childhood asthma. Pediatrics 134(2):e535-e546

Fujimura KE, Johnson CC, Ownby DR (2010) Man's best friend? The effect of pet ownership on house dust microbial communities. J Allergy Clin Immunol 126:410-412

Garbutt JM, Banister C, Spitznagel E, Piccirillo JF (2012) Amoxicillin for acute rhinosinusitis: a randomized controlled trial. JAMA 307:685-692

Garcia-Larsen V et al (2018) Diet during pregnancy and infancy and risk of allergic or autoimmune disease: a systematic review and meta-analysis. PLoS Med 15(2):e1002507

Gentry C, Andersson DA, Bevan S (2015) TRPA1 mediates the hypothermic action of acetaminophen. Sci Rep 5:12771. https://doi.org/10.1038/srep12771

Geoghegan JA, Irvine AD, Foster TJ (2018) Staphylococcus aureus and atopic dermatitis: a complex and evolving relationship. Trends Microbiol 26:484-497

Glasziou PP et al (2004) Antibiotics for acute otitis media in children. Cochrane Database Syst Rev 1:CD000219

Glatz M et al (2018) Emollient use alters skin barrier and microbes in infants at risk for developing atopic dermatitis. PLoS One 13(2):e0192443

Goleva E et al (2013) The effects of airway microbiome on corticosteroid responsiveness in asthma. Am J Respir Crit Care Med 188(10):1193-1201

Gollwitzer ES, Saglani S, Trompette A, Yadava K, Sherburn R, McCoy KD, Nicod LP, Lloyd CM, Marsland BJ (2014) Lung microbiota promotes tolerance to allergens in neonates via PD-L1. Nat Med 20(6):642-647

Gonzales R et al (2001) Principles of appropriate antibiotic use for treatment of uncomplicated acute bronchitis: background. Ann Intern Med 134: 521-529

Goossens H et al (2007) Comparison of Outpatient Systemic Antibacterial Use in 2004 in the United States and 27 European Countries. Clin Infect Dis 44(8):1091-1095. https://doi.org/10.1086/512810

Graham GG, Davies MJ, Day RO, Mohamudally A, Scott KF (2013) The modern pharmacology of paracetamol: therapeutic actions, mechanism of action, metabolism, toxicity and recent pharmacological findings. Inflammopharmacology 21(3):201-232. https://doi.org/10.1007/s10787-013-0172-x

Hadis $U$ et al (2011) Intestinal tolerance requires gut homing and expansion of FoxP3 + regulatory T cells in the lamina propria. Immunity 34:237-246

Hanski I, von Hertzen L, Fyhrquist N, Koskinen K, Torppa K, Laatikainen T et al (2012) Environmental biodiversity, human microbiota, and allergy are interrelated. PNAS 109:8334-8339

Harmsen HJ et al (2000) Analysis of intestinal flora development in breast-fed and formula-fed infants by using molecular identification and detection methods. J Pediatr Gastroenterol Nutr 30:61-67

Harris AM, Hicks LA et al (2016) Appropriate antibiotic use for acute respiratory tract infection in adults: advice for high-value care from the American college of physicians and the centers for disease control and prevention. Ann Intern Med 164(6):425434. https://doi.org/10.7326/M15-1840

Harvard School of Public Health. www.hsph.harvard. edu/nutitionsource/fiber.html

Heinrich J (2017) Modulation of allergy risk by breast feeding. Curr Opin Clin Nutr Metab Care 20(3):217-221

Hemilä H, Chalker E (2013) Vitamin C for preventing and treating the common cold. Cochrane Database Syst Rev 1:CD000980

Hersh AL, Shapiro DJ, Pavia AT, Shah SS (2011) Antibiotic prescribing in ambulatory pediatrics in the United States. Pediatrics 128(6):1053-1061. pmid:22065263

Hersh AL et al (2013) Priciples of judicious antibiotic prescribing for upper respiratory tract infections in paediatrics. Pediatrics 132(6):1146-1154

Hickner JM, Bartlett JG, Besser RE, Gonzales R, Hoffman JR, Sande MA, American Academy of Family Physicians (2001) Principles of appropriate antibiotic use for acute rhinosinusitis in adults: background. Ann Intern Med 134:498-505

Hicks LA, Chien YW, Taylor TH Jr, Haber M, Klugman KP (2011) Active Bacterial Core Surveillance (ABCs) Team. Outpatient antibiotic prescribing and nonsusceptible Streptococcus pneumoniae in the United States, 1996-2003. Clin Infect Dis 53(7):631639. pmid:21890767

Hilmenyuk T et al (2010) Effects of glycation of the model food allergen ovalbumin on antigen uptake and presentation by human dendritic cells. Immunology 129(3):437-445

Hilty $M$ et al (2010) Disordered microbial communities in asthmatic airways. PLoS One 5:e8578

Hooper LV et al (2012) Interactions between the microbiota and the immune system. Science 336:12681273

Horimukai K et al (2014) Application of moisturizer to neonates prevents development of atopic dermatitis. J Allergy Clin Immunol 134(4):824-830

Huang YJ (2014) The Microbiome and Asthma. Ann Am Thorac Soc 11(Suppl 1):S48-S51 
Huang N et al (2005) Antibiotic prescribing for children with nasopharyngitis (common colds), upper respiratory infections, and bronchitis who have health-professional parents. Pediatrics 116(4):826-832

Huang YJ, Nelson CE, Brodie EL et al (2011) Airway microbiota and bronchial hyperresponsiveness in patients with suboptimally controlled asthma. J Allergy Clin Immunol 127:372-381

Ilchmann A et al (2010) Gycation of food allergen by the Maillard reaction enhances T-cell immunogenicity: role of macrophage scavenger receptor class A type I and II. J Allergy Clin Immunol 125(1):175183

Indoor Air Quality UK. Available online at: http://www. iaquk.org.uk/

Jacquot A et al (2011) Dynamics and clinical evolution of bacterial gut microflora in extremely premature patients. J Pediatr 158:390-396

Jakobsson HE et al (2010) Short-term antibiotic treatment has differing long-term impacts on the human throat and gut microbiom. PLoS One 5:e9836

Jedrychowski W et al (2011) Wheezing and asthma may be enhanced by broad spectrum antibiotics used in early childhood. Concept and results of a pharmacoepidemiology study. J Physiol Pharmacol 62(2):189-195. pmid:21673367

Jelding-Dannemand E et al (2015) Breastfeeding does not protect against allergic sensitization in early childhood and allergy-associated disease at age 7 years. J Allergy Clin Immunol. 136(5): 1302-1308.e13. pii:S0091-6749(15)00272-9

Jenmalm MC, Duchén K (2013) Timing of allergypreventive and immunomodulatory dietary interventions - are prenatal, perinatal or postnatal strategies optimal? Clin Exp Allergy 43(3):273-278

Joseph CL, Ownby DR, Havstad SL, Woodcroft KJ, Wegienka G, MacKechnie H et al (2011) Early complementary feeding and risk of food sensitization in a birth cohort. J Allergy Clin Immunol 127:1203-1210

Kalliomäki M et al (2001) Probiotics in preliminary prevention of atopic disease: a randomised placebo controlled- trial. Lancet 357:1076-1079

Kalliomäki M et al (2003) Probiotics and prevention of atopic diseases: 4-year follow-up of a randomised placebo controlled- trial. Lancet 361:1869-1871

Kalliomäki M et al (2007) Probiotics during the first 7 years of life: a cumulative reduction of eczema in a randomized, placebo-controlled trial. J Allergy Clin Immunol 119(4):1019-1021

Karimi K et al (2015) Prenatal acetaminophen induces liver toxicity in dams, reduces fetal liver stem cells, and increases airway inflammation in adult offspring. J Hepatol 62(5):1085-1091

Karsch-Völk M, Barrett B, Kiefer D, Bauer R, ArdjomandWoelkart K, Linde K (2014) Echinacea for preventing and treating the common cold. Cochrane Database Syst Rev 2:CD000530
Keag OE, Norman JE, Stock SJ (2018) Long-term risks and benefits associated with cesarean delivery for mother, baby, and subsequent pregnancies: systematic review and meta-analysis. PLoS Med 15(1):e1002494. https://doi.org/10.1371/journal. pmed.1002494. eCollection 2018 Jan

Kenealy T, Arroli B (2013) Antibiotics for the common cold and acute purulent rhinitis. Cochrane Database Syst Rev 6:CD000247

Kim JS et al (2012) Food allergy: a glimpse into the inner workings of gut immunology. Curr Opin Gastroenterol 28(2):99-103

Kim HJ et al (2014) Effects of Lactobacillus rhamnosus on allergic march model by suppressing $\mathrm{TH} 2, \mathrm{Th} 17$, and TSLP responses via CD4+CD25+Foxp3+Tregs. Clin Immunol 153(1):178-186

King DE et al (2012) Trends in dietary fiber intake in the United States 1999-2008. J Acad Nutr Diet 112:642-648

Konieczna P, Groeger D, Ziegler M, Frei R, Ferstl R, Shanahan F, Quigley EM, Kiely B, Akdis CA, O'Mahony L (2012) Bifidobacterium infantis 35624 administration induces Foxp3 T regulatory cells in human peripheral blood: potential role for myeloid and plasmacytoid dendritic cells. Gut 61(3):354-366. https://doi. org/10.1136/gutjnl-2011-300936. Epub 2011 Nov 3

Kopf M (2015) The development and function of lungresident macrophages and dendritic cells. Nat Immunol 16:36-44

Koplin JJ et al (2010) Can early introduction of egg prevent egg allergy in infants? A population-based study. J Allergy Clin Immunol 126(4):807-813

Korpela K, Salonen A, Virta LJ, Kekkonen RA, Forslund K, Bork $P$ et al (2016) Intestinal microbiome is related to lifetime antibiotic use in Finnish pre-school children. Nat Commun 7:10410

Kronman MP et al (2012) Antibiotic exposure and IBD development among children: a population-based cohort study. Pediatrics. 2012 Oct; 130(4): e794-e803

Kukkonen K, Savilahti E et al (2007) Probiotics and prebiotic galacto-oligosaccharides in the prevention of allergic diseases: a randomized, double-blind, placebocontrolled trial. J Allergy Clin Immunol 119(1): 192-198

Kukkonen K, Kuitunen M, Haahtela T, Korpela R, Poussa T, Savilahti E (2010) High intestinal IgA associates with reduced risk of IgE-associated allergic diseases. Pediatr Allergy Immunol 21:67-73

Latvala J, von Hertzen L, Lindholm H, Haahtela T (2005) Trends in prevalence of asthma and allergy in Finnish young men: a nationwide study from 1966 to 2003. BMJ 330:1186-1187

Lee J et al (2013) Effect of orally administered lactobacillus brevis HY7401 in a food allergy mouse model. J Microbiol Biotechnol 23(11):1636-1640

Lee $\mathrm{HJ}$ et al (2014) Epidermal permeability barrier defects and barrier repair therapy in atopic dermatitis. Allergy Asthma Immunol Res 6:276-284 
Lemiengre $M B$, van Driel ML, Merenstein D, Young J, DeSutter Al (2012) Antibiotics for clinically diagnosed acute rhinosinusitis in adults. Cochrane Database Syst Rev 10:CD006089

Lewis K et al (2010) Enhanced translocation of bacteria across metabolically stressed epithelia is reduced by butyrate. Inflamm Bowel Dis 16(7):1138-1148

Li YF, Langholz B, Salam MT, Gilliland FD (2005) Maternal and grandmaternal smoking patterns are associated with early childhood asthma. Chest 127(4):1232-1241

Lieberthal AS et al (2013) The diagnosis and management of acute otitis media. Pediatrics. 2013;131(3):e964-e999

Ling $Z$ et al (2014) Altered fecal microbiota composition associated with food allergy in infants. Appl Environ Microbiol 80:2546-2554

Liu G (2001) Warm diseases. A clinical guide. Eastland Press, Seattle

Llor C, Moragas A, Bayona C, Morros R, Pera H, Plana-Ripoll $O$ et al (2013) Efficacy of anti-inflammatory or antibiotic treatment in patients with non-complicated acute bronchitis and discoloured sputum: randomised placebo controlled trial. BMJ 347:f5762

Lowe AJ et al (2018) A randomized trial of a barrier lipid replacement strategy for the prevention of atopic dermatitis and allergic sensitization: the PEBBLES pilot study. Br J Dermatol 178(1):e19-e21

Luoto $R$ et al (2014) Prebiotic and probiotic supplementation prevents rhinovirus infections in preterm infants: a randomized, placebo-controlled trial. J Allergy Clin Immunol 133(2):405-413. https://doi. org/10.1016/j.jaci.2013.08.020. Epub 2013 Oct 13

Ma A, Malynn BA (2012) A20: linking a complex regulator of ubiquitylation to immunity and human disease. Nat Rev Immunol 12:774-785

Macpherson AJ et al (2004) Induction of protective IgA by intestinal dendritic cells carrying commensal bacteria. Science 303:1662-1665

Macpherson A, McCoy K, Johansen F, Brandtzaeg P (2008) The immune geography of IgA induction and function. Mucosal Immunol 1:11-22

Madhok V et al (2015) What's new in atopic eczema? An analysis of systematic reviews published in 2012 and 2013. Part 2. Treatment and prevention. Clin Exp Dermatol 40:349-355

Makino H, Kushiro A, Ishikawa E et al (2011) Transmission of intestinal Bifidobacterium longum subsp. longum strains from mother to infant determined by multilocus sequencing typing and amplified fragment length polymorphism. Appl Environ Microbiol 8:43-49

Mangione-Smith R, Zhou C, Robinson JD, Taylor JA, Elliott MN, Heritage J (2015) Communication practices and antibiotic use for acute respiratory tract infections in children. Ann Fam Med 13:221-227

Marra F et al (2009) Antibiotic use in children is associated with increased risk of asthma. Pediatrics 123(3):2003-2010
Marri PR, Stern DA, Wright AL et al (2013) Asthmaassociated differences in microbial composition of induced sputum. J Allergy Clin Immunol 131: 346-352

Martin R, Nauta A, Ben AK, Knippels L, Knol J, Garssen J (2010) Early life: gut microbiota and immune development in infancy. Benefic Microbes 1:367-382

Maslova E, Hansen $S$, Jensen CB, Thorne-Lyman AL, Strom M, Olsen SF (2013) Vitamin D intake in midpregnancy and child allergic disease - a prospective study in 44,825 Danish mother-child pairs. BMC Pregnancy Childbirth 13:199

Maslowski KM (2011) Diet, gut microbiota and immune responses. Nat Immunol 12:5-9

Maslowski KM et al (2009) Regulation of inflammatory responses by gut microbiota and chemoattractant receptor GPR43. Nature 461:1282-1286

Mazmanian SK, Liu CH, Tzianabos AO, Kasper DL (2005) An immunomodulatory molecule of symbiotic bacteria directs maturation of the host immune system. Cell 122:107-118. https://doi.org/10.1016/ j.cell.2005.05.007

Mennini M, Dahdah L, Artesani MC, Fiocchi A, Martelli A (2017) Probiotics in Asthma and Allergy Prevention. Front Pediatr 5:165. https://doi.org/10.3389/ fped.2017.00165. eCollection 2017

Moghaddam AE et al (2014) Dry roasting enhances peanut allergic sensitization across mucosal and cutaneous routes in mice. J Allergy Clin Immunol 134(6):1453-1456

Müller-Rompa SEK et al (2018) An approach to the asthma-protective farm effect by geocoding: good farms and better farms. Pediatr Allergy Immunol 29(3):275-282. https://doi.org/10.1111/pai.12861. Epub 2018 Feb 7

Muraro A et al (2014) EAACl food allergy and anaphylaxis guidelines. Primary prevention of food allergy. Allergy 69(5):590-601

Nakajiama $S$ et al (2012) Langerhans cell are critical in epicutaneous sensitization with protein antigen via Thymic stromal lymphopoetin receptor signaling. J Allergy Clin Immunol 129:1048-1055

NHS Choices (2016) Caesarean section. Available online at: http://www.nhs.uk/Conditions/pregnancyand-baby/pages/caesarean-section.aspx Zugegriffen am 08.08.2018

Niers L, Martin R, Rijkers G, Sengers F, Timmerman H, van Uden $\mathrm{N}$ et al (2009) The effects of selected probiotic strains on the development of eczema (the PandA study). Allergy 64:1349-1358

Nwaru IN et al (2017) Vitamin D intake during the first 4 years and onset of asthma by age 5: a nested case-contol study. Pediatr Allergy Immunol 28:641-648

Oczypok EA et al (2015) Pulmonary receptor for advanced glycation end products promotes asthma pathogenes through IL-33 and accumulation of 
group 2 innate lymphoid tissues. J Allergy Clin Immunol 136(3):747-756

Orlando BJ et al (2015) The structure of ibuprofen bound to cyclooxygenase-2. J Struct Biol 189(1):62-66

Ostman S et al (2006) Impaired regulatory T cell function in germ free mice. Eur J Immunol 36:2236-2246

Ott C et al (2014) Role of advanced glycation end products in cellular signaling. Redox Biol 2:411-429

Ownby DR, Johnson CC, Peterson EL (2002) Exposure to dogs and cats in the first year of life and risk of allergic sensitization at 6 to 7 years of age. JAMA 288:963-972

Pabst O (2012) New concepts in the generation and functions of IgA. Nat Rev Immunol 12(12):821-832. https://doi.org/10.1038/nri3322. Epub 2012 Oct 29

Pabst O, Cerovic V, Hornef M (2016) Secretory IgA in the coordination of establishment and maintenance of the microbiota. Trends Immunol 37:287-296

Paturi G et al (2012) Influence of dietary blueberry and broccoli on coecal microbiota activity and colon morphology in mdr1a-/- mice, a model of inflammatory bowel diseases. Nutrition 28(3):324-330

Penders J et al (2006) Factors influencing the composition of the intestinal microbiota in early infancy. Pediatrics 118(2):511

Persson M et al (2012) Reduced IFN- $\gamma$ and IL-10 responses to paternal antigens during and after pregnancy in allergic women. J Reprod Immunol 95(12):50-58

Petersen I, Johnson AM, Islam A, Duckworth G, Livermore DM, Hayward AC (2007) Protective effect of antibiotics against serious complications of common respiratory tract infections: retrospective cohort study with the UK General Practice Research Database. BMJ 335(7627):982pmid:17947744

Petschow B et al (2013) Probiotics, prebiotics and the host microbiome: the science of translation. Ann N Y Acad Sci 306(1):1-17

Piccinini MP, Beloni L, Livi C, Maggi E, Scarselli G, Romagnani S (1998) Defective production of both leukemia inhibitory factor and type 2 T-helper cytokines by decidual $\mathrm{T}$ cells in unexplained recurrent abortions. Nat Med 4:1020-1024. https://doi. org/10.1038/2006

Prichard PJ, Yeomans ND, Mihaly GW, Jones DB, Buckle PJ, Smallwood RA et al (1985) Omeprazole: a study of its inhibition of gastric $\mathrm{pH}$ and oral pharmacokinetics after morning or evening dosage. Gastroenterology 88:64-69

Qin J et al (2010) A human gut microbial gene catalogue established by metagenomic sequencing. Nature 464:59-65

Raghavan CT et al (2016) AGEs in human lens capsule promote the TGF $\beta 2$-mediated EMT of lens epithelial cells: implications for age-associated fibrosis. Aging Cell 15(3):465-476
Riedler J (2001) Exposure to farming in early life and development of asthma and allegy: a crosssectional survey. Lancet 358:1129-1133

Rosenfeld RM et al (2015) Clinical practice Guidelines(Update): adult Rhinusinusitis. Otolaryngol Head Neck Surg 152(2 Suppl):1-39

Round JL, Mazmanian SK (2009) The gut microbiota shapes intestinal immune responses during health and disease. Nat Rev Immunol 9:313-323

Round JL, Mazmanian SK (2010) Inducible Foxp3 ${ }^{+}$regulatory T-cell development by a commensal bacterium of the intestinal microbiota. Proc Natl Acad Sci U S A 107(27):12204-12209

Rovers MM et al (2006) Antibiotics for acute otitis media: a meta-analysis with individual patient data. Lancet 368(9545):1429-1435

Ruokolainen L et al (2015) Green areas around homes reduce atopic sensitization in children. Allergy 70(2):195-202

Sakai M et al (2002) Experimental studies on the role of fructose in the development of diabetic complications. Kobe J Med Sci 48:125-136

Salzman NH et al (2010) Enteric defensins are essential regulators of intestinal microbial ecology. Nat Immunol 11:76-83

Sandberg M et al (2009) Cord blood cytokines and chemokines and development of allergic disease. Pediatr Allergy Immunol 20(6):519-527

Sathe SK, Teuber SS, Roux KH (2005) Effects of food processing on the stability of food allergens. Biotechnol Adv 23:423-429

Sausenthaler S et al (2011) Early diet and the risk of allergy: what can we learn from the prospective birth cohort studies GINIplus and LISAplus. Am J Clin Nutr 94:2012S-2017S

Schiekofer S et al (2003) Acute hyperglycemia causes intracellular formation of $\mathrm{CML}$ and activation of ras, p42/44 MAPK, and nuclear factor kappaB in PBMCs. Diabetes 52:621-633

Schnappert SM et al (2006) Ambulatory care visits to physician offices, hospital outpatient departments, and emergency departments. Vital Health Stat 13(159):1-66

Schuijs MJ et al (2015) Farm dust and endotoxin protect against allergy through A20 induction in lung epithelial cells. Science 349(6252):1106-1110

Seite S, Bieber T (2015) Barrier function and microbiotic dysbiosis in atopic dermatitis. Clin Cosmet Investig Dermatol 8:479-483

Shanahan F (2015) Changing the narrative on antibiotics. Gut 64:1674-1675

Shapiro DJ (2014) Antibiotic prescribing for adults in ambulatory care in the USA, 2007-09. J Antimicrob Chemother 69(1):234-240. https://doi.org/10.1093/ jac/dkt301) 
Sharma CV et al (2017) First evidence of the conversion of paracetamol to AM404 in human cerebrospinal fluid. J Pain Res 10:2703-2709

Sheehan WJ et al (2016) Acetaminophen versus Ibuprofen in young children with mild persistent asthma. N Engl J Med 375:619-630

Shulman ST, Bisno AL, Clegg HW, Gerber MA, Kaplan EL, Lee $\mathrm{G}$ et al (2012) Clinical practice guideline for the diagnosis and management of group A streptococcal pharyngitis: 2012 update by the Infectious Diseases Society of America. Clin Infect Dis 55:12791282

Sick E, Brehin S, Andre P, Coupin G, Landry Y, Takeda K et al (2010) Advanced glycation end products (AGEs) activate mast cells. Br J Pharmacol 161:442-455

Silvestri M et al (2015) Smoke exposure, wheezing, and asthma development: a systematic review and meta-analysis in unselected birth cohorts. Pediatr Pulmonol 50(4):353-362

Simpson EL, Chalmers JR, Hanifin JM et al (2014) Emollient enhancement of the skin barrier from birth offers effective atopic dermatitis prevention. J Allergy Clin Immunol 134:818-823

Singh $M$ et al (2013) Zinc for the common cold. Cochrane Database Syst Rev 6:CD001364. https://doi. org/10.1002/14651858.CD001364.pub4

Singh N et al (2014a) Activation of Gpr109a, receptor für niacin and commensal metabolite butyrate, supresses colonic inflammation and carcinogenesis. Immunity 40:128-139

Singh VP et al (2014b) Advanced glycation end products and diabetic complications. Korean J Physiol Pharmacol 18:1-14

Smith SM, Fahey T, Smucny J, Becker LA (2014) Antibiotics for acute bronchitis. Cochrane Database Syst Rev 3:CD000245

Smith PK et al (2017) The false alarm hypothesis: food allergy is associated with high dietary advanced glycation end-products and proglycating dietary sugars that mimic alarmins. J Allergy Clin Immunol 139(2):429-437

Sokol H et al (2008) Faecalibacterium Pausnitzii is an antiinflammatory commensal bacterium identified by gut microbiota analysis of Crohn disease patients. Proc Natl Acad Sci USA 105:16731-16736

Soluble Fiber from Certain Foods and Risk of Coronary Heart Disease, U.S. Government Printing Office, Electronic Code of Federal Regulations, Title 21: food and Drugs, part 101: food Labeling, Subpart E, Specific Requirements for Health Claims, 101.81 [1] Archived 1 June 2008 at the Wayback Machine

Sonnenburg ED, Smits SA, Tikhonov M, Higginbottom SK, Wingreen NS, Sonnenburg JL (2016) Dietinduced extinctions in the gut microbiota compound over generations. Nature 529:212-215

Sordillo JE et al (2015) Prenatal and infant exposure to acetaminophen and ibuprofen and the risk for wheeze and asthma in children. J Allergy Clin Immunol 135(2):441-448

Sozanska B et al (2014) Atopy and allergic respiratory disease in rural Poland before and after accession to the European Union. J Allergy Clin Immunol 133(5):1347-1353

Spergel JM, Mizoguchi E, Brewer JP, Martin TR, Bhan AK, Geha RS (1998) Epicutaneous sensitization with protein antigen induces localized allergic dermatitis and hyperresponsiveness to methacholine after single exposure to aerosolized antigen in mice. J Clin Invest 101:1614-1622

Spinks A, Glasziou PP, Del Mar CB (2013) Antibiotics for sore throat. Cochrane Database Syst Rev 11:CD000023

Stein MM et al (2016) Innate immunity and asthma risk in amish and hutterite farm children. N Engl J Med 375:411-421

Stensballe LG et al (2013) Use of antibiotics during pregnancy increases the risk of asthma in early childhood. J Pediatr 162(4):832-838

Stirban A, Gawlowski T, Roden M (2014) Vascular effects of advanced glycation endproducts: clinical effects and molecular mechanisms. Mol Metab 3:94-108

Suaini NHA et al (2015) Immune modulation by vitamin $D$ and its relevance to food allergy. Nutrients 7(8):6088-6108

Sudo N et al (1997) The requirement of intestinal bacterial for the development of an IgE production system fully susceptible to oral tolerance induction. J Immunol 159:1739-1745

Szajewska H et al (2015) Recommendations on probiotics in allergy prevention should not be based on pooling data from different strains. J Allergy Clin Immunol 136(5):1422

Tähtinen PA, Laine MK, Huovinen P, Jalava J, Ruuskanen O, Ruohola A (2011) A placebo-controlled trial of antimicrobial treatment for acute otitis media. $\mathrm{N}$ Engl J Med 364(2):116-126. pmid:21226577

Tan T, Little P, Stokes T, Guideline Development Group (2008) Antibiotic prescribing for self limiting respiratory tract infections in primary care: summary of NICE guidance. BMJ 337:a437

Tan J et al (2016) Dietary fiber and bacterial SCFA enhance oral tolerance and protect against food allergy through diverse cellular pathways. Cell Rep 15(12):2809-2824

Taussig LM et al (2003) Tucson children's respiratory study: 1980 to present. J Allergy Clin Immunol 111(4):661-675

Thavagnanam S et al (2008) A meta-analysis of the association between Caesarean section and childhood asthma. Clin Exp Allergy 38:629-633

The e-bug project. Available online at: www.e-bug.eu Thio CL, Chi PY, Lai AC, Chang YJ (2018) Regulation of type 2 innate lymphoid cell-dependent airway hyperreactivity by butyrate. J Allergy Clin Immunol 142(6):1867-1883 
Thompson PL et al (2009) Effect of antibiotics for otitis media on mastoiditis in children: a retrospective cohort study using the United Kingdom general practice research database. Pediatrics 123(2):424430. pmid:19171605

Thorburn AN et al (2014) Diet, Metabolites and „Western-Lifestyle" inflammatory diseases. Immunity 40:833-842

Trompette A et al (2014) Gut microbiota metabolism of dietary fiber influences allergic airway disease and hematopoiesis. Nat Med 20(2):159-166

Tsakok $T$ et al Does early life exposure to antibiotics increase the risk of eczema? A systematic review [published online ahead of print June 21, 2013]. $\mathrm{Br} J$ Dermatol. https://doi.org/10.1111/bjd.12476pmid:23782060

Turnbaugh PJ et al (2007) The human microbiome project. Nature 449:804-810

United Nations (2008) World urbanization prospects: the 2007 revision. United Nations, New York

Untersmayr E, Jensen-Jarolim E (2008) The role of protein digestibility and antacids on food allergy outcomes. J Allergy Clin Immunol 121(6):1301-1310

Untersmayr E, Schöll I, Swoboda I, Beil WJ, Förster-Waldl E, Walter F et al (2003) Antacid medication inhibits digestion of dietary proteins and causes food allergy: a fish allergy model in BALB/c mice. J Allergy Clin Immunol 112:616-623

Untersmayr E, Bakos N, Schöll I, Kundi M, Roth-Walter F, Szalai K et al (2005) Anti-ulcer drugs promote lgE formation toward dietary antigens in adult patients. FASEB J 19:656-658

Untersmayr E, Vestergaard H, Malling HJ, Jensen LB, Platzer MH, Boltz-Nitulescu G et al (2007) Incomplete digestion of codfish represents a risk factor for anaphylaxis in patients with allergy. J Allergy Clin Immunol 119:711-717

Uribarri J, Cai W, Sandu O, Peppa M, Goldberg T, Vlassara $\mathrm{H}$ (2005) Diet-derived advanced glycation end products are major contributors to the body's AGE pool and induce inflammation in healthy subjects. Ann N Y Acad Sci 1043:461-466

Uribarri J et al (2007) Circulating glycotoxins and dietary advanced glycation endproducts: two links to inflammatory response, oxidative stress, and aging. J Gerontol A Biol Sci Med Sci 62:427-433

Valencia JV, Mone M, Zhang J, Weetall M, Buxton FP, Hughes TE (2004) Divergent pathways of gene expression are activated by the RAGE ligands $5100 \mathrm{~b}$ and AGE-BSA. Diabetes 53:743-751

Van Niemwegen FA (2011) Mode and place of delivery, gastointestinal microbiota, and their influence on asthma and atopy. J Allergy Clin Immunol 128(5):948-55.e1-3

Venekamp RP, Sanders SL, Glasziou PP, Del Mar CB, Rovers MM (2015) Antibiotics for acute otitis media in children. Cochrane Database Syst Rev 6:CD000219.
https://doi.org/10.1002/14651858.CD000219. pub4

Venter C, Pereira B, Voigt K, Grundy J, Clayton CB, Higgins $B$ et al (2009) Factors associated with maternal dietary intake, feeding and weaning practices, and the development of food hypersensitivity in the infant. Pediatr Allergy Immunol 20:320-327

Vouloumanou EK et al (2009) Antibiotics versus placebo or watchful waiting for acute otitis media: a meta-analysis of randomized controlled trials. J Antimicrob Chemother 64(1):16-24

Wald ER et al (2013) Clinical practice guideline for the diagnosis and management of acute bacterial sinusitis in children aged 1 to 18 years. Pediatrics 132(1):204

Wang J, Li F, Sun R et al (2013) Bacterial colonization dampens influenza-mediated acute lung injury via induction of M2 alveolar macrophages. Nat Commun 4:2106

Wang CC, Wu H, Lin FH, Gong R, Xie F, Peng Y, Feng J, Hu CH (2018a) Sodium butyrate enhances intestinal integrity, inhibits mast cell activation, inflammatory mediator production and JNK signaling pathway in weaned pigs. Innate Immun 24(1):40-46. https://doi.org/10.1177/1753425917741970

Wang CS, Wang J, Zhang X et al (2018b) Is the consumption of fast foods associated with asthma or other allergic diseases? Respirology 23(10):901-913

de Weerth C, Fuentes S, Puylaert P, de Vos WM (2013) Intestinal microbiota of infants with colic: development and specific signatures. Pediatrics 131:e550e558

Weiner HL et al (2011) Oral tolerance. Immunol Rev 241(1):241-259

Wessels MR (2011) Clinical practice. Streptococcal pharyngitis. N Engl J Med 364(7):648-655

West CE, Hammarström ML, Hernell O (2009) Probiotics during weaning reduce the incidence of eczema. Pediatr Allergy Immunol 20:430-437

West CE, Rydén P, Lundin D, Engstrand L, Tulic MK, Prescott SL (2015) Gut microbiome and innate immune response patterns in IgE-associated eczema. Clin Exp Allergy 45:1419-1429

Westbrook JI, Duggan AE, McIntosh JH (2001) Prescriptions for antiulcer drugs in Australia: volume, trends, and costs. BMJ 323:1338-1339

Wickens K, Black PN, Stanley TV, Mitchell E, Fitzharris P, Tannock GW et al (2008) A differential effect of 2 probiotics in the prevention of eczema and atopy: a double-blind, randomized, placebo-controlled trial. J Allergy Clin Immunol 122:788-794

Wickens K, Beasley R, Town I et al (2011) The effects of early and late paracetamol exposure on asthma and atopy: a birth cohort. Clin Exp Allergy 41:399-406

Wickens K, Barthow C, Mitchell EA et al (2018) Effects of Lactobacillus rhamnosus HNO01 in early life on the cumulative prevalence of allergic disease to 11 ye- 
ars. Pediatr Allergy Immunol 29(8):808-814. https:// doi.org/10.1111/pai.12982. Epub 2018 Nov 14

Wolsk HM et al (2017) Prenatal vitamin D supplementation reduces risk of asthma/recurrent wheeze in early childhood: a combined analysis of two randomized controlled trials. PLoS One 12(10):e0186657

Wong EHC (2014) The role of macrolides in asthma: current evidence and future directions. Lancet Respir Med 2:657-670

Wopereis $\mathrm{H}$ et al (2014) The first thousand daysintestinal microbiology of early life: establishing a symbiosis. Pediatr Allergy Immunol 25(5):428-438

World Health Organization (WHO) (2015) Healthcareassociated infections fact sheet. Available online at: http://www.who.int/gpsc/country_work/gpsc_ ccisc_fact_sheet_en.pdf

Wu GD et al (2011) Linking long-term dietary patterns with gut microbial enterotypes. Science 334:105-108

Wypych TP, Marsland BJ (2018) Antibiotics as instigators of microbial dysbiosis: implications for asthma and allergy. Trends Immunol 39(9):697-711

Yamazaki Y, Nakamura Y, Núñez G (2017) Role of the microbiota in skin immunity and atopic dermatitis. Allergol Int 66:539-544

Yang J et al (2015) Induction of regulatory dentritic cells by Lactobacillus paracasei L9 prevents allergic sensitization to bovine ß-lactoglobulin in mice. J Microbiol Biotechnol 25(10):1687-1696

Yatsunenko T et al (2012) Human gut microbiome viewed across age and geography. Nature 486:222-227
Zelaya H, Tada A, Vizoso-Pinto MG, Salva S, Kanmani P, Aguero $G$ et al (2015) Nasal priming with immunobiotic Lactobacillus rhamnosus modulates inflammation-coagulation interactions and reduces influenza virus-associated pulmonary damage. Inflamm Res 64(8):589-602

Zhang GQ, Hu HJ, Liu CY, Zhang Q, Shakya S, Li ZY (2016) Probiotics for prevention of atopy and food hypersensitivity in early childhood: a PRISMAcompliant systematic review and meta-analysis of randomized controlled trials. Medicine (Baltimore) 95:e2562

Ziegler SF et al (2006) Thymic stromal Lymphopoetin in normal and pathogenic $\mathrm{T}$ cell development and fundciton. Nat Immunol 7:709-714

Zink DA, Pohlman M, Barnes M, Cannon ME (2005) Long-term use of acid suppression started inappropriately during hospitalization. Aliment Pharmacol Ther 21:1203-1209

Zosky GR et al (2014) Vitamin D deficiency at 16 to 20 weeks' gestation is associated with impaired lung function and asthma at 6 years of age. Ann Am Thorac Soc 11:571-577

Zuccotti G, Meneghin F, Aceti A, Barone G, Callegari ML, Di Mauro A et al (2015) Probiotics for prevention of atopic diseases in infants: systematic review and meta-analysis. Allergy 70:1356-1371

Zwart S et al (2003) Penicillin for acute sore throat in children: randomised, double blind trial. BMJ 327(7427):1324. pmid:13656841 